\title{
RAMAN SPECTRA OF THE WATER STRETCHING FREQUENCIES IN RARE EARTH CHLORIDE SOLUTIONS AS A FUNCTION OF CONCENTRATION
}

\author{
Ph.D. Thesis Submitted to lowa State University, \\ November, 1972
}

W. C. Mundy

\begin{tabular}{|c|}
\hline 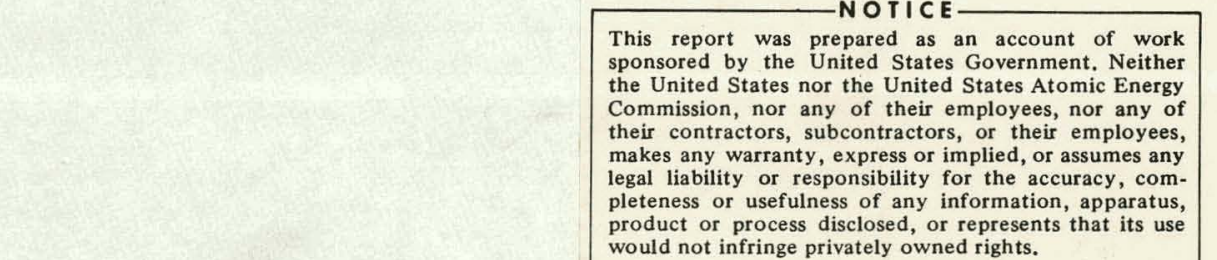 \\
\hline
\end{tabular}

Ames Laboratory, USAEC

lowa State University

Ames, lowa 50010

Date of Manuscript: November, 1972

PREPARED FOR THE U. S. ATOMIC ENERGY COMMISSION

DIVISION OF RESEARCH UNDER CONTRACT NO. W-7405-eng-82 


\section{DISCLAIMER}

This report was prepared as an account of work sponsored by an agency of the United States Government. Neither the United States Government nor any agency Thereof, nor any of their employees, makes any warranty, express or implied, or assumes any legal liability or responsibility for the accuracy, completeness, or usefulness of any information, apparatus, product, or process disclosed, or represents that its use would not infringe privately owned rights. Reference herein to any specific commercial product, process, or service by trade name, trademark, manufacturer, or otherwise does not necessarily constitute or imply its endorsement, recommendation, or favoring by the United States Government or any agency thereof. The views and opinions of authors expressed herein do not necessarily state or reflect those of the United States Government or any agency thereof. 


\section{DISCLAIMER}

Portions of this document may be illegible in electronic image products. Images are produced from the best available original document. 
This report was prepared as an account of work sponsored by the United States Government. Neither the United States nor the United States Atomic Energy Commission, nor any of their employees, nor any of their contractors, subcontractors, or their employees, makes any warranty, express or implied, or assumes any legal liability or responsibility for the accuracy, completeness or usefulness of any information, apparatus, product or process disclosed, or represents that its use would not infringe privately owned rights.

Available from: National Technical Information Service Department A

Springfield, VA 22151

Price: Microfiche $\$ 0.95$ 


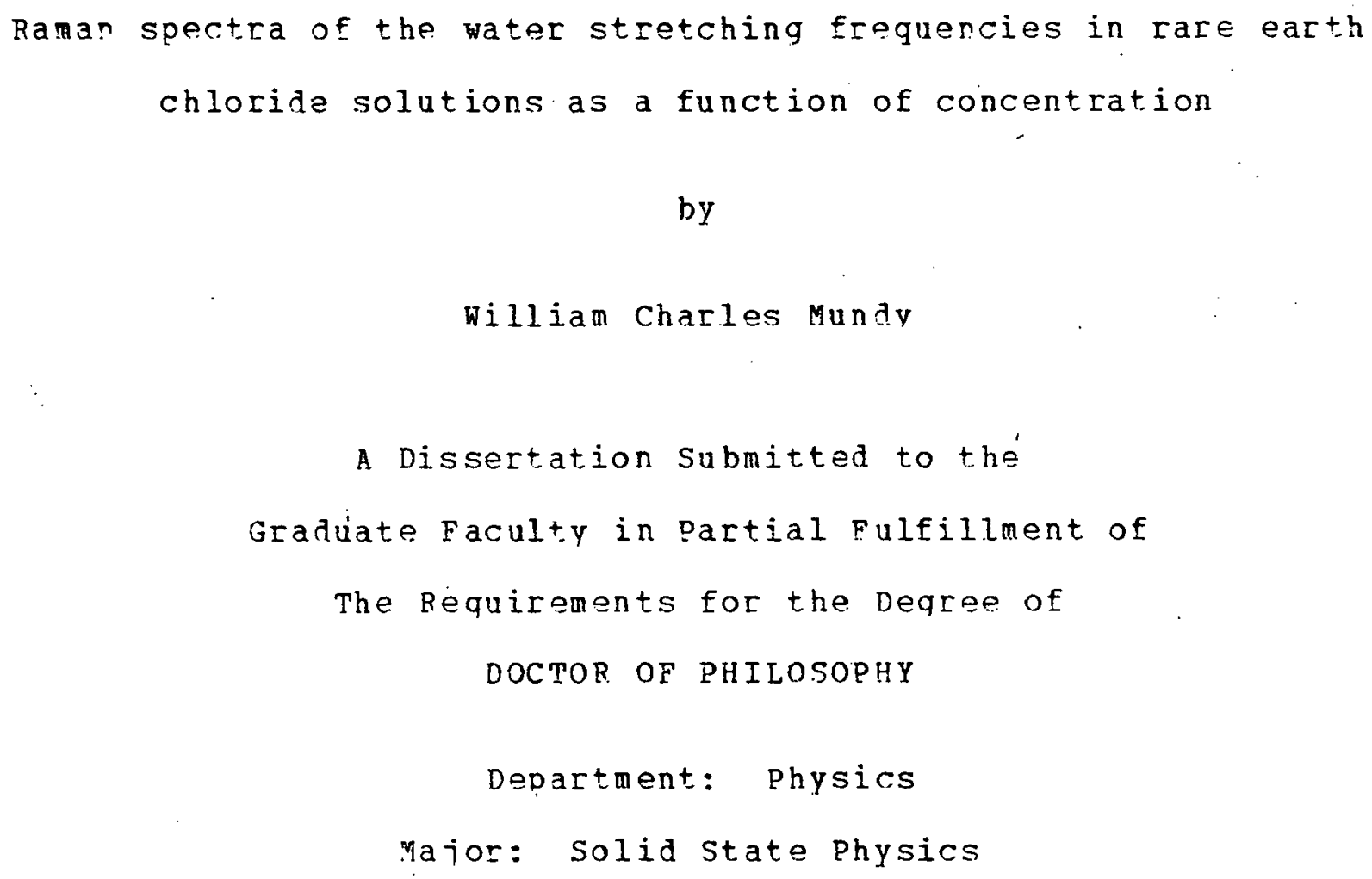


TABLE OF CONTENTS

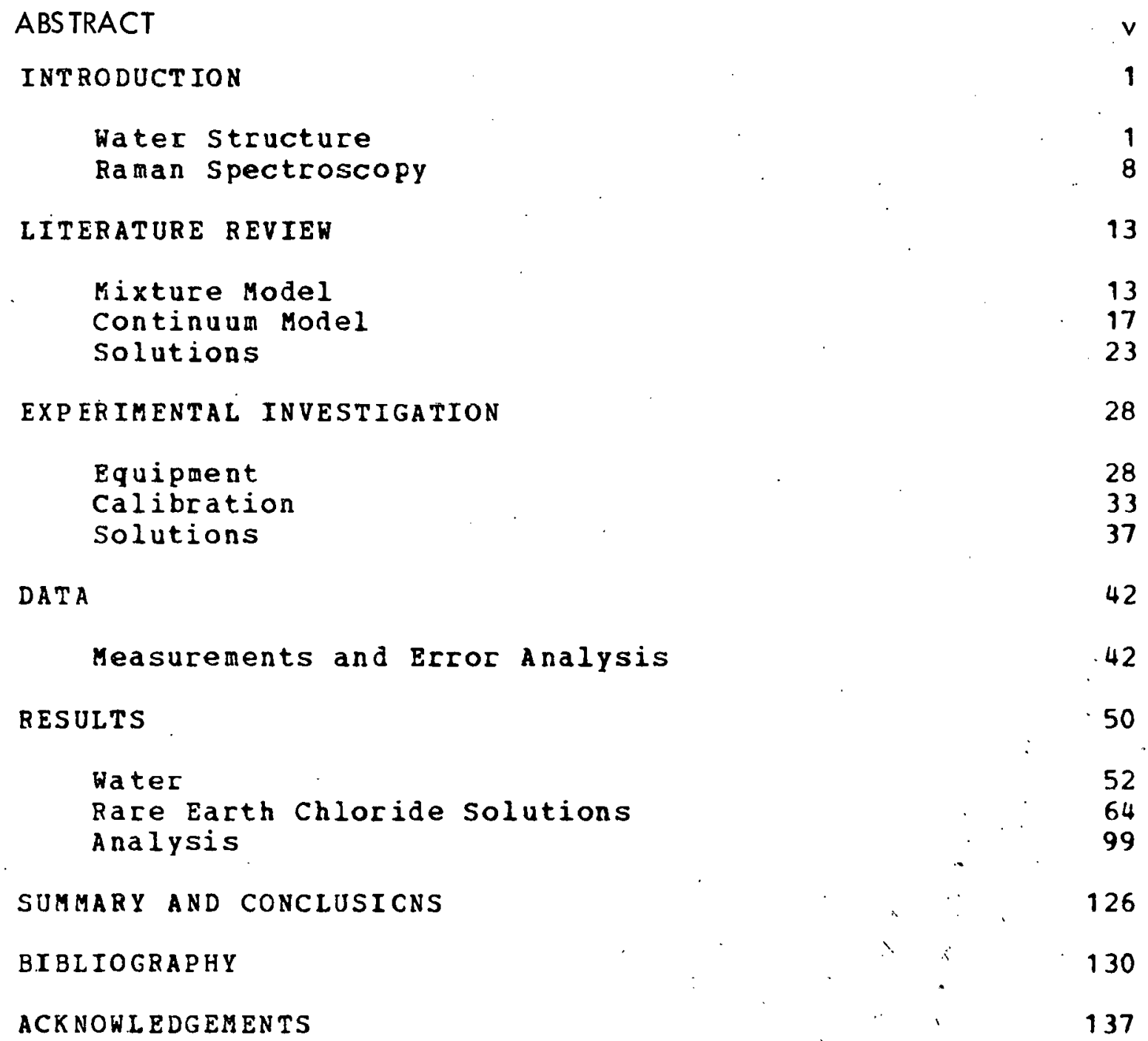


Raman spectra of the water stretching frequencies in rare earth chloride solutions as a function of concentration

\section{Gilliam Charles Mundy}

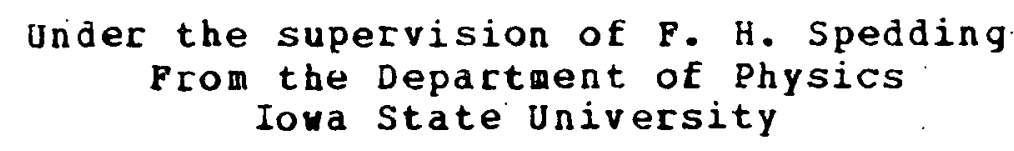

Bam data was obtained for both polarizations of the $O D$ stretching spectral band of water and six concentrations of aqueous solutions of $\mathrm{LaCl}_{3}, \mathrm{GdCl}_{3}$ and $\mathrm{LuCl}_{3}$ in which $5 \%$ of the water was $D_{2} O$. The six concentrations of the rare earth salt solutions were approximately $0.5,1.0,1.5,2.0,2.5$ and 3.0 molal. For comparison, Raman data was also obtained for the $O H$ stretching frequency of water and aqueous $\mathrm{GdCl}_{3}$ ' having similar concentrations as indicated above, in which $95 \%$ of the water was $\mathrm{D}_{2} \mathrm{O}$. All of this data was taken at room temperature.

Both the $O D$ and $O H$ spectral bands are superimposed on a finite background. For the solutions in which $5 \%$ of the water was $D_{2} O$, it was assumed that the background could be approximated in the $O D$ spectral region by the spectrum of solutions of the same concentration made with $100 \% \mathrm{H}_{2} \mathrm{O}$. Like- 
wise, for solutions in which $95 \%$ of the water was $\mathrm{D}_{2} \mathbf{0}$, solutions made entirely with deuterated water vere used to approximate the background in the spectral region of the oH band.

The resulting data was corrected for the intensity response of the detection system and is listed with estimated standard deviations. Depolarization ratios were calculated which demonstrated that these ratios vary with Raman frequency.

At least four normal Gaussian curves or three skewed curves were required to fit within experimental error the data for water as well as the solutions. But it appears that these fits are nothing more than curve fitting equations.

A differential analysis technique was developed which allowed the identification of distributions of the stretching vibrations associated with water molecules which are clearly affected in different ways by the rare earth and chloride ions. 


\section{INTRODUCTION}

Water Structure

Knowledge concerning the structure in liquid water is important fur many areas of chemical, biological, geological and metecrological research $(43,49,51,60,77)$. The individual water molecule is well characterized and manp of its froperties can be computed with results in good agreement with experiment. But in many respects the behavior of 1.iquid water is very puzzling $(36,50)$. Water is anomalous in nearly all of its physicochemical properties when compared to similar liquids. The higher melting and boiling point, the unusually high heat capacity, the decrease in volume when welting and the decrease in viscosity with increasing fressure are some of its unusual characteristics $(28,51,60$, 76). These unique properties indicate that there is a fundamental difference between water and most other liquids. No definite model exists yet that correctly explains all these froperties of water. It is felt that the unusual nature of water results from the dipole moment of the water molecule and from the fact that water molecules can form as many as four hydrogen bonds with each other. This allows the formation of a spatially extended network of interconnected molecules (15, 36, 75). Experimental data, such as $x$-ray diffraction, seem to confirm that close neighbors are not randomly distribured but have short range order (73). 
The nature of the observed structure depends on the time scale employed and is discernible only if the average lifetime of a structure exceeds by an order of magnitude the period cf the vibration of the bonds that define the structure $(6,27)$. Implicit in this statement is the fact that different experimental methods may indicate different structures for a system.

A satisfactory theory. of the structure of liguids has laqged far behind that of other states of matter because of the intrinsic difficulty of characterizing fluids $(8,9,23)$. In gases the kinetic energy of tise nearly free molecules dominates the behavicr of the system; in solids it is the periodicity of the potential energy in ubich lattice vibrations occur that is most important. But in liquids these tro energies may be similar in magnitude.

The theory of water has been hampered by a lack of a general theory of the liquid state even for simple or normal Iiquids $(27,60\}$. In addition, the directionality of interactions in liquid vater exerts an influence on local order which is not present in other liquids, thus making its theoretical treatment even more difticult (57, 84). And a thoory for water will depend on the type of theory adopted for hydrogen tonds, since the hydrogen bond plays a fundamental rcle in the structure of any aggregate that water molecules can form (6). The pctentials between molecules are non- 
additive to a significant degree, with the hydrogen bond depending in a complicated way on both the number and configuration of neighboring bonds (82). Also the cohesive energy between pairs of molecules is an order of magnitude larger than for liquified acble gases (35). Thus, the statisticalmechanical approximations that can be applied to equilibrium and transport properties of liquified inert gases can not be applied to liquid water (23). This makes it difficult to folmulate a theory of licquid water (36).

Existence of a structured or ice-like component of water has long been postulated to account for the phenomenon of maximum density in liquid water (34). As early as 1880 . H. A. Rowland suggested that liquid water contained ice, and in 1892 w. C. Roentgen described water as a saturated solution of ice in a liquid composed of simpler molecules (26, 35). After the turn of the century, water was generally considered to consist of a mixture of different water polymers with varying deqrees of association (5). These theories explained qualitatively some of the properties of water but gave little quantitative results.

$\triangle$ Eaper by Bernal and Fowler in 1933 was the first significant quantitative contribution to the theory of liquid water (7, 19, 57). They suggested that the unusual nature of water was due, not only to the dipole character of the individual water molecule, but even more to its geometrical 
Raman spectra of the water stretching frequencies in rare earth chloride solutions as a Eunction of concentration

by

William Charles mundy

\begin{abstract}
A Dissertation subitted to the
Graduate Faculty in Partial Folfillment of

The Reguirements for the Degree of

DOCTOR OE PHILOSOPHY
\end{abstract}

Department: Physics

Major: Solid State Physics

Approved

In Charge of Major tork

For the Major Department

For the Graduate College

Iowa State University

Ames, Iova

1972 
structure. A comparison of x-ray diffraction of ice and water led thew to propose a model for water consisting of molecules held together in an irregular tetrahedral arrangement by hydrogen bonds as in ice and in addition a certain fraction of monomers. They assumed that upon melting the structure of water was transformed from an ice-tridymite-like form. Which persisted in some degree up to $4^{\circ} \mathrm{C}$, to a quartzlike structure at ordinary temperatures. In the structural change, nearest neighbor distance remained about the same, tut the next nearest neighbor distances decreased by about $0.4 \AA$. This accounted for the abrupt change in density when water melted. The structured vater was quessed to be like quartz, which was tetrahedrally coordinated, because of the similarity in the $x$-ray patterns.

In retrospect Bernal noted that he was originally inspired by the analcgy between the scattering patterns of liquids and the corresponding solids (8). He stated that he presently felt that this was a delusive approach which imposed a greater degree of order than actually existed in liquids - that liquids were not just a blurred solid.

Most recent models of liquid vater emphasize extensive hydrogen bonding and formation of spatial netrorks (76). These theories range from the concept that the orientation of colliding dipoles may be correlated for short times (26) to the idea that each molecule may be bonded to its nearest 
neighbors and they to theirs, so that the entire volume in a certain sense forms a single loosely bonded molecule (29).

A number of models have been proposed for liquid water. They can be classified in two basic categories - continuu model and mixture model (60).

In the continum model, the entire liquid is considered tc be homogeneous, having an irregular extensively bydrogentcnded structure $(27,77)$. The hydrogen bond is regarded as reing bent (as if it were electrostatic) rather than broken, and there is a continuous distribution of byarogen bond energies and qecmetries $(19,57)$.

The basic premise of the mixture model is that liquid water is composed of a small number of distinctly different short-lived species cf vater molecules characterized by different numbers of hydrogen bonds (30). Generally the hydrogen bond is regarded as no longer existing when it is bent, since substantial covalency, which is very directional, is assumed for the bonds (19).

In general, the mixture model is attractive to many chemists. They find it useful for qualitatively interpreting thermodynamic properties of water and the behavior of aqueous solutions. On the other hand, chemical physicists, who see difficulties in conceiving bow one molecule in a liquid should avoid being subject to the same strong forces that act on other molecules in the same system, tend to support the 
continuum model (36). All the models considered so far are intuitive, and none have a firn theoretical and physical basis $(60)$.

Experimentally several models, which differ significantIy at the molecular level, more or less satisfactorily support a number of thermodynamic, spectroscopic and transport properties of water $(27,99)$. For instance, radial distribution curves obtained from x-ray diffraction data can be refroduced by most models $(74)$. This points up one of the principal problems in developing a model for liquid water. It is difficult to find an experiment which uniquely deterwines a model (64). Any model which invokes very äifferent environments, continuous or discrete, for water molecules in Iiquid water can acccunt qualitatively for most of the properties of liquid water (60). So far, no unequivocal experimental citeria relating to the properties of water determine a choice between the uniform and non-uniform models, and none of the models proposed so far is entirely satisfactory $(40$, 102). Even among the mixture models there is disagreement about the number of mononeric molecules in water. Estimates range from $2.5 \%$ to $70 \%(102)$. In spite of much theoretical and experimental work, the structure of liquid water is still not well understood (15). Spectroscopists are also divided as to whether spectral data support the continum or mixture concept of liquid 
water. Unfortunately, the vibrational spectrum of liquid water is complex and difficult to interpret, but it is expected to supply an important restraint on the selection of water models $(60)$.

Water in its vafor phase has three normal modes of vitration: a bending mode around $1600 \mathrm{~cm}^{-1}$, a symmetric and an antisymetric stretching vibration around $3650 \mathrm{~cm}^{-1}$ and $3750 \mathrm{~cm}^{-1}(27)$. In addition, there are pure rotational bands in the far infrared. The condensed liguid and ice phases have broad bands in similar regions of the spectrum. Since the water molecule maintains its identity in the condensed phases $(60,67,84)$, it is assumed that the bands in liquid water and ice correspond to the normal modes of the isolated water molecule. The frequency displacements of the bands from their isolated values are presumably due mainly to the static field effect cf neighboring molecules (27). While the creadth of the spectral bands associated with the stretching frequencies is primarily due to different local strengths of the static field, inter- and intra-molecular coupling, and perhaps Fermi resonance, contribute to the widths of these bands. Relaxation times may also augment the band widths (27. 30, 59). Due to the asymmetrical nature of the HDO molecule, the intramolecular modes are decoupled, and many of the overtones and combination lines are well separated so that in general Fermi cesonance does not occur. Further, the 
spectra of dilute $\mathrm{HDC}$ in $\mathrm{H}_{2} \mathrm{O}$ or $\mathrm{D}_{2} \mathrm{O}$ are essentially free from intermolecular coupling of vibrations $(30)$. As a result, the shape of the bands of BDo are simpler than those of $\mathrm{H}_{2} \mathrm{O}$ or $\mathrm{D}_{2} \mathrm{O}$ and may be interfreted in terms of the local environment of the molecule $(27,111,114)$.

The stretching frequencies of water are highly sensitive to the strength and extent of hydrogen bonding: so the vibrational spectra of these frequencies are strongly dependent on the enviconment of the bond $(27,30,73)$. Thus the oD spectral band of $\mathrm{HDO}$ in $\mathrm{H}_{2} \mathrm{O}$ (Or the OH band of $\mathrm{HDO}$ in $\mathrm{D}_{2} 0$ ) ought to frovide information about the nature of structure in liquid water, even for lifetimes as short as 10-23 seconds $(30)$

\section{Raman Spectroscopy}

The Raman effect is an inelastic scattering of photons by wolecules, atoms cr crystals. It can be visualized as the abscrption of a photon by a system, leaving the system in an excited virtual state from wich it relaxes imediately (according to the Heisenberg uncertainty principle) to a final eigenstate that is different from the initial one and emitting a photon in the process. The frequency difference betreen the incident and scattered photons corresponds to the energy difference between the associated eigenstates of the system. 
In 1928 Sir C. V. Raman of India reported the discovery of this type of light scattering for which he received the Nobel frize in physics in $1930(85,86,58)$. Independently, and almost at the same time, Mandelstam and Landsberg of Bussia observed the same type of scattering (12).

Stimulated by the compton effect, Smekal in Germany had predicted this scattering effect in 1923 (94). He suggested that a light quantum might inelastically scatter from an atom cr molecule. Conservation of energy requires that

$$
\text { , } 1 / 2 \mathrm{mv}+E_{\mathrm{n}}+h v=1 / 2 \mathrm{mv} \cdot 2+E_{k}+b v^{\prime} .
$$

Momentum considerations shoy that $1 / 2$ myz and $1 / 20 v^{\prime 2}$ differ no more than one part in $10^{\circ}$. So to a good approximation.

$$
E_{n}+h_{v}=E_{k}+h_{v} \cdot
$$

where $E_{n}$ and $E_{k}$ are the initial and final eigenstates of the system: $\nu$ and $v^{\prime}$ are the frequencies of the incident and scattered photons.

Raman and infrared spectra of a sample frequently look sixilar. However, there are important fundamental differences (95). Classically, the intensity of the normal Raman effect is proportional to the change in the polarizability tensor of the system during the transiticn, whereas the infrared intensity is proportional to the change of the vector dipole woment of the system: hence, different selection rules apply (39). And since 'the Raman intensity depends on a, tensor, information is contained in the polarization of 
the scattered light which is due to the anisotropy of the polarizability change. This Raman tensor can be decomposed into an isotropic tensor and an anisotropic tensor. This aids in identifying the symmetry of the scattering system. Raman spectroscopy is valuable in investigating vibrational and rotational energy levels of molecules in liquids and gases and for the determination of lattice vibration frequencies of solids. In spite of the fact that the Raman effect is very weak (the scattered intensity is six to ten orders of maqnitude less than the incident intensity). it has the practical advantage of bringing the infrared spectrum into the visible and avoids infrared techniques (93).

After the initial discovery of the Raman effect, there was much activity and development of instruments, techniques and phenomenological theory for this field of spectroscopy (95). Mercury lamps became the most common light sources. and fast prism spectrographs were developed. However, in spite of ingenious filters, it was difficult to reduce the intensity of extraneous light below that of the Baman spectrum. Also, because of the weak nature of the Raman effect, frequently hours and even days cf exposure time were needed to obtain discernible exposures. During this time, infrared techniques were improved. Hence, Baman spectroscopy fell largely into a state of disuse. 
In the 1960 's three instrumental developments generated ney interest in this field. The innovations were lasers, sensitive low noise photoelectric detection systems and high speed double monochromators $(58,111)$.

The laser has several advantages over the mercury lamp as an excitation source. In addition to selections of lasers that operate at many different wavelengths, the laser beam is normally polarized, monochromatic and directional. Since the laser has negligible bean divergence and the radiation is usually plane polarized; by virtue of the optical gecmetry of the laser cavity, it is easy to measure the polarization of the Raman scattered radiation. Because the laser beam is very monochromatic, it is possible to detect Raman lines which are very close to the Rayleigh line and to do profile studies of Raman spectral lines. Also, the monochromatic beam can be focused to a very small spot, giving a high pover density and permitting efficient collection of Raman light Even from very small samples.

Photomultiplier tubes and fast electronics have been developed that are capable and sensitive enough to detect individual optical photons. This shortens the scan times needed to detect Raman lines by several orders of magnitude when compared to traditional photographic methods. In addition, these electronic detection systems are linear in signal respcnse over a range of six orders of magnitude or more. 
Finally. double (and triple) monochromators have been developed, so that the intensity of stray incident light is reduced by ten orders of magnitude or more for a monochromator setting just one nanometer (nm) avay from the frequency of the incident light.

Several gcod reviews have appeared in the literature which cover in greater detail laser Raman instrumentation and techniques $(44,45,48,78)$. 


\section{LITERATURE REVIEW}

This review is confined primarily to spectroscopic information relevant to the stretching frequencies of the water molecule in liguid rater and aqueous solutions.

uixture Model

Walrafen was amcng the first to interpret spectral evidence in terms of the mixture model, first by his studies of the librational and hindered translational modes, but even more persuasively with his laser Raman spectral studies at different temperatures of the $O D$ stretching frequency of dilute solutions of HDO in water $(107,108,109,110,111$, 112, 113, 114, 115, 116). The appearance of a frequency at wich the intensity in the spectral band was independent of temperature (an isosbestic point) and the fact that the $O D$ band could be approximately resolved into tro Gaussian components. which had opposite intensity dependence on temperature, were suggested to be strong reasons for assuming that water was composed of two classes of water molecules (111). The Gaussian at the lower frequency (around $2520 \mathrm{~cm}^{-1}$ ), the intensity of which decreased with increasing temperature, was associated with hydrogen-bonded oD units. The other curve (at about $2650 \mathrm{~cm}^{-1}$ ) was identified with non-hydrogen-bonded $O D$ units which, hovever, were involved in other strong interactions sucb as dipole-dipole forces (18). Walrafen considered that the stimulated Raman spectra of normal and heavy 
water justified the decomposition that he used and supported the idea that distinguishable molecular species existed in liquid water $(18,23)$. Further, he obtained results for the OT stretching vibration of HTO in water which he claimed was consistent $\forall i t h$ the above analysis (117). He noted, though, that there was a marked difference betueen the shapes of the $C T$ stretching contour and those of the $O D$ and $O H$ stretching bands.

The fact that the component spectral bands were Gaussian in shape and fairly broad, was explained by him to be due to swall random distortions involving different major classes of interactions. In the case of the hydrogen-bonded interactions, small random distributions of 0-0 distances and O-H-- 0 angles were suggested to be the cause of the spectral shape. For non-hydrcgen-bonded molecules he felt that random dipole-dipole interactions may bave accounted for the breadth of the band (114). Similar results were obtained for the OH band of dilute solutions of HDO in deuterated water. While the infrared spectrum is not as structured as the more complicated Raman bands (presumably because of more stringent selection rules) (66). Vand and senior were able to verify by means of differential technigues that the infrared spectrum of the $O D$ stretching frequency was also asymmetrical, resolvable into two components and had an isosbestic point when the temperature of the sample was var- 
ied (92). They also did a simple calculation which showed that in general an isosbestic point might occur in a system having any number of components, but that it was most likely tc be characteristic of a two component system that was in equilibrium. Even for this simple system, it had to be assumed, in addition to the equilibrium between the two components, that the half-widths and positions of the component spectral bands remained constant for changing temperature for any other parameter, such as pressure or solute concentration for which an isosbestic point was observed) (112). Their conclusion was that if it could be demonstrated that a spectral envelope was decomposible into two sub-bands, then an isosbestic pcint indicated that the system was composed of two types of molecules in equilibrium with each other. So they supported Walrafen's contention that liquid water consisted of two classes of water molecules.

Recently, O'Perrall, Koeppl and Kresge did normal mode vibraticnal analysis of liquid water (69). The Eully bonded species of water was approximated by a nine-atom model consisting of a water molecule (or its equivalent) surrounded tetrabedrally by two oxygens and two OH groups. Lover states of bydrogen bonding were represented by removing one or more of the surcounding oxygens and $O H$ groups. stretching force constants were chosen to reproduce the frequencies reported by walrafen. It was found that the vibrational frequencies 
were only slightly affected by the hydrogen bonding of the oxygen lone pairs of the water molecule, and this effect could be neglected. Consequently they found four principal frequencies for the $O D$ (Or similarly for the $O H$ ) stretching frequency of HDO. These were identified with 1) the HDO molecule having no hydrogen bonds, 2) the on unit of the HDO molecule being hydrogen bonded, 3) the OD unit of the molecule being hydrogen bonded, and 4 ) both the $O D$ and $O H$ units having hydrogen bonds, i.e.. a fully bonded molecule. The first tro situations involved non-hydrogen-bonded OD units, and for the $O D$ stretching vikrations their frequencies vere calculated to be $264 \mathrm{C}^{\mathrm{cm}^{-1}}$ and $2650 \mathrm{~cm}^{-1}$. The other pair of frequencies were associated with hydrogen-bonded OD units alsc having frequencies close together $-2490 \mathrm{~cm}^{-1}$ and $2505 \mathrm{~cm}^{-1}$ - but well separated from the former pair. Because the frequencies within the pairs vere sc close, they vere qrouped into two classes of vater. Halrafen also suggested on the basis of the stimulated Raman spectra of normal and beavy water that eacb of the classes of water molecules gave rise to one intense spectral band and one very weak component at a slightly lower frequency (18). Thus he felt that the contribution of the two smaller components to the total intensity of the band yas so small that they.did not destroy the isosbestic point which indicated that the system was composed of predominanty two components. 
Continuum Model

In spite of these arguments, many spectroscopists do not accept the mixture concept $(36)$.

Infraced spectra of ice II show that four distinctly resolvable and relatively narrou peaks are apparent in the OD stretching frequency of $\mathrm{BDO}$ in water $(10,86)$. On the basis of this evidence, Bertie and whalley predicted that there would be four discrete $0-0$ distances in ice II.l Crystallograpbers subsequently verifjed this (54). So it seemed natural to them to explain the single peaked broad band of the same stretching frequency in ice I to the known random distributions of the 0-o distances in that type of ice. And then it seemed plausible to extend the concept and associate the even broader band of liguid water with a continuous distribution of 0-0 distances (27).

Yelling and courchene demonstrated that the infrared band of the $O D$ stretching freguency in ice I at $-7.6^{\circ} \mathrm{C}$ was symmetrical and could be fitted with a single Lorentzian function with a half-width of $31 \mathrm{~cm}^{-1}(119,102)$. It was found that this same band in liquid water at $4^{\circ} \mathrm{C}$ was also symmetrical, but it reguired a Gassian curve with a halfwidth of $150 \mathrm{~cm}^{-1}$ for a satisfactory fit. According to ther.

1 It was assumed that all of the molecules in ice vere fully hydrogen bonded (27). 
it took ten to fifteen closely spaced Lorentzians to achieve a comparable fit to that of the single Gaussian. So the concluded that the spectral band of liquid water consisted of a large number of overlapping Lorentzian bands arising frcm a continucus distribution of perturbed OD (OI OH) oscillators (112). They noticed that at higher temperatures the oD spectral band became asymetric.

Wyss and ralk reported that at room temperatures the uncoupled $O D$ infrared band was asymetrical (118). But from considerations of the asyaptotic behavior of the shift in frequency from the corresponding frequency in vapor as a function of geometrical parameters, they showed that a continuum model could display asymmetry, have inflections and even an isosbestic point in the spectral band. In their argument they utilized functions (dependent on temperature. Erequency and sample density) to formally relate Raman scattering $c r$ infrared intensities to the density of vibrational states. This qualitatively explained the measurable difference between the Raman and infrared spectrum of water 157 , 118).

Weak isosbestic points have been observed in the infrared spectra of certain solids (ice, d-ribose, d-galactos and pentaerythritol) (31). It was suggested that these were obviously not dependent on equilibrium between hydrogenkonded and non-hydrogen-bonded groups. 
Perram showed that it was possible to decompose a single Gausian curve into two Gaussians that were displaced symmetrically one from the other by about $25 \%$ of the halfwidh of the band. The new Gaussians had approximately the same half-widths as the original Gaussian. Thus, he felt that Walrafen's decomposition of the water band was probably arbitrary.

Empirically a ccrelation exists between oH stretching frequencies and 0-0 distances in bydrogen bonded systems 162 . 83). Assuming that this relation for crystals was also true for bydrogen bonds in liquids and assuming that the intensity of the Baman band at each freguency was proportional to the number of oscillators having that fiequency. Wall and hornig converted the Raman spectrum of the $O D$ and $O H$ stretching frequencies into distribution functions of the $0-0$ distances. (103). They reported that this distribution agreed substantially with the distributions derived from $x$-ray scattering and supported the suggestion that structural disorder was the cause cf the breadth of the uncoupled $O D$ and $O H$ spectral bands (19).

Ford and Palk asserted that overtones, combination and bot bands (transitions from thermally excited rotational states). as well as life time broadening. contributed negligibly to the $O D$ or $O H$ spectral band-width of the HDO stretch band. They concluded that a continuous distribution 
cf 0-0 distance was responsible for the breadth of the bands (32).

Hall took the Fourier transform of the OD and $O H$ spectral bands of HDO to obtain time correlation functions of these bands $(105,106)$. From theoretical considerations he interpreted the results to indicate that intermolecular vibrational modulation was responsible for the observed band yidth. So he concluded that the spectral envelope associated with the HDO stretching frequencies was a superpositicn cf many molecular oscillator bands.

Walrafen, who, as noted above, advocated the mixture model of water, noted in his recent report that pressures up to 7.2 kbar did not significantly affect the Raman OD stretching frequency. He recognized that this indicated that structural inhomogeneities in water must occur primarily in small regions since large, distinctly dissimilar regions having greatly different densities should yield large Fressure effects. And he admitted that the Raman pressure data appears to be consistent with a redistribution of angles and distances $(115,116)$. These findings agreed with Frank and Roth's earlier orservations of the infrared spectra of the $O D$ band at high fressures (33). It vas their conclusion that few if any non-ronded water molecules existed in the liguid and that there was no evidence of small clusters of Hater since separate bands failed to appear in their fressure 
studies of water.

Rabman and Stillinger did a molecular dynamics study of a model of liquid water consisting of 216 molecules at a tenperature of $34.30^{\circ} \mathrm{C}$. They claimed that their results agreed moderately well with the direct comparisons that could be made ith experiment (84). Their calculations indicated that 1) the neighbors around a water molecule tended to be tetrahedrally criented as expected, 2) there were substantial deviations away from linear hydrogen bonds, 3) there were no recognizable large clusters of molecules, 4) no patterns of known ices or clathrates appeared, 5) dangling bonds did exist which could account for the shoulders and inflections Evident in the infrared and Raman spectra, 6) no separation of molecules into network and interstitial species uas apparent. 7) all rotational angles about the hydrogen bond axis existed and 8) no significant network interpenetrations were observed. They felt that the theoretical correlation. functions resulting from this calculation indicated that liquid vater was a random, defective and highly strained network of hydrogen bonds that filled space rather uniformly. Even for a wide choice of effective pair potentials, they alyays cbserved a single maximum in the coordination numbers, which implied that there were no two classes of molecules in liguid water. 
This computation is consistent with an earlier report by Schiffer and Hornig that vibrational dynamics calculations for liquid water demonstrated that most of the hydrogen bonds were greatly distorted (89). They felt that the spectral envelope associated with the $O H$ (Or OD) stretching frequency was due to a distribution of different potential energy environments for the HDO molecule which resulted from collisions in molecules. Thereby three types of environments could result from collisions: 1) near linear a-H---0 systems with different lengths: 2) highly non-linear $0-H---0$ bonds with a distribution of bond angles and 0---0 distances and 3) perturbations of electron densities in the hydrogen bonds caused by lateral collisions. All of these effects were. they expected, to be associated with a continuun of energies, not discrete states.

In 1972 Curnutte and Bandekar reported normal vibrational computations based on the continuum model of water (21). These calculations for the $O D$ and $O H$ stretching frequencies of HDO reproduced nearly all spectroscopic features, including inflections, shoulders and isosbestic points. They sugqested that the difference in the spectral band shape between the calculated bands and observed bands might be evidence of the existence of bent hydrogen bonds in liquid water. which they did not assume. It could also be a fault of their assumption that the efficiency of scattering or ab- 
sorption was constant for all frequencies.

Solutions

From the above discussion it is clear that it is difficult to find a unique model for liquid water in general or for the vibrational spectrum of water specifically $(47,60)$. In fact, it is not even established whether different species cf water molecules can be detected in the vibrational spectrum of water. If electrolytes are added to the water, the interpretation becomes more complex $(49,50)$ : Some feel that until a fer of the unique properties of water are better understood. it is premature to expect to model the specific properties of ions in aqueous solutions (19). However, an important criterion in considering models for liquid water is their applicability to solutions (74). Any definitive theory of water must be able to describe the changes that occur in the solvent when either electrolytes or non-electrolytes are added. for it seems that the special features observed of solvents in water are associated with the specific structure of water $(101)$.

The Raman spectrum should offer a useful technigue for characterizing the water of hydration in solutions (104). As noted earlier, the stretch frequency of water is sensitive to the local environments, and the frequencies are primarily determined by the nature and character of the immediate bydrogen-bonded neighbors. The information which might be 
obtained from the Raman spectrum of water in ionic solutions wculd be related to the duration, extent and strength of the ion-water interaction (104).

It would seem that in a dilute solution, there should exist two general classes of water molecules, 1) the water of hydration or affected water that is in the immediate vicinity of the anions or cations and 2) the water that is so far avay from the ion that it is unaffected (104). Sillce the water of bydraticn is structured differently, than the unaffected water, it perhaps would be expected to shor a range of frequencies resolvable from those of pure water. However, only slight modifications in the oD or OH spectral bands occur for wost hydrated salts $(1,14,56)$. Only the anions $\mathrm{ClO}_{4}$ - and $\mathrm{BF}_{4}$ - have been reported to give clear evidence for separate species (1). This is consistent with the infrared investigations of simple hydrates $\left(\mathrm{NaCl} \cdot 2 \mathrm{H}_{2} \mathrm{O}\right.$, NaI. $2 \mathrm{H}_{2} \mathrm{O}, \mathrm{CuCl}_{2} \cdot 2 \mathrm{H}_{2} \mathrm{O}$, $\mathrm{CaSO}_{4} \cdot 2 \mathrm{H}_{2} \mathrm{O}, \mathrm{Li}_{2} \mathrm{SO}_{4} \cdot \mathrm{H}_{2} \mathrm{O}, \mathrm{SrCl}_{2} \cdot 2 \mathrm{H}_{2} \mathrm{O}$ and $\left.\mathrm{CaCl}_{2} \cdot 6 \mathrm{H}_{2} \mathrm{O}\right)$ which reveal that water molecules in many of these crystals have intermolecular energies close to those found in liquid water (89). So the water stretching frequencies in these systems fall in the same region as in pure vater, and this suggests that the local envircnment of the water molecules is not greatly different for liguid water and many hydrates.

consistently, it has been reported that the cations have small or negligible effect on the spectral frequencies of 
water $(1,16,19,92,107,109,114,118)$. This is said to Le related to the lover polarizabilities of cations, compared to that of the anions. which is due to the fact that the interaction between cations and water is chiefly ionic. Also. the insensitioity of the $O H$ stretching frequency to the nature of cations is consistent with the normal mode calculations discussed earlier. which showed that bonding at the oxygen lone pairs negligibly affected the stretching frequencies (69). However, Deloze and Brown recently claimed that their infrared work indicated that cations and not anions were chiefly responsible for structure making or breaking features of salt solutions. (24). And Hass and stein demonstrated that there was vibrational coupling of $\mathrm{H}_{2} \mathrm{O}$ and $\mathrm{D}_{2} \mathrm{O}$ to electronic levels of $\mathrm{Gd}^{3+}$ in aqueous perchlorate solutions (42). They stated that this froved the existence of a quasimolecular entity consisting of the rare earth ion and its bydrated shell.

Walrafen reported that large effects are caused by $\mathrm{Cl}^{-}$ on the libraticnal and hindered translational spectra of water $(107,109,114)$. These changes supposedly indicated that the $\mathrm{O}-\mathrm{H}---\mathrm{Cl}-$ bonds were less polar than the $\mathrm{O}_{-\mathrm{H}---0}$ bonds. Also be asserted that the depolarization ratios of these bands confirmed that the $\mathrm{O}-\mathrm{H}---\mathrm{Cl}$ - units were nearly Iinear. 
He associated principal effects of $\mathrm{cl}^{-}$"ön the stretching frequencies of water with the hydration of the c1-ion (114). The integrated intensity of the stretching band increased, but no separate resolvable peaks occurred $(115,118)$. Thus it vas suggested, as already indicated above, that the hydrogen bond energy was similar for both oxygen and cl-.

Wyss and Falk reported that for one mole of $\mathrm{NaCl}$ in eleven moles of vater having a small fraction of HDO, the infrared spectrum showed an increase in peak intensity, decrease in half width and an upward shift in frequency for the $O D$ stretcining frequency (118). They expected these band parameters to vary almost linearly with sclute concentration. otherwise they observed no new features in the IR spectrum of HDO. Since no new bands are resolved, they felt that the a-H--CI- groups must have a distribution of frequencies similar to that of $0-\mathrm{H}---0$ groups. This was taken to mean that no distinct hydration sphere existed in aqueous solutions of NaC1.

In a Ram spectral study that included nearly saturated soluticns of $\mathrm{KCl}, \mathrm{HCCl}_{2}, \mathrm{ZnCl}_{2}, \mathrm{BeCl}_{2}, \mathrm{SnCl}_{2}, \mathrm{CuCl}_{2}, \mathrm{AlCl}_{3}$, $\mathrm{IaCl}_{3}$ and $\mathrm{PrCl}_{3}$. Hall and Hornig reported that no evidence for water of bydraticn appeared (104). They observed no satellites, and no band distortion or broadening produced by these ions is apparent. In their estimate, this placed a limit on the duration, extent and strength of the ion water 
interaction. Further, for different potassium halides, the frequency of the $O D$ stretching band increased in the order $\mathrm{F}^{-}<\mathrm{H}_{2} \mathrm{O}<\mathrm{Cl}^{-}<\mathrm{Br}<\mathrm{I}-$ They felt, like Wys and Falk, that this demonstrated that the anions were affecting the frequency of water rather than changing the relative populations of water molecules associated vith a fer species in the liguid.

Adams. Blandamer. Symons and Haddington compared the two anions, $\mathrm{ClO}_{4}-$ and $\mathrm{BE}_{4}-$, that made distinct resolvable stretching bands (1). There was a slight but definite difference between the two newly formed bands. They beliered that this indicated that the new bands were due to an anion effect on the stretching frequency of vater and were not due to water molecules that have become non-hydrogen bonded. 


\section{EXEERIMENTAL INVESTIGATION}

Equipment

Por the majority of the Raman experiments reported here, a Spectra-Physics model 165 argon ion laser with an advertised pover output of four watts was used as an excitation source. This laser yas provided with a prism at the rear of the laser cavity to permit discrete selection of any of nine argon laser frequencies which are in the blue and green region of the spectrum. The band yidth for any of these frequencies operating in the TEM node was about $0.2 \mathrm{~cm}^{-1}(5 \times 109$ hertz). The laser came with a pover stabilizer that maintained a constant laser output to within 0.5\%. For most of the work reported bere, the $488.0 \mathrm{~nm}$ laser line was used at a power of 1.5 watts. Some of the early work recorded for water was done on an older argon laser (Spectra-Physics model 140) using the $514.5 \mathrm{~nm}$ laser line at a power of about 0.9 vatts. For both of these lasers, the emerging beam was vertically polarized and was directed in a horizontal plane.1.

Pollowing the laser was a mount for a 900 polarization rotator (a guartz half-wave plate). By taking spectral data vith and without this optical component, Raman spectral data

Isee Fig. 1 for schematic of equipment. 

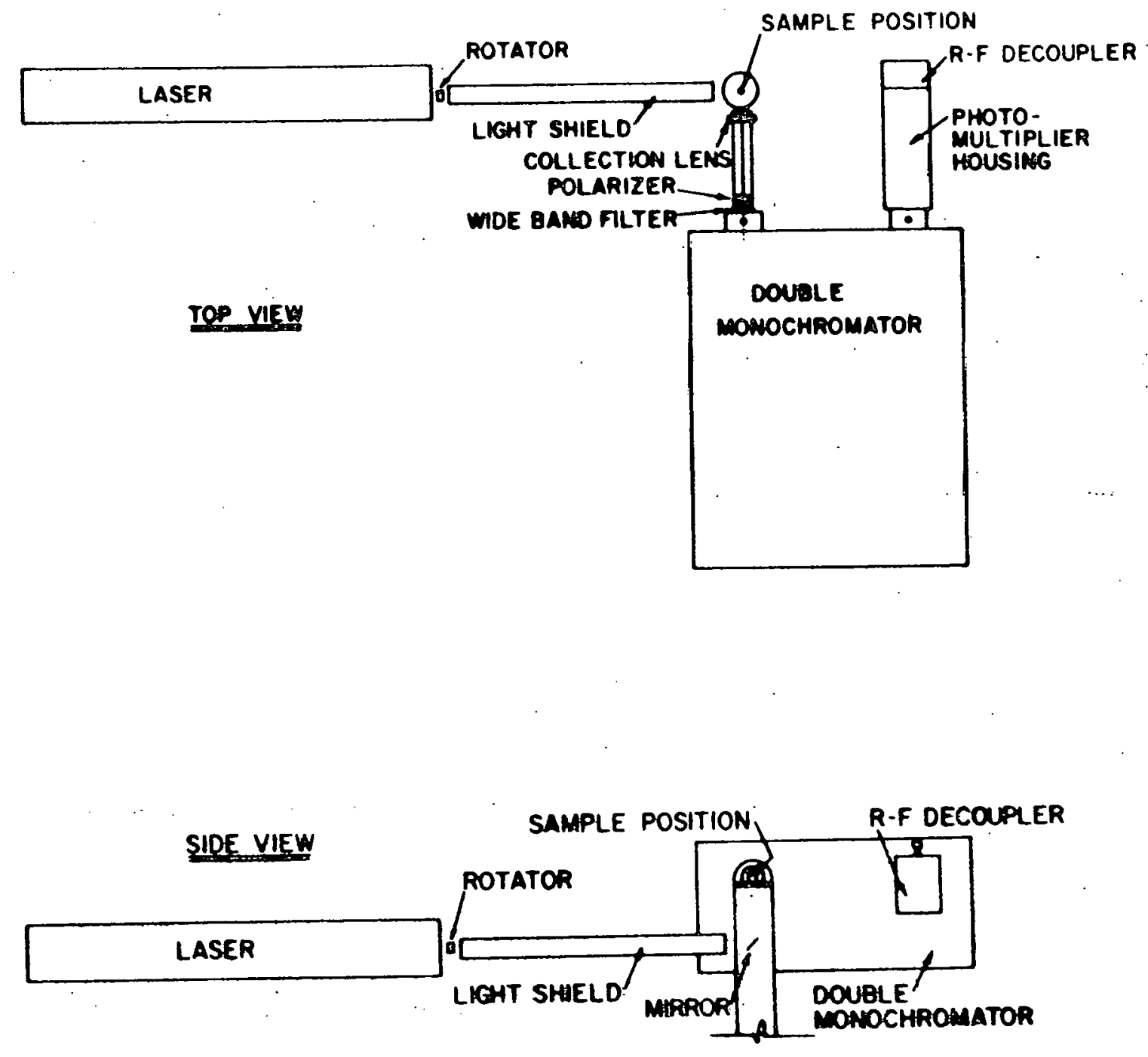

Fig. 1. Schematic of experimental set-up. 
was obtained for two polarizations.l In order to ascertain that the rotator worked and was properly oriented, it was tested with the aid cf a polarizer. When the optical rotator was inserted into the optical path of the system, the laser power was increased so that there still was 1.5 watts of laser pover entering the Baman sample chamber. This vas verified by an independent laser poyer weter.

In the Raman sample compartment, which was constructed at this laboratory, the laser beam was first deflected to a vertical path so that it us parallel to the entrance slit of the moncchromator. Then it was focused by an anti-reflection coated lens which had a focal length of $3.0 \mathrm{~cm}$. This biconvex lens vas designed for minimum spherical aberration so as to give a nearly diffraction-limited focus. With this lens the diameter of the laser beam in the sample was approximately 50 microns over a distance of a conple of millimeters. $X-Y-z$ adjustments vere provided for this lens.

The liguid samples were contained in a one milliliter cylindrical quartz silica cell obtained from spex which was mounted in one of their sample holders. The laser beam passed along the axis of the cell.

1Cardamone, Hunt and stevens verified that there vas only one depolarization ratic for pure liquids far from their critical temperature, and hence there were only two independent polarizations of the scattered light (17). 
scattered light from the sample was collected by a three inch non-reflection coated lens at right angles to the laser beam. The lens yas located so that it magnified its object by a factor of four and focused the image on the silt jars of the moncchromator. The aperture of this lens approximately watched the acceptance solid angle of the monochromator, which was about 0.014 . All of these optical arrangements vere designed to achieve optimum illumination geometry 13,4 . 91).

At the entrance to the monochromator, a short GianThompson polarizer with anti-reflection coatings was positioned. Normally. this vas kept in a fixed orientation and the polarization rotator described earlier was consistently used tc obtain the two polarizaticns of the Raman spectra of a solution. It was verified that similar results vere obtained whether the rotator was kept fixed (that is not placed in the laser beam) and the polarizer rotated 900 between measurements or the polarizer kept fixed and the rotator inserted between measurements. The latter procedure yas followed for these experiments for sake of simplicity. The polarizer vas aligned in the mount by reflecting the laser beam through it into the monochromator to the electronic detection system and obtaining a null. When the optic axis of the polarizer was perpendicular to the electric vector of the laser ream, then the intensity of the 
transmitted light was three orders of magnitude less than when they vere parallel. As an additional test, the depolarization ratio was determined for the $450 \mathrm{~cm}^{-1}$ line of $\mathrm{CCl}_{4}$. A value of $0.0076 \pm 0.0005$ was obtained, which compared favorably uth values of $0.0039-0.0075$ given in the literature $(71,90)$.

Immediately following the polarizer and mounted on the entrance slit of the monochromator was a wide band filter (500-650 $\mathrm{nm}$ which was chosen to be opaque outside of the spectral region in which Raman data was taken.

The dispersing element used in this Raman system was a Spex 1400 double grating monochromator. Both gratings vere ruled with 600 grooves per millimeter and vere blazed at 1.6 microns. These gratings were used in third order for all of the experiments reported here. Because of the use of the broad band filter, no order overlap cccurred in the relatively narrow spectral region investigated.

The radiation emerging from the exit slit of the monochroator was focused onto the cathode of an ITT FH-130 photcoultiplier tube wich had an $s-20$ frequency response. This was a specially selected tube which had a photon dark current of about 130 ccunts fer second at $22^{\circ} \mathrm{C}$ when operated at 1900 volts. Although this dark current could be reduced by an order of magnitude when the tube was cooled to $0^{\circ} \mathrm{C}$, it was sufficient to use the tute at roow temperature for the 
experiments reported here. Pover was supplied to this tube by a Keithley model 246 high voltage pover supply.

output from the photomultiplier tube vas passed through an r-f decoupler intc the preamplifier-discriminator of an SSR 1100 series photcn counter system. The tube, its socket, the $r$-f decoupler and the preamplifier-discriminator vere shielded by an alumioum housing which was grounded. The ratemeter was used in its digital mode to operate a CMC model 707 BN frequency-period electronic counter. The counting system was able to respond linearly to the random pulses from the photomultiplier tube up to about 500,000 counts per seccnd, rates more than an order of magnitude greater than maximum readings taken for data. This was determined by comparing the diqital readings with simultaneous analogue readings. The electronic counter was the first element in the system that vent non-linear.

\section{Calibration}

A neon lamp was used to wavelength calibrate the monochrcmator, using 26 of the neon emission lines listed by Lcader (63). The calikration was made before, during and after the experiments vere conducted, a total of six times over the entire frequency range of interest. The systematic difference between the initial and final checks was about $1 \mathrm{~cm}^{-1}$, and the repeatability for consecutive calibrations was $0.5 \mathrm{~cm}^{-1}$. The entrance slits were adjusted to a width of 
200 microns, which corresponded to the diameter of the laser beam image. The intermediate and exit slits were opened to 400 microns. With these sitwidths, the effective half-width frequency band-pass of the monochromator for a fixed grating position in the spectral region of interest was about $17 \mathrm{cat}^{-1}$ or less. 2 When this is convoluted with a spectral band having a half-width of $150 \mathrm{~cm}^{-1}$ or more, the effect on the observed baad is negligible $(38,52,53)$. So the observed spectral band is a yery good approximation to the real band shape for the data in this report.

The intensity response versus frequency of the entire system from saple location to counter was calibrated using a tungston ribbon filament lamp which was temperature calibrated in a 8641 Mark I Precision Automatic optical Pyrometer (Leeds and Northrup). The filament of this bulb was located at the sample position and operated at a temperature of $2666 \pm 20^{\circ} \mathrm{K}$. Since only relative Raman intensities vere sought, it was permissible to reduce the slitwidths of the monochromatcr so that the detected spectral intensity of the standard lamp was compatible with the detection system.

$10 f$ course, for fixed slitwidths the band-pass was a function of monochromator setting, as shown in Pig. 2. But since the monochromator was intensity calibrated with fixed slituidths, the relative intensities across the entire spectral band ought to be correct. 


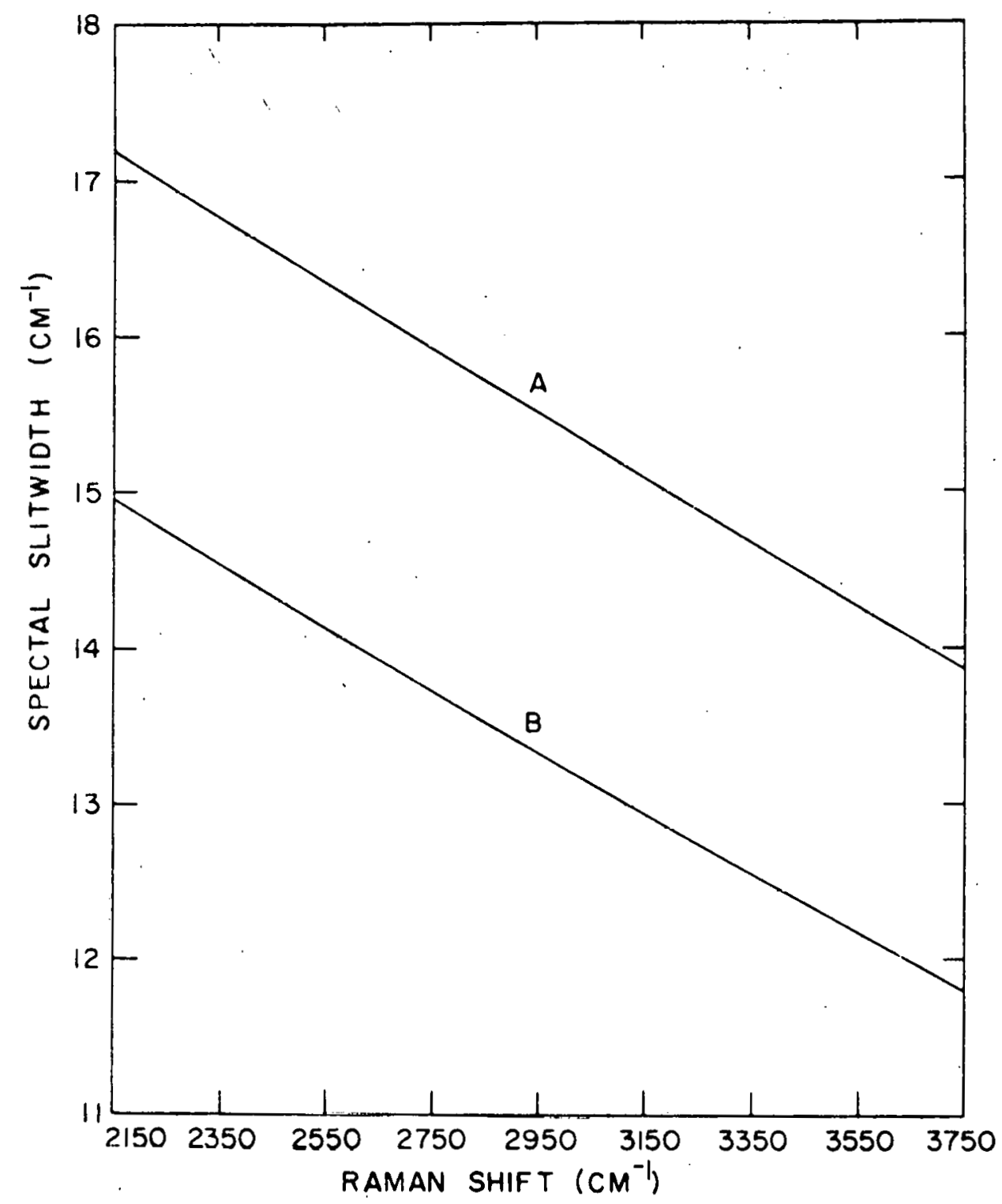

Fig. 2. The effective spectral half-width of the monochromator as a function of the Raman shift for A) the $488.0 \mathrm{~nm}$ and B) the $514.5 \mathrm{~nm}$ exciting laser lines and ith the monochromator entrance slit set at $200_{\mu}$ and the exit slit at $400_{\mu}$. 
Calibration was done four times before Raman data yas taken, once in the midst of data collection and three times at the conclusion of the runs. There were no systematic differences apparent among the separate calibration scans, and the average standard deviations for the intensities taken at 58 different frequencies in the spectral region of interest was 0.33 in counting units, where the detected intensity of the sfectra of the lamp ranged from 40 to 70 in the same units.1

The actual relative intensity of the standard lamp as a function of frequency was calculated frcm the equation

$$
I(v)=R \varepsilon(v) v^{s} \exp \left(-1.438_{v} / T\right)
$$

were the constant $K$ was chosen so that the magnitude of the calculated intensity us comparable to the experimental intensity in the frequency range of interest, values for the emissivity, $\varepsilon(v)$, which takes into account the fact that the lamp was not a black-body, were obtained from devos (25), $\checkmark$ was the frequency in $c^{-1}$ and $T$ was the temperature in Kelvin units. Corrections for the absorption of the glass envelope were approximately constant over the small range of spectral frequency scanned in these experiments. Hence, this effect was included in the constant $R$. The relative error in

I ne counting unit was equivalent to 1000 counts per second on the electronic counter. In these units, the dark current of the photomultiplier tube was 0.13 . 
the calibrated intensity due to the error associated with the filament temperature was negligible.

solutions

stock rare earth solutions were prepared frow highly purified rare earth oxides obtained from the rare earth separation group of the Ames Laboratory of the U. S. Atomic Energy commission. These oxides were estimated to contain no more than $0.08 \%$ rare earth impurities, and other inorganic impurities vere less than $0.04 \%$ of the total content. Slightly insufficient acid was added to the dry oxides, and the excess oxide was removed by fiitering the solutions through a fine sintered glass filter. These stock solutions were then adjusted to their equivalence pH by adding dilute acid. Then they vere heated for several hours to dissolve any remaining oxy-chloride or colloidal oxide. After the solutions cooled, the pH was adjusted again to the equivalence pH, and again the solutions were heated for several hours. This procedure was repeated until the stock solutions maintained their equivalence $\mathrm{pH}$. The concentrations of the stock solutions were determined by EDTA and chloride analysis. Soluticns made frow these stock solutions vere prepared by weighing various amounts of the stock solution into stoppered flasks. From the amount of stock solution weighed out the proper amount of $\mathrm{H}_{2} \mathrm{O}$ and $\mathrm{D}_{2} \mathrm{O}$ needed to obtain the desired solvent mixture was determined and weighed into each flask. 
All weights vere corrected to vacuum. Prom the corrected weights of the stock solution, $\mathrm{H}_{2} \mathrm{O}$ and $\mathrm{D}_{2} \mathrm{O}$ in each flask the concentration of rare earth salt per mole of solvent mixture uas calculated for each solution.

Solutions in which $95 \%$ of the water was $D_{2} \mathrm{O}$ were prepared from anhydrous rare earth chlorides. Under a dry helium atmosphere appropriate amounts of anhydrous salts were placed in previously weighed stoppered flasks and then weighed. Then the appropriate amounts of $\mathrm{H}_{2} \mathrm{O}$ and $\mathrm{D}_{2} \mathrm{O}$ were weighed into the stofpered flasks to obtain the desired sclient mixture. From the weights corrected to vacuum, the concentrations of the clear solutions of the rare earth cblorides vere determined. To ensure that no suspended materials vere still present, each solution was pressure filtered through a $25 \mathrm{~m}_{\mu}$ Millipore filter directly into the sample cell wich was subseguently capped with a quartz flat. The deuterium oxide used in making these solutions yas obtained from J. T. Baker Chemical Company and was reported to have a minimum $99.75 \%$ atom per cent $D_{2}{ }^{0}$. This estimate was consistent with the observed Raman intensity of the $O H$ spectrum made of a sample taken directly from the bottle. All of the normal water used was conductivity water which had a specific conductance of less than $1 \times 10^{-6}$ mho per $\mathrm{cm}$.

From simple probability considerations of water or solutions in which $5 \%$ of the water is $D_{2} O$, $95 \%$ of the $D_{2}{ }^{O}$ is con- 
verted to HDO by exchange with $\mathrm{H}_{2} \mathrm{O}$. Hence, at equilibriuw, 9.5\% of the water will be HDO, $0.25 \%$ will be $\mathrm{D}_{2} \mathrm{O}$ and the remining $90.25 \%$ will be $\mathrm{H}_{2} \mathrm{O}$. The resulting equilibrium constant will be 4.00 . Of the HDO, $66.34 \%$ vill have normal water wolecules for its four nearest neighbors. The remaining HDO's will have one or more HDO's or $\mathrm{D}_{2} \mathrm{O}^{\prime} \mathrm{s}$ among its four nearest neighbors. There is a $90.25 \%$ chance that an $\mathrm{H}_{2} \mathrm{O}$ will be bonded to the OD unit of the HDO molecule. All of this assumes the chemical identity of hydrogen and deuterium. i. e. that no selective properties exist: Identical consideration would be true for of units of HDO where 95\% of the water is $\mathrm{D}_{2} \mathrm{O}$.

However. Bonner stated that the equilibrium constant for

$$
\mathrm{H}_{2} \mathrm{O}+\mathrm{D}_{2} \mathrm{O} \neq 2 \mathrm{HDO}
$$

was 3.80 at $25^{\circ} \mathrm{C}(13)$. Using this for a sample of water, 95x of which is $\mathrm{H}_{2} \mathrm{O}$ and the remaining $5 \%$ is $\mathrm{D}_{2} \mathrm{O}$, calculations show that at equilibrium about $94.76 \%$ of the $D_{2}{ }^{0}$ reacts with $\mathrm{H}_{2} \mathrm{O}$ to form HDO.

Walrafen reported that for $3.1 \mathrm{M}$ and $6.2 \mathrm{M} \mathrm{D}_{2} \mathrm{O}$ in $\mathrm{H}_{2} \mathrm{O}$ and 2.8 and $6.5 \mathrm{M} \mathrm{H}_{2} \mathrm{O}$ in $\mathrm{D}_{2} \mathrm{O}$ the Raman frequencies of the maximum intensities and the relative intensities across the $O D$ or $O H$ stretching rand vere essentially the same which indicated that intermolecular interactions as vell as intramolecular couplings were negligible (114) . However, Ford and Falk noted that the balf-widths for their infrared 
ice spectra of $0.3 \%$ HDO in $\mathrm{D}_{2} \mathrm{O}$ and $0.5 \%$ HDO in $\mathrm{H}_{2} \mathrm{O}$ was measurably narrower than similar york yhich had involved 5-10\% HCO in water $(32,10,41)$. They interpreted this to wean that in vater with $5 \%$ or more, of $D_{2} O$, HDO coupled vibrations vere affecting the spectra measurements.

Unless noted othervise; in all solutions used in the experiments reported here, about $5 \%$ of the total water (by number of moles) was $\mathrm{D}_{2} \mathrm{O}$ or $\mathrm{H}_{2} \mathrm{O}$ for the study of the $O D$ and $O H$ stretching frequencies respectively.

There is a marked visual difference in the $O D$ and $O H$ stretching band contours $(114)$. While it is felt that the substitution of $D$ for $H$ affects the properties of water very little (102), the smaller dissociation constant, greater viscosity, heat capacity, melting. point and temperature of maximum density indicate that the hydrogen bonds are slightly strcnger for deuterium than for normal vater $119,22,43,46$, 50. 79, 87, 100, 102). So, heavy water is commonly regarded as being more structured than normal water. It was felt that the overall effect of deuteriun substitution could be due to two effects: 1) Contraction of the 0-0 bond length due to an increase in dipole moment and 2) The zero point energy difference causing an expansion of the 0-0 distances (102). vinogradov and Linnell stated that at 0-0 distance of about $2.7 \&$ these effects should be equal and cancel each other. The expansion term uas expected to predominate at shorter 
bond lengths, and the contraction term should dominate at longer bcnd lengths leading to a shortening and strengthening of the bydrogen bond when deuterium was substituted. Since liguid vater has an average $0-0$ distance greater than 2.88 (73), the above analysis yould also indicate that deuterium ought to have stronger hydrogen bonds than normal vater. From a consideration of the difference between the apparent activation energy for deuterium and normal water and from gas electron diffraction techniques, it was suggested that the energy difference in the two hydrogen bonds was $0.27-0.30$ Kcal mole-1 $(2,33,65,102)$. Generally, the od stretching vibration is studied in preference to the $O H$ frequency because of the difficulty in maintaining a constant low concentration of $\mathrm{H}_{2} \mathrm{O}$ in $\mathrm{D}_{2} \mathrm{O}(14)$. 


\section{DATA}

Raman data uas obtained for the OD stretching spectral band of water and six concentrations of aqueous solutions of $\mathrm{LaCl}_{3} \cdot \mathrm{GdCl}_{3}$ and $\mathrm{LuCl}_{3}$ in which $5 \%$ of the water was $\mathrm{D}_{2} \mathrm{O}$. The six concentrations of the rare earth salt solutions were approximately $0.5,1.0,1.5,2.0,2.5$ and 3.0 molal. Por comparison. Raman data was also obtained for the of stretching frequency of ater and aqueous $\mathrm{GdCl}_{3}$, having similar concentrations as indicated above, in which $95 x$ of the water was $\mathrm{D}_{2} \mathrm{O}$. The temperature of these solutions vas allowed to core to equilibrium with the thermostated room which vas, when data was taken, kept at $22^{\circ} \pm 10 \mathrm{C}$. A thermocouple used in several test solutions verified that the temperature of the solution in the laser bean was less than $0.5^{\circ} \mathrm{C}$ above room temperature. The solution obtained its eguilibrium temperature vithin several minutes after the laser was turned on. Measurements and Error Analysis

Intensity readings were taken for bcth polarizations at frequency intervals of $10 \mathrm{~cm}^{-1}$. The electronic counter was activated for ten seconds at each frequency for each scan. For the $O D$ stretching frequency, the spectral region was scanned from $2150 \mathrm{~cm}^{-1}$ to $2800 \mathrm{~cm}^{-1}$. Por the or stretching frequencies scans were made from $3050 \mathrm{~cm}^{-1}$ to $3800 \mathrm{~cm}^{-1}$. Scans were made for each concentration two or more times. 
Both the $O D$ and $O H$ spectral bands are superimposed on a finite background. For the solutions in which $5 \pi$ of the yater was $\mathrm{D}_{2} \mathrm{O}$. it was assumed that the background could be approximated in the OD spectral region by the spectrum of solutions of the same concentration wade with $100 \times \mathrm{H}_{0} \mathrm{O}$. Likewise, fcr solutions in which $95 \%$ of the water was $D_{2} 0$, solutions made entirely with deuterated water vere used to approximate the background in the spectral region of the $\mathrm{OH}$ band. Evident in the spectrum of $H_{2} \mathrm{O}$ in the low frequency region of the $O D$ stretching vibration is the high frequency side of the combination band. The tail of the $\mathrm{H}_{2} \mathrm{O}$ stretching band is apparent in the high frequency region of the oD stretching band. The spectra of $D_{2} 0$ in the spectral region of the CB stretching vibration is essentially flat except for the tail of the $D_{2} O$ band on the low frequency side of the region scanned. The integrated intensity for consecutive runs of the same undisturbed solution ncrally varied less than 1x. However. the integrated intensities of separate runs of two different samples of the same solution vere different on the average by approximately $2.5 \%$. Since comparisons were to be made of relative intensities, the integrated intensity for the several scans of a solution were normalized to a common value (normally the averaged integrated intensity). then averaged and a variance obtained for the intensity at each frequency. a similar procedure was followed for cor- 


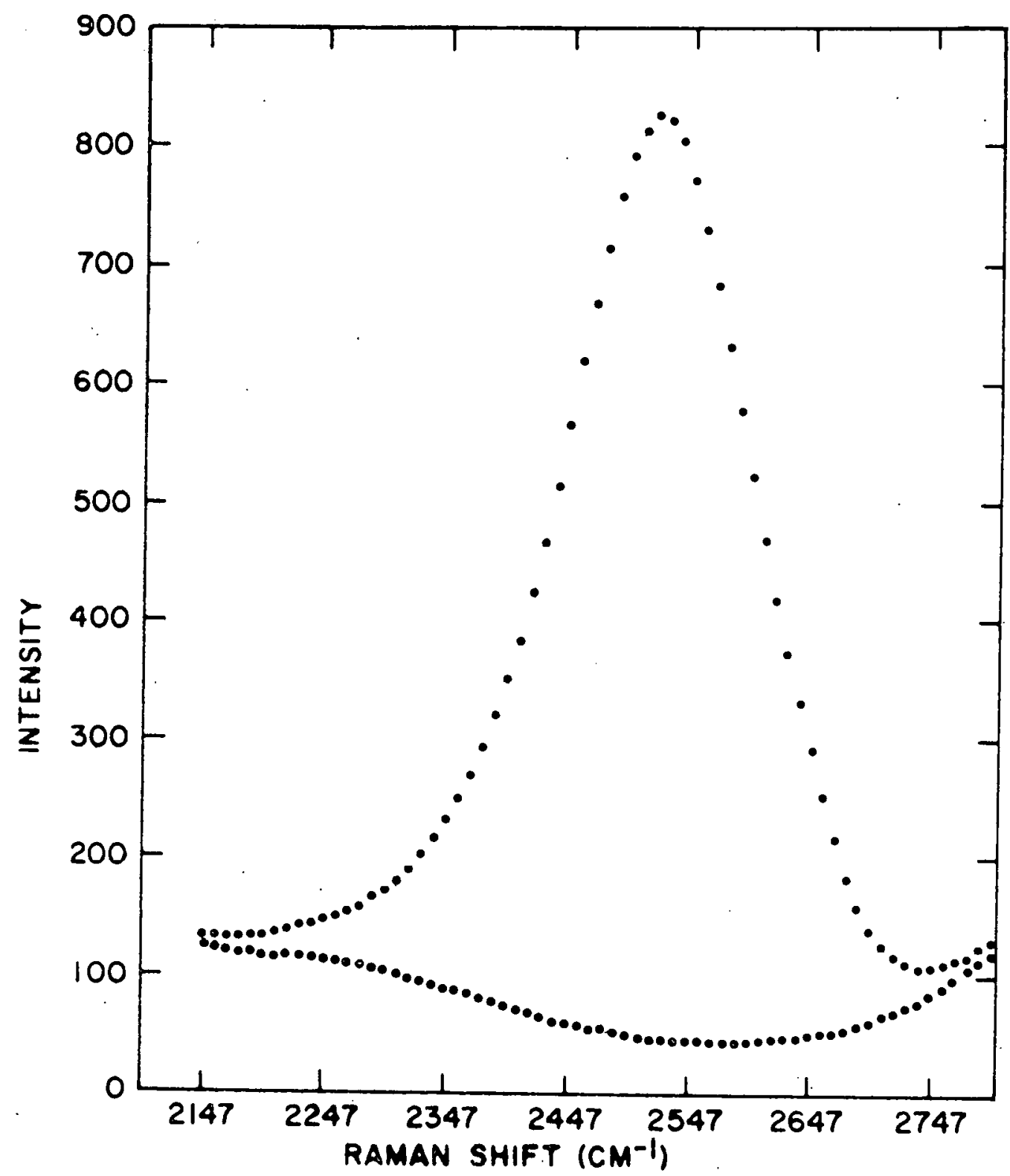

Fig. 3. A typical Raman spectrum of the oD stretching vibration of HDO in a $3.2 \mathrm{~m}$ solution of $\mathrm{GdCl}_{3}$ with its corresponding background which needs to be subtracted. 
responding background scans. These intensities were then converted into intensities per mole of $\mathrm{D}_{2} \mathrm{O}$ for solutions which were used for spectral scans of the oD stretching freguency and to intensities per mole of $\mathrm{H}_{2} \mathrm{O}$ for solutions that were used for the of frequency studies.

The corrected relative molar intensity of the spectrum at each frequency was then deterwined by the relation

$$
I=(R-B) L / S L
$$

where at each frequency

$$
\begin{aligned}
& \text { I - the corrected relative molar intensity of the } \\
& \text { Raman band } \\
& \text { B - the experimental molar band intensity } \\
& \text { B - experimental background readings } \\
& \text { L - the calculated lamp intensity } \\
& \text { SL - the observed standard lamp intensity.1 }
\end{aligned}
$$

The variance associated with the corrected relative wolar intensity of the Raman spectral band at each frequency was obtained from the relation

$$
\sigma^{2}(I)=[L / S L]^{2}\left\{\sigma^{2}(R)+\sigma^{2}(B)+[[B-B] / S L]^{2} \sigma^{2}(S L)\right\}
$$

where at each Raman frequency

$\sigma(I)$ - the standard deviation cf the corrected molar. intensity at each frequency

$\sigma(B)$ - the standard deviation the experimental molar intensity of the band

see fig. 4 for the ratio. L/SL. 


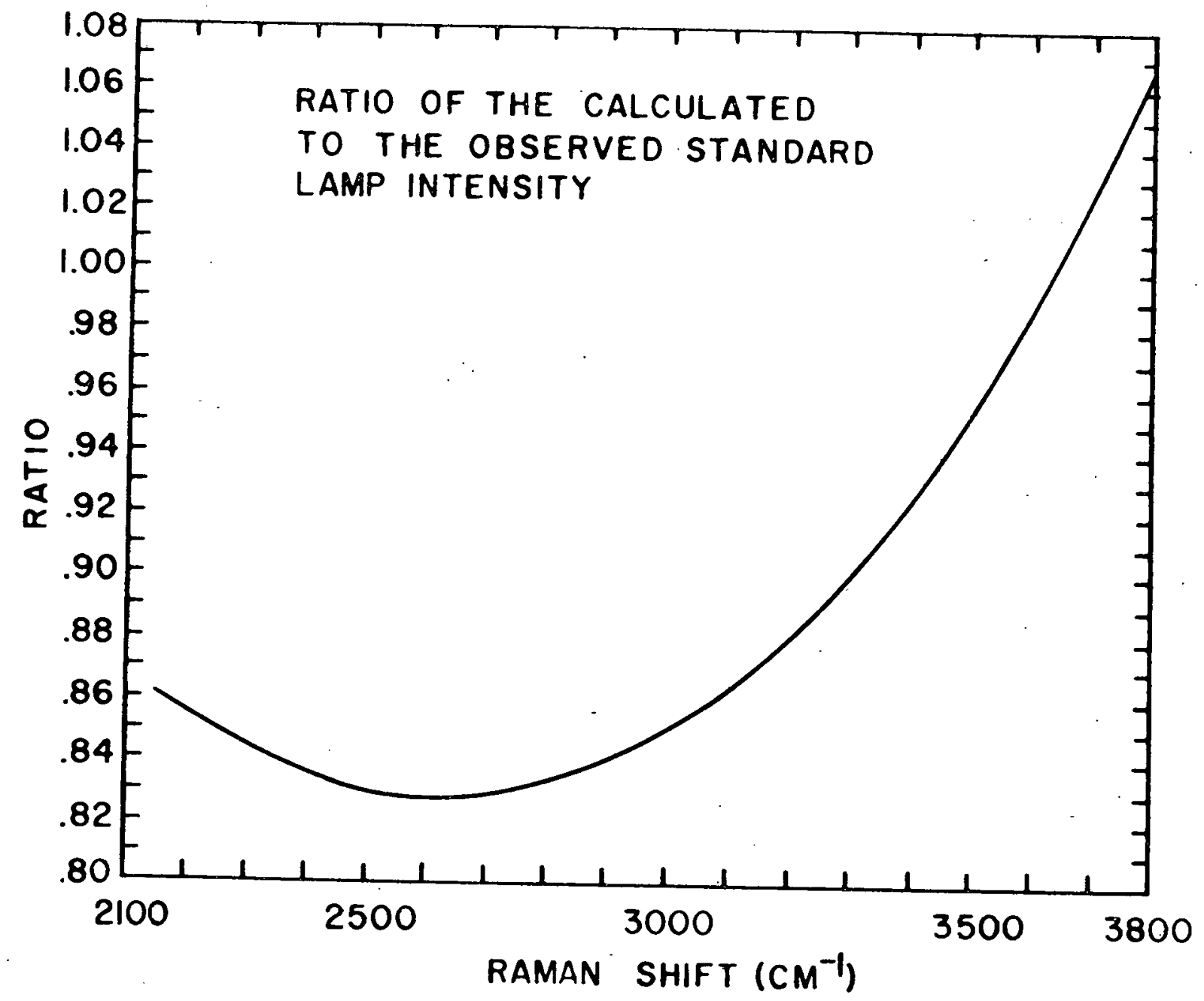

Fig. 4. The ratio of the calculated standard lamp intensity to the observed lamp intensity as a function of the Raman shift for the 488.0 na exciting laser line. 


$$
\begin{aligned}
& \dot{\sigma}(B) \text { - the standard deviation of the experimental } \\
& \text { background data } \\
& \sigma(S L) \text { - the standard deviation cf the experimental } \\
& \text { standard lamp intensity }=0.33 \text { as explained } \\
& \text { earlier. }
\end{aligned}
$$

A term associated with the error in the calculated lamp intensity. $\sigma(L)$. was neglected since this error vas several orders of magnitude smaller than the above terms, as indicated earlier. $\sigma^{2}(I)$ is subsequently referred to as the "estiwated variance", and $\sigma(I)$ is called the "estimated standard deviation".

Aiso, at the same time, all observed Raman frequencies vere corrected to freguencies in vacuum, using tables and equation $\$ 5$ in Loader (63). See also reference (97).

after these calibrations, corrections and calculations of estimated variances were completed, the data was entered into a non-linear least-squares fitting routine to obtain a suitable weighted fit of the data to an analytic function (37. 80). The analytic functions used vere a combination of two or more Gaussian or skewed-Gaussian functions of the form

$$
\begin{aligned}
& A=I_{0} \exp \left(-4 \ln (2)\left(v-v_{0}\right)^{2} / \Delta^{2}\right) \\
& B=I_{0} \exp \left(-4 \ln (2)\left(v-v_{0}\right)^{2} /\left(\Delta-s\left(v-v_{0}\right)\right)^{2}\right): \text { skewed-Gaussian }
\end{aligned}
$$

where

Io is the maximum ralue of the Gaussian

$v_{0}$ is the peak fosition in units of $\mathrm{cm}^{-1}$

$\Delta$ is the half-uidth in units of $\mathrm{cm}^{-2}$

s is the unitless skewing parameter. 
The parameters associated with each Gaussian vere adjusted to obtain a least-square fit. A factor multiplying the background vas also used as a parameter in the fitting procedure. This adjustment was permitted because of the fact that the collection efficiency for separate runs differed with a standard deviation of about 2.5\%. And it vas also a recognition of the fact that the data used for the background was an approximation to the ccrrect background. The final paraneters of the least-sguares Gaussian fits were used to determine the total integrated intensity under the spectral band.

Independant of the least-squares fit routine, this computcr program was also designed to calculate the frequency of the experinental peak intensity of the data by taking numerical derivaties, using a convolution procedure described by Savitzky and Golay (88), and interpolating to find the frequency for which the derivative was equal to zero. Then, also by interpolating. the magnitude of the peak intensity was obtained wich was used to find the widh of the experimental spectral band at half waximum intensity - commonly called the half-widtb.

The reduced chi-square statistic was utilized to indicate if the analytic function suitably fit the data (11). If the variance between the data and the least-squares functicnal fit is called the "calculated variance", then the reduced chi-square can be described as the ratio of the cal- 
culated variance to the veighted average of the estimated. variances. If the analytic fit to the data is suitable, this ratio should be about one. For values of chi-square much larger than one it is probable that the chosen function does not fit within the noise level of the experimental data and is not descriptive of the data. When the ratio is much less than one, then this may be evidence that the function is accommodating itself to noise in the data as vell as fitting the data. Tables are given in standard statistical terts that assign percentage probabilities to values of chi-square for different numbers of data measurements (11). 


\section{RESULTS}

Spectral data associated with the isotropic and anisotropic Baman tensorsi were separately obtained for both the $O D$ and $O B$ stretching vibrations of HDO in vater and aqueous rare earth chloride solutions, the water content of which was predominantly $\mathrm{H}_{2} \mathrm{O}$ or $\mathrm{D}_{2} \mathrm{O}$ respectively. This data is subsequently referred to as belonging to the isotropic or anisotropic $O D$ or $O H$ bands. Unless stated otheruise, the Fredominant species of water comprises about $95 \%$ of the total number of water molecules used in preparing the sample. Often a sample will be referred to as $\mathrm{H}_{2} \mathrm{O}-5 \times \mathrm{D}_{2} \mathrm{O}, \mathrm{LaCl}_{3}-5 \mathrm{DD}_{2} \mathrm{O}$ or $6 \mathrm{dCl}_{3}-5 \mathrm{xH}_{2} \mathrm{O}$, where the approximate mole per cent of the lesser water species is used to identify the water content of the solution.2 Except for some of the isotropic od band of the water saples, all of the data was taken with the $488.0 \mathrm{~nm}$ argon ion laser line used as the Raman excitation source.

The standard deviations and the error bars of band intensities and depolarization ratios at each frequency are the

1 see page 9.

2 Naturally, as explained in a previous section; when equilibrium is achieved among the $\mathrm{H}_{2} \mathrm{O}, \mathrm{D}_{2} \mathrm{O}$ and resulting $\mathrm{HDO}$ molecules, mcst of the lesser molecular species will react to become participating couponents in HDO molecules. 
estimated ${ }^{2}$ standard deviations of the mean values of the data at that freguency. These estimated standard deviations of the mean are determined by dividing the estinated standard deviaticns of the data by the square-root of the number of data averaged. By contrast, the error bars and standard deviations listed with all of the peak intensities, half-widths and integrated intensities are strictly a measure of the estimated standard doviation of the data from the average. of course, all of these standard deviations do not account for systematic errors that may exist. The fitting of the background to the spectral band data is expected to be the largest source of systematic deviations. However, the main features and analysis of the data in this report were largely insensitive to small adjustments of the background.

Another cause of undetermined variance could be the exchange of $\mathrm{D}_{2} \mathrm{O}$ with atmospheric $\mathrm{H}_{2} \mathrm{O}$. This was especially a problem with solutions in which all cr most of the water was $\mathrm{D}_{2}$. But the fact that the analysis of this data was consistent with that for soluticns in which $5 \%$ of the water was $D_{2} O$ indicates that this problem did not hide features of interest. There was no apparent change with tise in the

1 The estimated standard deviations, determined from a finite number of measurements, is to be contrasted uith the standard deviation resulting from an infinite number of measurements. 
water composition of solutions in which $5 \%$ of the water was $\mathrm{c}_{2} \mathrm{O}$

1so, different indices of refraction for the different solution concentrations could have had systematic effects on the amount of the Raman light scattered into the acceptance solid angle of the monochromator. However, when the laser beam in the sample vas casually viewed through a low porer wicrosccpe, there was no evidence of any observable change in beam diameter or focus for different concentrations of the solution.

Nater

Isotropic OD band.

The average corrected intensities of the scans of this band along with the expected standard deviations of the averages are tabulated in Table 1. In the first column of this table are the wave numbers, corrected to values in vacuum, to be associated with the Raman shifts. The second column has the average intensity, at each of sixty-six Raman displacenents. of six scans wade with the $488.0 \mathrm{~nm}$ laser line. The calculated position of the peak intensity is $2519.2 \pm 0.7 \mathrm{~cm}-1$. and the half-vidth of this band is $183.6 \pm 0.7 \mathrm{~cm}^{-1}$. This data was compared with the arerages of nine scans of the same $O D$ stretching vibration but excited by the $514.5 \mathrm{~nm}$ argon laser 1ine. With the integrated intensity normalized to that of the above data, these intensities are listed in the fourth 
Table 1. Average intensities of the $O D$ stretching frequencies of the isotropic and anistropic spectrus of $H D O$ in water using the $488.0 \mathrm{~nm}$ (B) and $514.5 \mathrm{~nm}$ (G) laser line.

\begin{tabular}{|c|c|c|c|c|c|c|c|c|c|c|c|}
\hline \multirow[b]{2}{*}{$\begin{array}{c}c{ }^{-1} \\
2146.6 \\
2156.6 \\
2166.6 \\
2176.6 \\
2186.6 \\
2196.6 \\
2206.6 \\
2216.6 \\
2226.6 \\
2236.6 \\
2246.6 \\
2256.6 \\
2266.6 \\
2276.5 \\
2286.5 \\
2296.5 \\
2306.5 \\
2316.5 \\
2326.5 \\
2336.5 \\
2346.5 \\
2356.5 \\
2366.5 \\
2376.5 \\
2386.5 \\
2396.5\end{array}$} & \multicolumn{2}{|c|}{$5 \times(B)$} & \multicolumn{2}{|c|}{$5 \%(G)$} & \multicolumn{3}{|c|}{ 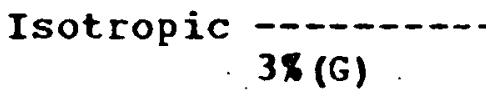 } & \multicolumn{2}{|c|}{$108(G)$} & \multicolumn{2}{|c|}{$\begin{array}{l}\text { Anisotropic } \\
5 \pi(B)\end{array}$} \\
\hline & $\begin{array}{r}\text { Int } \\
1.9 \\
2.9 \\
3.9 \\
4.3 \\
5.7 \\
7.2 \\
8.3 \\
10.3 \\
11.8 \\
14.0 \\
15.6 \\
19.1 \\
21.1 \\
24.5 \\
28.2 \\
33.0 \\
37.9 \\
44.8 \\
51.3 \\
60.5 \\
70.4 \\
82.7 \\
95.8 \\
114.1 \\
135.6 \\
161.3\end{array}$ & $\begin{array}{l}S D \\
0.4 \\
0.5 \\
0.4 \\
0.6 \\
0.3 \\
0.4 \\
0.3 \\
0.4 \\
0.4 \\
0.3 \\
0.4 \\
0.4 \\
0.3 \\
0.4 \\
0.4 \\
0.4 \\
0.4 \\
0.4 \\
0.5 \\
0.6 \\
0.5 \\
0.7 \\
0.8 \\
0.8 \\
0.9 \\
1.1\end{array}$ & $\begin{array}{r}\text { Int } \\
2.3 \\
4.8 \\
4.1 \\
4.5 \\
6.3 \\
6.7 \\
8.9 \\
10.2 \\
12.2 \\
13.5 \\
15.6 \\
18.1 \\
20.6 \\
24.8 \\
28.6 \\
33.5 \\
37.1 \\
43.9 \\
50.3 \\
59.8 \\
68.7 \\
83.3 \\
96.5 \\
114.5 \\
135.5 \\
161.9\end{array}$ & $\begin{array}{l}S D \\
1.3 \\
0.4 \\
0.5 \\
0.9 \\
1.0 \\
1.1 \\
0.6 \\
0.6 \\
0.5 \\
0.3 \\
0.7 \\
0.7 \\
0.4 \\
0.7 \\
0.4 \\
0.5 \\
1.0 \\
0.3 \\
0.5 \\
0.7 \\
1.4 \\
0.6 \\
0.8 \\
1.1 \\
1.0 \\
1.3\end{array}$ & $\begin{array}{r}\text { Diff } \\
-0.5 \\
-1.8 \\
-0.2 \\
-0.2 \\
-0.6 \\
0.4 \\
-0.6 \\
0.2 \\
-0.4 \\
0.5 \\
0.1 \\
1.0 \\
0.5 \\
-0.3 \\
-0.3 \\
-0.5 \\
0.8 \\
0.9 \\
1.0 \\
0.6 \\
1.7 \\
-0.6 \\
-0.7 \\
-0.3 \\
0.2 \\
-0.5\end{array}$ & $\begin{array}{c}\text { Int } \\
3.9 \\
5.1 \\
3.8 \\
3.2 \\
5.4 \\
7.7 \\
13.7 \\
11.1 \\
12.5 \\
15.6 \\
14.8 \\
19.7 \\
21.3 \\
26.3 \\
27.9 \\
35.0 \\
37.6 \\
43.2 \\
50.5 \\
61.1 \\
64.8 \\
81.4 \\
93.3 \\
109.7 \\
126.5 \\
152.2\end{array}$ & $\begin{array}{r}\text { Diff } \\
-2.1 \\
-2.2 \\
0.1 \\
1.2 \\
0.3 \\
-0.6 \\
-5.4 \\
-0.7 \\
-0.7 \\
-1.6 \\
0.9 \\
-0.6 \\
-0.2 \\
-1.8 \\
0.3 \\
-1.9 \\
0.3 \\
1.6 \\
0.8 \\
-0.6 \\
5.6 \\
1.3 \\
2.5 \\
4.4 \\
9.1 \\
9.2\end{array}$ & $\begin{array}{r}I n t \\
0.8 \\
2.0 \\
1.7 \\
4.5 \\
6.0 \\
6.6 \\
7.8 \\
8.8 \\
12.2 \\
13.4 \\
14.8 \\
18.1 \\
20.4 \\
24.8 \\
29.1 \\
33.8 \\
38.6 \\
44.6 \\
55.0 \\
64.1 \\
73.3 \\
89.3 \\
105.9 \\
126.9 \\
150.7 \\
180.2\end{array}$ & $\begin{array}{r}\text { Diff } \\
1.1 \\
0.9 \\
2.2 \\
-0.2 \\
-0.3 \\
0.6 \\
0.5 \\
1.6 \\
-0.4 \\
0.6 \\
0.8 \\
1.0 \\
0.8 \\
-0.3 \\
-0.8 \\
-0.8 \\
-0.7 \\
0.3 \\
-3.7 \\
-3.6 \\
-2.9 \\
-6.7 \\
-10.1 \\
-12.8 \\
-15.0 \\
-18.8\end{array}$ & $\begin{array}{r}\text { Int } \\
0.6 \\
0.5 \\
0.7 \\
0.5 \\
0.7 \\
1.6 \\
2.0 \\
1.5 \\
2.0 \\
2.1 \\
2.3 \\
3.1 \\
3.5 \\
3.8 \\
4.1 \\
4.9 \\
5.6 \\
6.3 \\
7.1 \\
8.0 \\
9.0 \\
10.4 \\
12.0 \\
13.8 \\
16.1 \\
18.8\end{array}$ & $\begin{array}{l}S D \\
0.2 \\
0.1 \\
0.2 \\
0.3 \\
0.3 \\
0.4 \\
0.3 \\
0.3 \\
0.2 \\
0.0 \\
0.2 \\
0.3 \\
0.2 \\
0.3 \\
0.2 \\
0.1 \\
0.2 \\
0.2 \\
0.1 \\
0.2 \\
0.2 \\
0.1 \\
0.2 \\
0.2 \\
0.2 \\
0.3\end{array}$ \\
\hline
\end{tabular}


Table 1 (continued).

\begin{tabular}{|c|c|c|c|c|c|c|c|c|c|c|c|}
\hline \multirow[b]{2}{*}{$\begin{array}{c}C B^{-1} \\
2406.5 \\
2416.5 \\
2426.5 \\
2436.5 \\
2446.5 \\
2456.4 \\
2466.4 \\
2476.4 \\
2486.4 \\
2496.4 \\
2506.4 \\
2516.4 \\
2526.4 \\
2536.4 \\
2546.4 \\
2556.4 \\
2566.4 \\
2576.4 \\
2586.4 \\
2596.4 \\
2606.4 \\
2616.4 \\
2626.4 \\
2636.3 \\
2646.3 \\
2656.3 \\
2666.3\end{array}$} & \multicolumn{2}{|c|}{$5 \%(B)$} & \multicolumn{2}{|c|}{$5 \%(G)$} & \multicolumn{3}{|c|}{ Isotropic } & \multicolumn{2}{|c|}{$10 \times(G)$} & \multicolumn{2}{|c|}{$\begin{array}{c}\text { Anisotropic } \\
5 \times(B)\end{array}$} \\
\hline & $\begin{array}{l}\text { Int } \\
191.6 \\
229.0 \\
272.1 \\
322.3 \\
377.1 \\
432.5 \\
486.9 \\
535.6 \\
581.3 \\
618.2 \\
643.2 \\
652.5 \\
649.8 \\
634.8 \\
605.1 \\
569.0 \\
531.9 \\
494.3 \\
453.1 \\
412.9 \\
375.5 \\
340.9 \\
310.3 \\
282.0 \\
256.5 \\
232.0 \\
205.2\end{array}$ & $\begin{array}{l}S D \\
1.2 \\
1.4 \\
2.3 \\
2.3 \\
2.6 \\
2.8 \\
3.2 \\
3.4 \\
3.5 \\
3.4 \\
3.6 \\
3.6 \\
3.5 \\
3.5 \\
3.3 \\
3.4 \\
3.1 \\
3.0 \\
2.7 \\
2.4 \\
2.4 \\
2.0 \\
2.1 \\
1.9 \\
1.6 \\
1.6 \\
1.4\end{array}$ & $\begin{array}{c}\text { Int } \\
193.6 \\
231.2 \\
272.3 \\
317.7 \\
370.3 \\
430.2 \\
486.6 \\
539.7 \\
586.3 \\
620.9 \\
644.7 \\
652.7 \\
650.0 \\
635.2 \\
609.7 \\
573.9 \\
539.7 \\
494.5 \\
452.2 \\
409.4 \\
372.1 \\
337.8 \\
308.8 \\
282.3 \\
257.6 \\
233.2 \\
207.8\end{array}$ & $\begin{array}{l}S D \\
1.1 \\
1.3 \\
1.7 \\
1.7 \\
1.8 \\
2.4 \\
2.6 \\
2.8 \\
3.2 \\
3.3 \\
3.4 \\
3.6 \\
3.4 \\
3.2 \\
3.2 \\
3.0 \\
3.6 \\
2.6 \\
2.9 \\
2.2 \\
2.0 \\
2.0 \\
1.8 \\
1.6 \\
1.8 \\
1.3 \\
1.2\end{array}$ & $\begin{array}{l}\text { Diff } \\
-2.0 \\
-2.2 \\
-0.2 \\
4.7 \\
6.8 \\
2.4 \\
0.3 \\
-4.0 \\
-5.0 \\
-2.7 \\
-1.5 \\
-0.2 \\
-0.2 \\
-0.4 \\
-4.6 \\
-4.9 \\
-7.8 \\
-0.2 \\
1.0 \\
3.5 \\
3.5 \\
3.1 \\
1.4 \\
-0.3 \\
-1.1 \\
-1.3 \\
-2.6\end{array}$ & $\begin{array}{l}\text { Int } \\
185.3 \\
221.1 \\
259.1 \\
302.5 \\
357.0 \\
417.9 \\
474.7 \\
527.8 \\
584.6 \\
621.8 \\
656.9 \\
662.7 \\
655.9 \\
641.7 \\
614.1 \\
584.1 \\
544.4 \\
499.9 \\
455.9 \\
409.8 \\
378.6 \\
340.4 \\
307.4 \\
281.4 \\
256.4 \\
238.8 \\
211.0\end{array}$ & $\begin{array}{r}\text { Diff } \\
6.3 \\
7.9 \\
13.0 \\
19.8 \\
20.1 \\
14.6 \\
12.2 \\
7.8 \\
-3.3 \\
-3.6 \\
-13.8 \\
-10.2 \\
-6.1 \\
-6.8 \\
-9.0 \\
-15.1 \\
-12.5 \\
-5.6 \\
-2.7 \\
3.1 \\
-3.0 \\
0.5 \\
2.9 \\
0.6 \\
0.0 \\
-6.8 \\
-5.8\end{array}$ & $\begin{array}{l}\text { Int } \\
213.8 \\
254.2 \\
295.9 \\
336.1 \\
391.9 \\
443.7 \\
498.3 \\
550.7 \\
589.7 \\
619.4 \\
637.2 \\
639.9 \\
630.7 \\
609.4 \\
585.7 \\
548.6 \\
512.2 \\
472.6 \\
431.0 \\
390.8 \\
351.5 \\
319.7 \\
293.9 \\
269.3 \\
244.0 \\
217.9 \\
197.0\end{array}$ & $\begin{array}{r}D \bar{i} f \bar{f} \\
-22.2 \\
-25.2 \\
-23.8 \\
-13.8 \\
-14.8 \\
-11.2 \\
-11.4 \\
-15.1 \\
-8.4 \\
-1.2 \\
5.9 \\
12.6 \\
19.1 \\
25.4 \\
19.4 \\
20.4 \\
19.7 \\
21.7 \\
22.1 \\
22.1 \\
24.0 \\
21.1 \\
16.3 \\
12.7 \\
12.4 \\
14.1 \\
8.2\end{array}$ & $\begin{array}{l}\text { Int } \\
22.3 \\
26.0 \\
30.8 \\
36.4 \\
42.6 \\
48.7 \\
54.9 \\
61.4 \\
67.0 \\
71.2 \\
75.5 \\
77.6 \\
77.5 \\
75.5 \\
73.0 \\
68.5 \\
64.0 \\
58.5 \\
53.8 \\
47.7 \\
42.8 \\
37.7 \\
33.4 \\
29.1 \\
25.3 \\
22.5 \\
19.3\end{array}$ & $\begin{array}{l}S D \\
0.2 \\
0.3 \\
0.4 \\
0.2 \\
0.4 \\
0.4 \\
0.7 \\
0.6 \\
0.5 \\
0.5 \\
0.4 \\
0.5 \\
0.6 \\
0.6 \\
0.5 \\
0.6 \\
0.4 \\
0.5 \\
0.4 \\
0.4 \\
0.3 \\
0.3 \\
0.3 \\
0.2 \\
0.2 \\
0.3 \\
0.3\end{array}$ \\
\hline
\end{tabular}


rable 1 (continued).

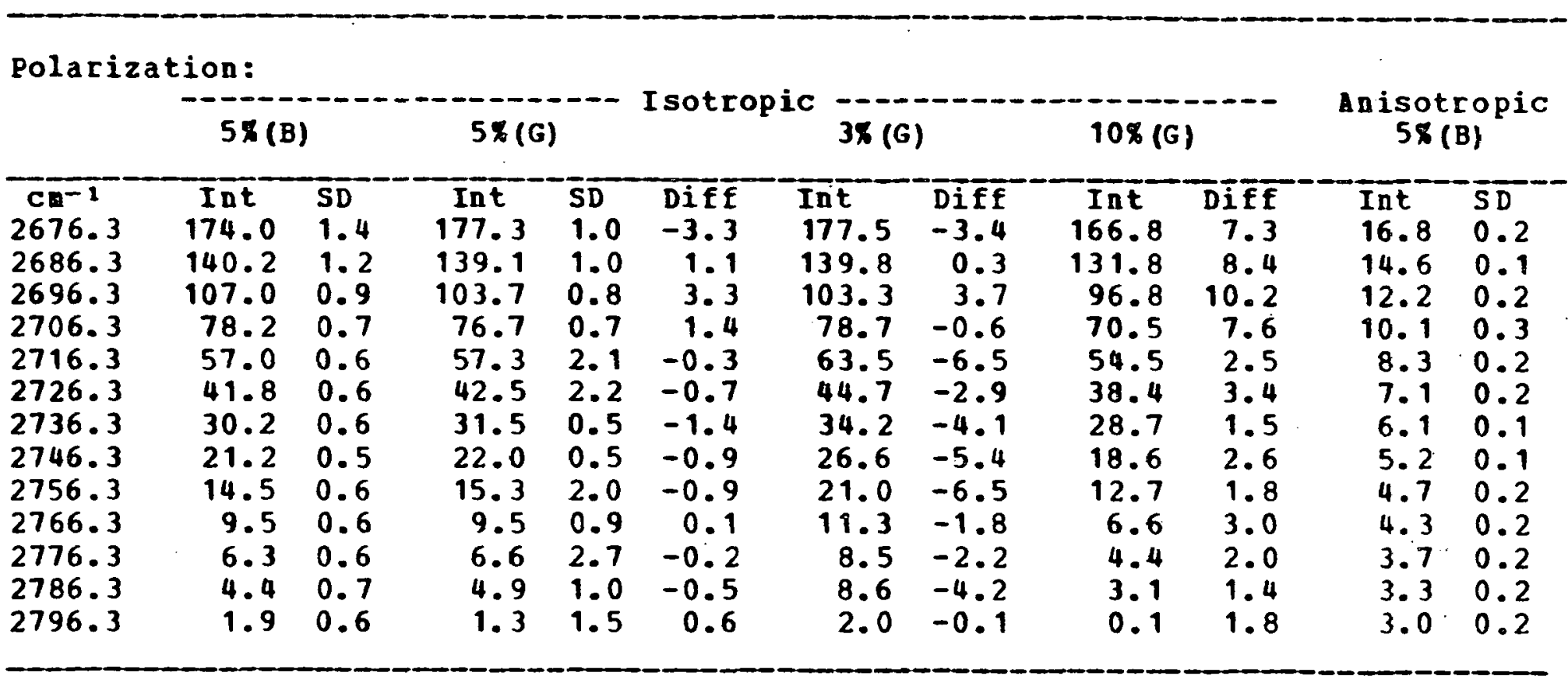


column. The resulting peak position is $2518.8 \pm 1.2 \mathrm{~cm}^{-1}$ : the half-yidth is $181.7 \pm 1.4 \mathrm{~cm}^{-1}$. Differences between these two data sets, listed in the sixth column, demonstrate that there are no systematic variations and that their intensities at each Raman shift are generally within experimental error. This indicates that there are no apparent systematic errors in the intensity or frequency calibration of the monochrcmator. The slightly larger deviations belonging to the data taken with the $514.5 \mathrm{~nm}$ laser line are attributed to the smaller intensities obtained at the longer wave lengths due to the dependence of the Raman scattering efficiency on the fourth power of the frequency of the exciting light and to the reduced quantum efficiency of the photomultiplier tube in the red part of the spectrum. The slightly narcover halfwidth of the spectral band excited by the green laser light way well be due to experimental error. On the other hand, it way be partly due to the smaller spectral slit width of the monochromator at longer wavelengths as shown in Fig. 2. One and two scans respectively were made of water samples, $3 \%$ and $10 x$ of which were $D_{2} 0$. Taken with the $514.5 \mathrm{~nm}$ laser line also, their integrated intensities are normalized to the common value of the previous data and recorded in the seventh and ninth columns. The variations between these intensities and that of the $5 \% \mathrm{D}_{2} \mathrm{O}$ data of the fourtb column are listed in the eigth and tenth columns. 
Systematic discrepancies are apparent which indicate that the Fresence of $D_{2} O$ and the effects due to coupled OD oscillators are still waking small contributions to the band intensities in the $5 \%$ solutions. In spite of these small contributions, all of the remaining data was taken of solutions in which the lesser water species represented about $5 \%$ of the total water. in order to obtain a suitable signal to noise ratio across the entire band. It is felt that the accuracy thus gained werits the compromise. While the shapes of the resulting bands are perhaps slightly different than for the pure HDO spectruw, it is expected that this will have negligible effect on the relative differences of the spectrum for different concentrations of aqueous rare earth chlorides.

using a non-linear least-squares routine, attempts were made to obtain analytic fits to the isotropic data using primarily sets of two, three and four Gaussians. Reasonable fits were not obtained with less than a set of four normal Gaussians or a set of three skewed-Gaussians. While only one set of four Gaussians and one set of three skered-Gaussians yield fits with chi-sguare less than or equal to one, there were other combinaticns of Gaussian curves with conpletely different sets of parameters wich gave fits with chi-square less than two. Visually these appeared to be good fits. In addition, a fair fit, with chi-square about two, was obtained vitb a set of three product functions (72). Therefore it 
appears that nothing more than curve fitting equations have been obtained, and unless some physical theory provides sufficient criterion for determining an equation, all such results are meaningless.

Interestingly enough, when the component peak positions and half-widths of four Gaussians were kept constant at values reported by balrafen (116). poor fits to this isotropic data were obtained. It is not knoun if he corrected his intensity readings for the response efficiency of his instrument or if he used a polarizer. In order to check if the latter was the only difference between his data and that reported here, the isotropic and anisotropic data (discussed next) were added at each frequency and the corresponding standard deviations determined. Again the resulting band differed from the spectrum calculated using his parameters. The average difference vas about an order of magnitude larger than the estimated average standard deviation for this data. So it appears that the ability to fit the water band with a combination of a fer standard functions is not sufficient by itself to determine the number of so-called species in water.

Anisotropic oD band.

Four scans vere made of this band, and the data are listed in the elerenth column of Table 1. The corresponding estimated standard deviations of the averages are in the last 
column. This band has a peak position at $2521.6 \pm 1.6 \mathrm{~cm}^{-1}$ and a half-width of $174.3 \pm 1.2 \mathrm{~cm}^{-1}$.

Smootb curves drawn through the data for the isotropic and anisotropic intensities of the $O D$ stretching vibration are superimposed in Fig. 5. The depolarization ratio is flotted at the top of the same figure. The calculated depolarization ratio of $0.119 \pm 0.041$, near the position of the Feak intensities of the spectra, compares vith a value of 0.13 given by cunningham (20). This ratio dips to a value of $0.096 \pm 0.002$ near $2666 \mathrm{~cm}^{-1} \mathrm{fcr}$ the measurements reported here. Hence, the depolarization ratio is not constant across the $O D$ band, as Cunningham cautiously suggested. Isotropic and anisotropic OH band. Averages of these data are tabulated in Table 2 along with their expected standard deriations.l The position of maximum intensity for the isotropic spectrum, which is the arerage of seven scans, is $3431.9 \pm 1.35 \mathrm{Cm}^{-1}$. For the anisotropic spectrum (average of six scans) the position of peak intensity is $3422.2 \pm 2.8 \mathrm{~cm}^{-1}$. The half-widths are $296.2 \pm 2.4 \mathrm{~cm}^{-1}$ and $265.5 \pm 2.4 \mathrm{~cm}^{-1}$ respectively. The intensities of these two polarizations are graphed in Pig. 6.

The $0.25 \% \mathrm{H}_{2} \mathrm{O}$ in the scans of $99.75 \% \mathrm{D}_{2} \mathrm{O}$ was apparent in the spectral scans to be used for background. This vas corrected for both polarizations by extrapolating the data for the $5 \%$ and $0.25 \%$ scans to $0 \% \mathrm{H}_{2} \mathrm{O}$. 


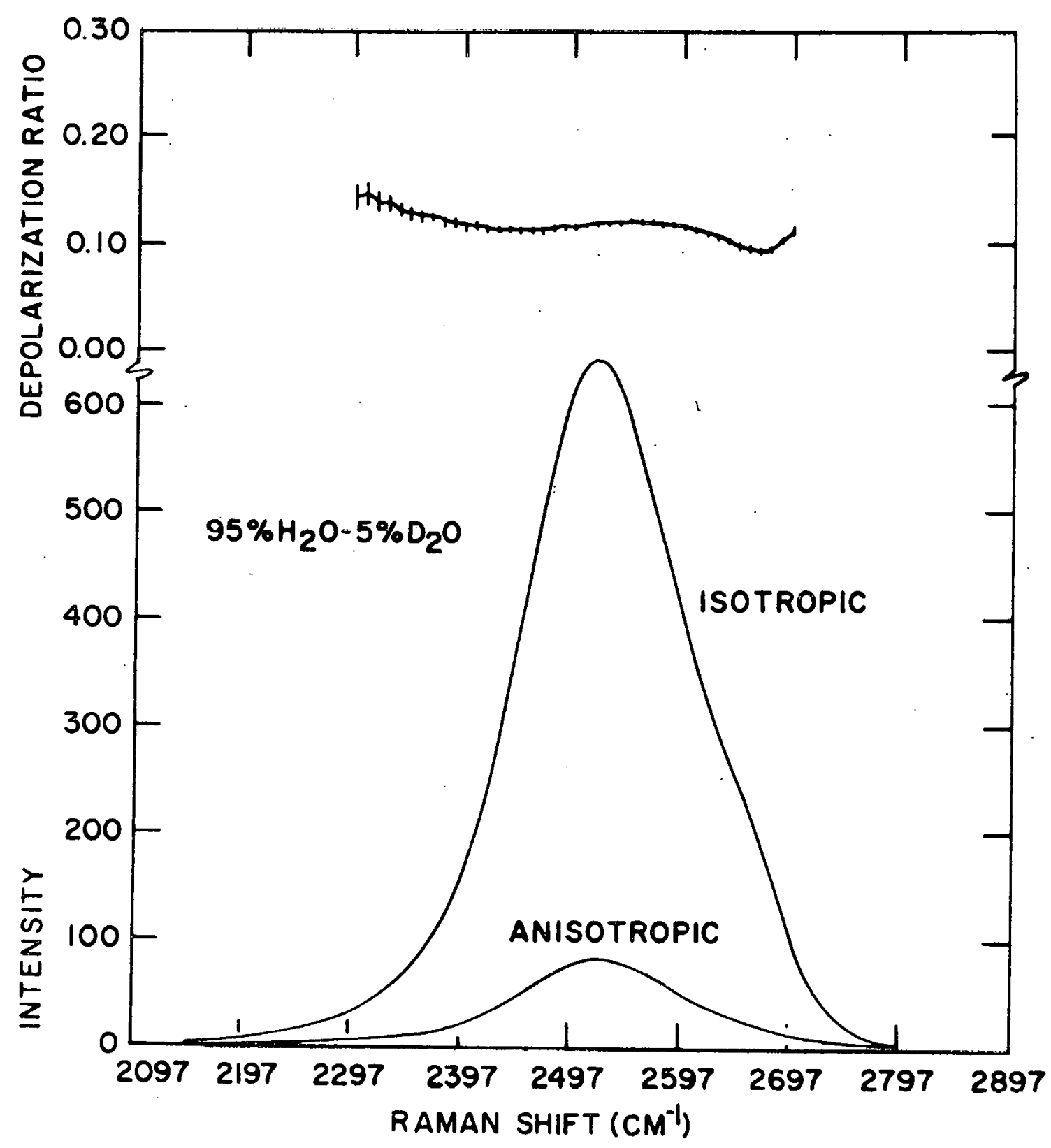

Pig. 5. Intensities of the isotropic and anisotropic Raman bands of the OD stretching vibration of $H D O$ in water. At the top is the corresponding depolarization ratio. 
Table 2. Average intensities of the $O H$ stretching frequencies of the isotropic and anisotropic spectrum of HDO in uater.

\begin{tabular}{|c|c|c|c|c|c|}
\hline Polarization: & Isotr & pic. & Anisot & opic & \\
\hline $\begin{array}{c}c{ }^{\prime}=1 \\
3046.1 \\
3056.1 \\
3066.1 \\
3076.1 \\
3086.1 \\
3096.1 \\
3106.1 \\
3116.1 \\
3126.1 \\
3136.1 \\
3146.1 \\
3156.1 \\
3166.1 \\
3176.0 \\
3186.0 \\
3196.0 \\
3206.0 \\
3216.0 \\
3226.0 \\
3236.0 \\
3246.0 \\
3256.0 \\
3266.0 \\
3276.0 \\
3286.0 \\
3296.0 \\
3306.0 \\
3316.0 \\
3326.0 \\
3336.0 \\
3346.0 \\
3355.9 \\
3365.9 \\
3375.9 \\
3385.9 \\
3395.9 \\
3405.9 \\
3415.9 \\
3425.9 \\
3435.9 \\
3445.9 \\
3455.9\end{array}$ & $\begin{array}{r}\text { Int } \\
5.1 \\
5.4 \\
6.8 \\
7.7 \\
9.8 \\
10.6 \\
12.7 \\
14.1 \\
16.8 \\
19.5 \\
22.1 \\
25.5 \\
29.3 \\
33.3 \\
38.2 \\
42.8 \\
49.0 \\
55.5 \\
63.0 \\
71.7 \\
81.0 \\
91.4 \\
103.8 \\
117.0 \\
131.4 \\
145.1 \\
160.5 \\
176.4 \\
194.1 \\
211.0 \\
227.2 \\
243.7 \\
260.1 \\
273.7 \\
285.8 \\
295.9 \\
302.6 \\
307.2 \\
309.8 \\
310.6 \\
307.7 \\
303.2\end{array}$ & $\begin{array}{l}5 . \overline{1} \\
0.4 \\
0.3 \\
0.4 \\
0.2 \\
0.3 \\
0.5 \\
0.5 \\
0.3 \\
0.3 \\
0.3 \\
0.4 \\
0.4 \\
0.4 \\
0.3 \\
0.4 \\
0.4 \\
0.4 \\
0.6 \\
0.6 \\
0.5 \\
0.6 \\
0.7 \\
0.7 \\
0.8 \\
0.7 \\
0.8 \\
0.9 \\
1.0 \\
1.1 \\
1.1 \\
1.2 \\
1.3 \\
1.4 \\
1.5 \\
1.6 \\
1.6 \\
1.7 \\
1.6 \\
1.6 \\
1.6 \\
1.6 \\
1.6\end{array}$ & $\begin{array}{l}\text { Int } \\
-0.0 \\
0.2 \\
0.8 \\
0.9 \\
1.1 \\
1.1 \\
1.9 \\
1.8 \\
2.8 \\
3.1 \\
3.6 \\
4.4 \\
5.3 \\
6.0 \\
6.7 \\
7.7 \\
8.9 \\
10.3 \\
11.4 \\
13.2 \\
14.7 \\
16.8 \\
18.7 \\
21.2 \\
23.5 \\
26.1 \\
28.9 \\
31.5 \\
34.9 \\
37.7 \\
40.9 \\
44.3 \\
46.4 \\
48.9 \\
51.2 \\
52.1 \\
53.8 \\
55.0 \\
54.6 \\
54.4 \\
53.1 \\
52.7\end{array}$ & $\begin{array}{l}\text { SD } \\
0.4 \\
0.4 \\
0.4 \\
0.3 \\
0.3 \\
0.3 \\
0.2 \\
0.4 \\
0.4 \\
0.2 \\
0.2 \\
0.3 \\
0.4 \\
0.2 \\
0.2 \\
0.2 \\
0.2 \\
0.3 \\
0.2 \\
0.2 \\
0.2 \\
0.2 \\
0.3 \\
0.2 \\
0.3 \\
0.3 \\
0.2 \\
0.4 \\
0.3 \\
0.3 \\
0.3 \\
0.4 \\
0.4 \\
0.4 \\
0.3 \\
0.5 \\
0.4 \\
0.4 \\
0.5 \\
0.3 \\
0.4 \\
0.4\end{array}$ & . \\
\hline
\end{tabular}


Table 2 (continued).

\begin{tabular}{|c|c|c|c|c|c|}
\hline Polarization: & \multicolumn{2}{|c|}{ Isotropic } & \multicolumn{2}{|c|}{ Anisotropic } & \\
\hline $\begin{array}{l}C \mathbb{B}^{-1} \\
3465.9 \\
3475.9 \\
3485.9 \\
3495.9 \\
3505.9 \\
3515.9 \\
3525.9 \\
3535.8 \\
3545.8 \\
3555.8 \\
3565.8 \\
3575.8 \\
3585.8 \\
3595.8 \\
3605.8 \\
3615.8 \\
3625.8 \\
3635.8 \\
3645.8 \\
3655.8 \\
3665.8 \\
3675.8 \\
3685.8 \\
3695.8 \\
3705.8 \\
3715.8 \\
3725.8 \\
3735.7 \\
3745.7 \\
3755.7 \\
3765.7 \\
3775.7 \\
3785.7 \\
3795.7\end{array}$ & $\begin{array}{l}\text { Int } \\
296.5 \\
288.5 \\
278.3 \\
267.6 \\
256.9 \\
244.1 \\
232.0 \\
219.6 \\
208.1 \\
195.6 \\
185.9 \\
175.4 \\
166.5 \\
157.7 \\
148.8 \\
138.6 \\
128.0 \\
114.2 \\
95.1 \\
74.6 \\
55.0 \\
39.4 \\
27.8 \\
20.2 \\
13.8 \\
9.9 \\
7.4 \\
5.6 \\
4.2 \\
3.4 \\
2.4 \\
2.4 \\
2.2 \\
1.6\end{array}$ & $\begin{array}{l}\text { SD } \\
1.6 \\
1.5 \\
1.6 \\
1.7 \\
1.5 \\
1.4 \\
1.3 \\
1.2 \\
1.2 \\
1.2 \\
1.2 \\
1.1 \\
1.0 \\
1.0 \\
1.1 \\
1.0 \\
0.8 \\
0.7 \\
0.6 \\
0.5 \\
0.4 \\
0.4 \\
0.4 \\
0.4 \\
0.2 \\
0.3 \\
0.3 \\
0.2 \\
0.2 \\
0.2 \\
0.2 \\
0.2 \\
0.1 \\
0.2\end{array}$ & $\begin{array}{l}\text { Int } \\
50.8 \\
49.4 \\
46.9 \\
45.2 \\
42.7 \\
40.1 \\
37.6 \\
34.9 \\
32.3 \\
30.4 \\
27.6 \\
25.5 \\
23.2 \\
21.8 \\
19.6 \\
17.9 \\
15.7 \\
13.4 \\
10.8 \\
8.6 \\
7.1 \\
5.6 \\
4.2 \\
2.9 \\
2.6 \\
1.5 \\
1.3 \\
1.4 \\
1.1 \\
0.8 \\
0.8 \\
0.9 \\
0.6 \\
0.6\end{array}$ & $\begin{array}{l}\text { SD } \\
0.4 \\
0.5 \\
0.4 \\
0.4 \\
0.4 \\
0.3 \\
0.3 \\
0.3 \\
0.3 \\
0.4 \\
0.2 \\
0.3 \\
0.3 \\
0.3 \\
0.2 \\
0.3 \\
0.2 \\
0.2 \\
0.2 \\
0.2 \\
0.1 \\
0.2 \\
0.2 \\
0.1 \\
0.2 \\
0.1 \\
0.2 \\
0.2 \\
0.2 \\
0.2 \\
0.2 \\
0.3 \\
0.2 \\
0.2\end{array}$ & \\
\hline
\end{tabular}




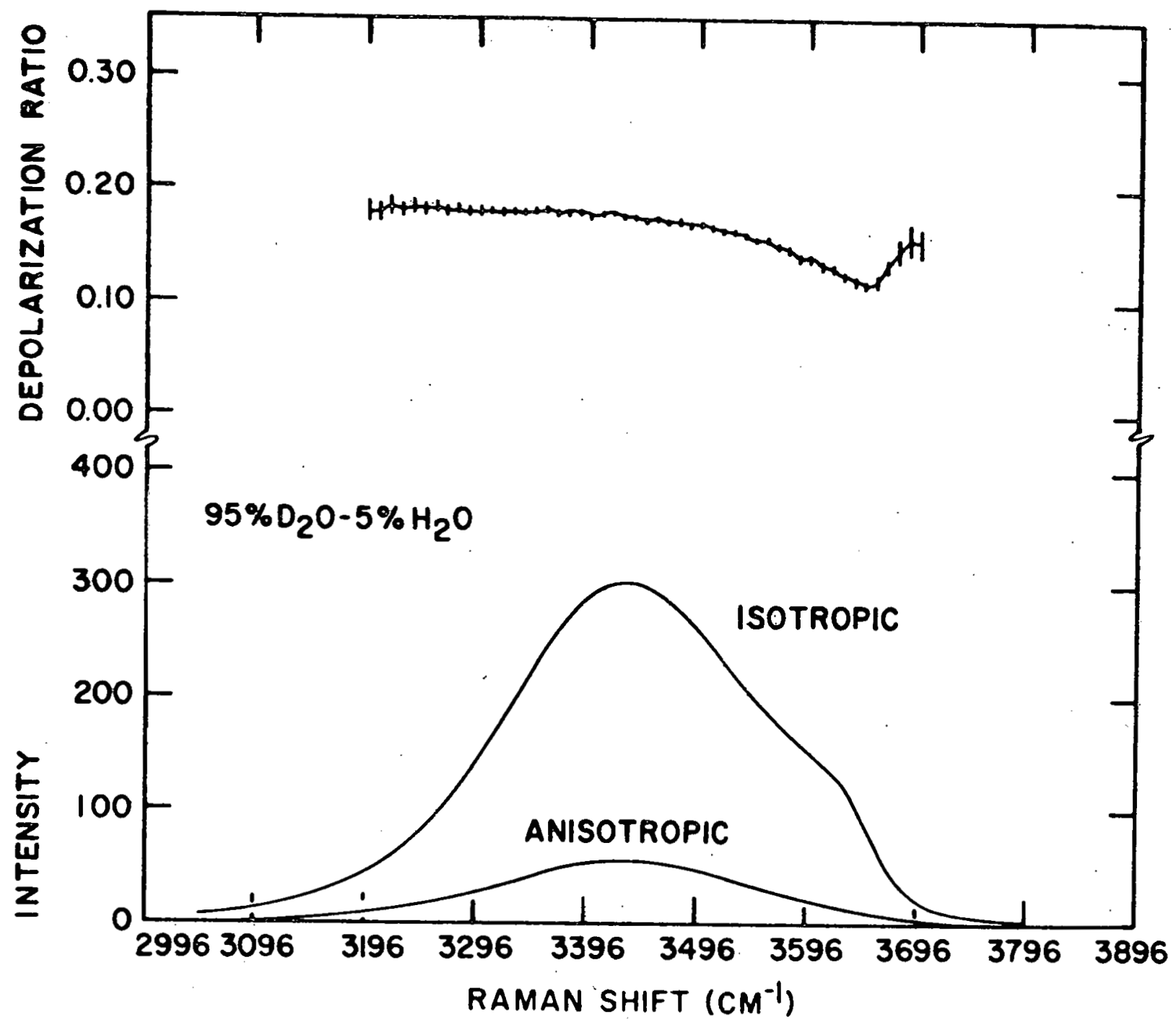

Pig. 6. Intensities of the isotropic and anisotropic Raman

bands of the OH stretching vibration of HDO in

water. The corresponding depolarization ratio is at

the top. 
As expected, these bands are much broader and have different relative shapes than the corresponding OD spectral bands. Surprisingly though, the integrated intensity for the isotropic $O H$ band is about $29 \times$ less than for the OD band. Under the anisotropic bands, the integrated intensities are similar for both of the isotcpes.

The depolarization ratio near the peak intensities for the $O H$ spectral band is $0.176 \pm 0.002$, a larger value than that for the OD vibration. However. Fig. 6 shows that this ratio for the $O H$ band as a function of wave number has a similar shape to that exhibited in Fig. 5 for the OD vibration. A winimus of $0.114 \pm 0.002$ occurs for the depolarization ratio of the $O H$ band at $3646 \mathrm{~cm}^{-1}$. The similarity of the shape of the depolarization ratios for the two isotopes verifies that this ratio is not constant across the $O D$ or $O H$ spectral band of HDO. This will be seen to be consistently true for all of the solution data discussed next.

\section{Rare Earth Chloride Solutions}

Data similar to that obtained for vater vas aquired for bcth polarizations of the $O D$ and $O H$ stretching vibrations of HDO in agueous solutions of $\mathrm{GdCl}_{3}$ at six concentrations and for the OD stretching vibration of HDO in aqueous solutions of $\mathrm{LaCl}_{3}$ and $\mathrm{LuCl}_{3}$ at five concentrations each. A Iinear grovth in integrated intensity with increasing molality for all solutions was characteristic of both polarizations of the 


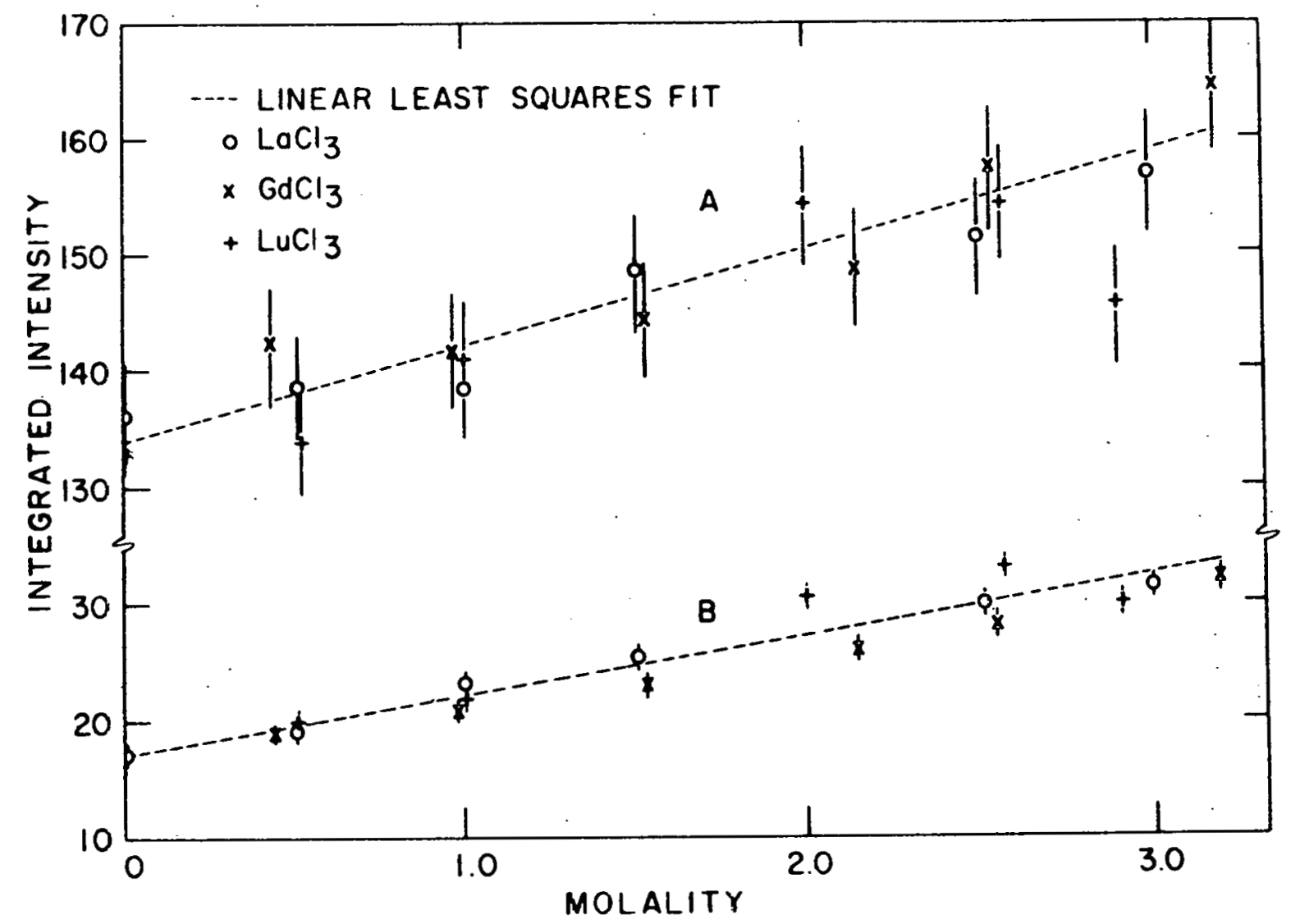

in

Fig. 7. Integrated intensities of the A) isotropic and B) anisotropic Ram bands of the OD stretching vibra$t i o n$ of HDO in vater and aqueous solutions of $\mathrm{LaCl}_{3}$, $\mathrm{GdCl}_{3}$ and $\mathrm{LuCl}_{3}$. 


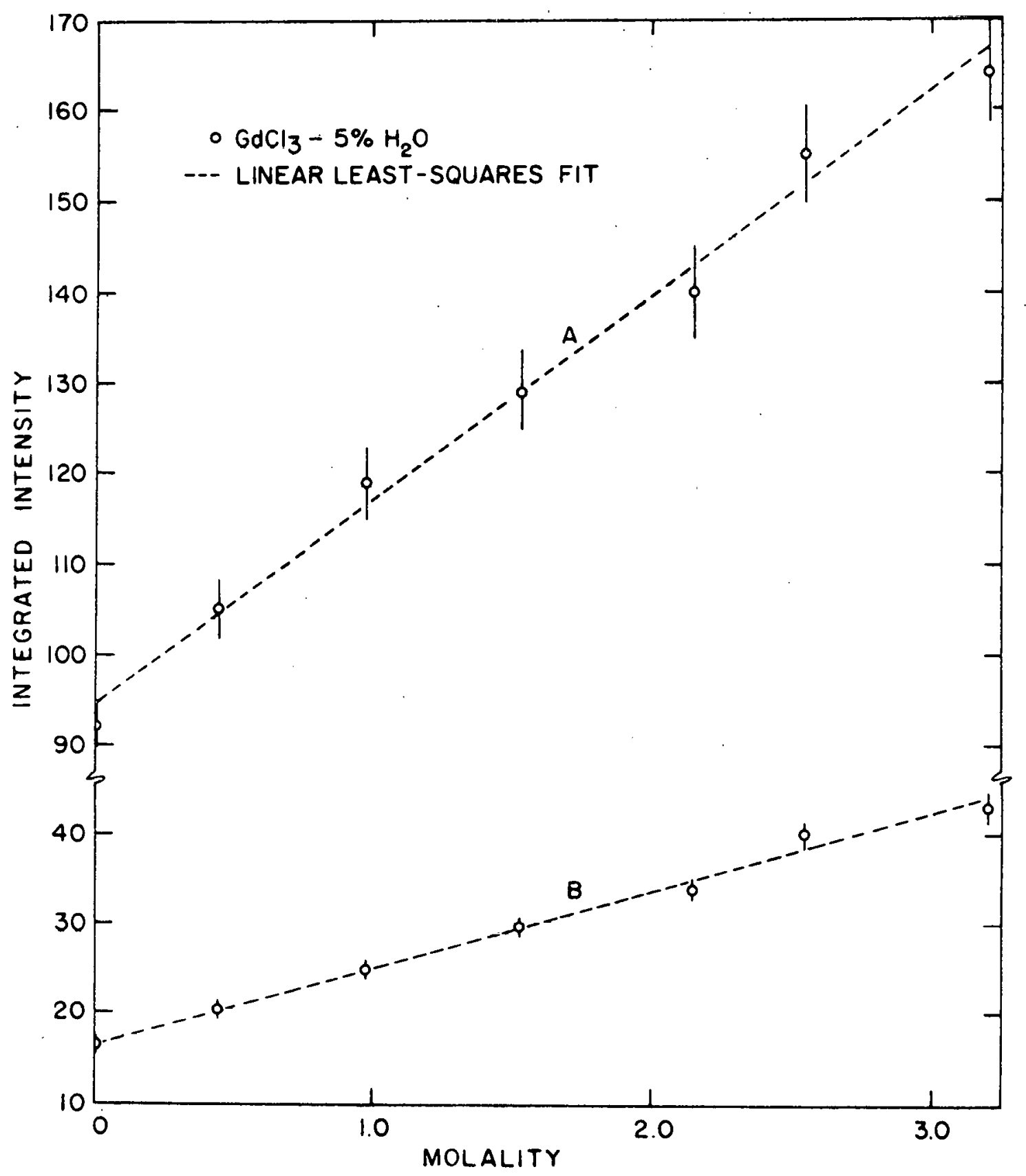

Fig. 8. Integrated intensities of the A) isotropic and B) anisotropic Raman bands of the OH stretching vibration of HDO in water and aqueous solutions of $\mathrm{GdCl}_{3}$. 
$O H$ and $O D$ spectral bands. This is exhibited in Pigs. 7 and 8 along with estimated error bars and the linear least-squares fits. The linear equations are generally within experimental errors of the integrated intensity data, and the scatter about them is apparently random. These facts vere assumed to justify a renormalization of the integrated intensities of all the spectral data to the appropriate least-squares values to facilitate the comparison of the changes in spectral features with changes in concentration. The average intensities at each frequency, including all of the previously discussed water data, have been recorded after this renormalization had been done.1 The fact that the slope for the equation obtained for the $O H$ spectra is steeper than that for the $O D$ band is a surprise as is the small integrated intensity of the $O H$ band in water when compared vith the $O D$ band. $\operatorname{LaCl}_{3}-5 \% \mathrm{D}_{2} \mathrm{O}$

The isotrcpic intensities for these solutions are supplied in Table 3. The 0.50 .1 .00 and 2.52 molal concentrations were scanned three times each and averaged, the 1.51 molal solution five times and the most concentrated solution six times.

1 Recall that all intensities given, in fact are directly proportional to the intensities per number of OD or $O H$ oscillators. 
Table 3. Average intensities of the OD stretching frequencies of the isotropic spectrum of $\mathrm{LaCl}_{3}-5 \mathrm{XD}_{2} \mathrm{O}$.

\begin{tabular}{|c|c|c|c|c|c|c|c|c|c|c|}
\hline molality & \multicolumn{2}{|c|}{0.500} & \multicolumn{2}{|c|}{1.000} & \multicolumn{2}{|c|}{1.503} & \multicolumn{2}{|c|}{2.515} & \multicolumn{2}{|c|}{3.003} \\
\hline $\begin{array}{c}C 1-1 \\
2146.6 \\
2156.6 \\
2166.6 \\
2176.6 \\
2186.6 \\
2196.6 \\
2206.6 \\
2216.6 \\
2226.6 \\
2236.6 \\
2246.6 \\
2256.6 \\
2266.6 \\
2276.5 \\
2286.5 \\
2296.5 \\
2306.5 \\
2316.5 \\
2326.5 \\
2336.5 \\
2346.5 \\
2356.5 \\
2366.5 \\
2376.5 \\
2386.5 \\
2396.5 \\
2406.5 \\
2416.5\end{array}$ & $\begin{array}{r}\text { Int } \\
2.0 \\
3.7 \\
3.9 \\
4.1 \\
5.8 \\
6.6 \\
8.8 \\
11.7 \\
12.8 \\
14.7 \\
16.4 \\
20.3 \\
23.0 \\
27.6 \\
31.0 \\
35.1 \\
41.0 \\
47.5 \\
56.2 \\
65.8 \\
76.6 \\
88.5 \\
104.0 \\
122.4 \\
144.0 \\
170.3 \\
201.6 \\
237.2\end{array}$ & $\begin{array}{l}S D \\
0.6 \\
0.4 \\
0.5 \\
0.7 \\
0.7 \\
0.8 \\
0.8 \\
0.6 \\
0.6 \\
0.2 \\
0.9 \\
0.4 \\
0.3 \\
0.4 \\
0.5 \\
0.8 \\
0.6 \\
0.6 \\
0.6 \\
0.6 \\
0.5 \\
0.9 \\
0.7 \\
1.0 \\
0.9 \\
1.2 \\
1.2 \\
1.7\end{array}$ & $\begin{array}{c}\text { Int } \\
3.5 \\
4.8 \\
5.6 \\
7.2 \\
8.6 \\
10.1 \\
12.4 \\
15.1 \\
17.2 \\
17.9 \\
20.4 \\
23.6 \\
27.0 \\
31.0 \\
35.0 \\
40.9 \\
45.2 \\
52.4 \\
61.6 \\
71.7 \\
82.4 \\
94.5 \\
111.3 \\
130.4 \\
152.6 \\
178.9 \\
208.4 \\
242.5\end{array}$ & $\begin{array}{l}\text { SD } \\
0.9 \\
1.2 \\
1.0 \\
1.0 \\
0.6 \\
0.6 \\
0.2 \\
0.4 \\
0.8 \\
0.4 \\
0.6 \\
0.7 \\
0.6 \\
0.4 \\
0.6 \\
1.1 \\
0.5 \\
0.6 \\
0.8 \\
0.9 \\
0.8 \\
1.2 \\
1.4 \\
0.9 \\
1.2 \\
1.0 \\
1.6 \\
1.5\end{array}$ & $\begin{array}{r}\text { Int } \\
4.3 \\
5.4 \\
6.9 \\
5.8 \\
8.3 \\
10.3 \\
12.6 \\
14.0 \\
16.6 \\
18.4 \\
21.7 \\
24.0 \\
27.7 \\
31.6 \\
36.7 \\
41.3 \\
46.4 \\
55.2 \\
65.2 \\
76.1 \\
88.9 \\
103.6 \\
118.6 \\
139.6 \\
163.8 \\
190.4 \\
222.3 \\
258.9\end{array}$ & $\begin{array}{l}\text { SD } \\
0.6 \\
1.1 \\
0.7 \\
0.9 \\
0.6 \\
1.2 \\
1.0 \\
1.1 \\
0.6 \\
0.5 \\
0.4 \\
0.5 \\
0.5 \\
0.4 \\
0.6 \\
0.7 \\
1.1 \\
0.8 \\
0.7 \\
0.8 \\
0.8 \\
1.0 \\
1.0 \\
1.1 \\
1.2 \\
1.3 \\
1.7 \\
1.6\end{array}$ & $\begin{array}{r}\text { Int } \\
5.0 \\
7.7 \\
7.1 \\
8.4 \\
9.9 \\
11.2 \\
12.4 \\
14.3 \\
17.8 \\
22.7 \\
24.3 \\
25.1 \\
28.9 \\
32.8 \\
38.6 \\
45.3 \\
53.5 \\
62.5 \\
72.2 \\
82.5 \\
97.1 \\
115.0 \\
134.6 \\
156.4 \\
181.8 \\
210.0 \\
243.2 \\
282.4\end{array}$ & $\begin{array}{l}\text { SD } \\
1.7 \\
1.5 \\
1.1 \\
1.1 \\
0.6 \\
0.9 \\
0.8 \\
1.1 \\
1.8 \\
1.7 \\
1.7 \\
1.6 \\
1.9 \\
2.3 \\
2.2 \\
1.2 \\
0.8 \\
1.6 \\
0.8 \\
1.0 \\
1.5 \\
1.2 \\
1.2 \\
1.7 \\
1.7 \\
1.3 \\
1.6 \\
2.0\end{array}$ & $\begin{array}{r}\text { Int } \\
4.0 \\
5.2 \\
6.3 \\
7.4 \\
9.0 \\
11.1 \\
11.7 \\
15.0 \\
18.4 \\
21.2 \\
24.9 \\
27.7 \\
32.0 \\
36.4 \\
43.0 \\
49.9 \\
57.5 \\
67.6 \\
78.1 \\
90.4 \\
105.9 \\
122.7 \\
141.0 \\
164.5 \\
191.6 \\
221.1 \\
256.7 \\
298.1\end{array}$ & $\begin{array}{l}S D \\
0.6 \\
1.0 \\
1.0 \\
0.8 \\
0.6 \\
0.7 \\
0.7 \\
0.6 \\
0.6 \\
0.7 \\
0.7 \\
0.5 \\
0.9 \\
1.0 \\
1.1 \\
1.0 \\
0.9 \\
0.8 \\
0.9 \\
1.2 \\
1.0 \\
1.4 \\
1.4 \\
1.4 \\
1.6 \\
1.5 \\
1.8 \\
1.8\end{array}$ \\
\hline
\end{tabular}


Table 3 (continued).

\begin{tabular}{|c|c|c|c|c|c|c|c|c|c|c|}
\hline molality & \multicolumn{2}{|c|}{0.500} & \multicolumn{2}{|c|}{1.000} & \multicolumn{2}{|c|}{1.503} & \multicolumn{2}{|c|}{2.515} & \multicolumn{2}{|c|}{3.003} \\
\hline $\begin{array}{c}c m^{-1} \\
2426.5 \\
2436.5 \\
2446.5 \\
2456.4 \\
2466.4 \\
2476.4 \\
2486.4 \\
2496.4 \\
2506.4 \\
2516.4 \\
2526.4 \\
2536.4 \\
2546.4 \\
2556.4 \\
2566.4 \\
2576.4 \\
2586.4 \\
2596.4 \\
2606.4 \\
2616.4 \\
2626.4 \\
2636.3 \\
2646.3 \\
2656.3 \\
2666.3 \\
2676.3 \\
2686.3 \\
2696.3 \\
2706.3\end{array}$ & $\begin{array}{c}\text { Int } \\
280.0 \\
326.4 \\
379.7 \\
433.2 \\
485.2 \\
534.3 \\
582.2 \\
623.8 \\
653.9 \\
667.7 \\
675.5 \\
662.6 \\
640.6 \\
606.6 \\
566.3 \\
524.8 \\
481.1 \\
436.9 \\
397.7 \\
356.4 \\
321.7 \\
291.4 \\
261.5 \\
233.0 \\
201.4 \\
165.9 \\
131.6 \\
99.8 \\
73.2\end{array}$ & $\begin{array}{l}S D \\
1.8 \\
1.8 \\
2.2 \\
2.5 \\
3.1 \\
3.0 \\
3.3 \\
3.6 \\
3.7 \\
3.8 \\
4.0 \\
3.8 \\
3.5 \\
3.3 \\
3.2 \\
2.8 \\
2.7 \\
2.3 \\
2.2 \\
2.4 \\
1.8 \\
1.7 \\
1.6 \\
1.4 \\
1.2 \\
1.1 \\
0.9 \\
0.7 \\
1.1\end{array}$ & $\begin{array}{c}\text { Int } \\
283.6 \\
330.2 \\
382.5 \\
435.4 \\
488.4 \\
537.8 \\
586.8 \\
632.1 \\
663.3 \\
686.5 \\
695.6 \\
688.8 \\
667.3 \\
632.3 \\
594.2 \\
550.6 \\
503.4 \\
457.2 \\
412.0 \\
372.5 \\
333.1 \\
299.4 \\
264.5 \\
231.0 \\
195.2 \\
159.6 \\
126.8 \\
97.0 \\
72.2\end{array}$ & $\begin{array}{l}S D \\
1.7 \\
1.9 \\
2.1 \\
2.9 \\
2.9 \\
3.2 \\
3.2 \\
3.7 \\
3.7 \\
3.9 \\
3.8 \\
3.8 \\
4.0 \\
3.4 \\
3.2 \\
3.1 \\
2.8 \\
2.5 \\
2.3 \\
2.0 \\
1.8 \\
2.0 \\
1.6 \\
2.1 \\
2.2 \\
1.6 \\
0.8 \\
0.6 \\
0.9\end{array}$ & $\begin{array}{l}\text { Int } \\
300.9 \\
346.9 \\
399.8 \\
453.0 \\
505.7 \\
558.2 \\
610.0 \\
656.1 \\
692.4 \\
715.5 \\
726.5 \\
718.1 \\
697.8 \\
660.8 \\
615.4 \\
572.1 \\
520.2 \\
469.5 \\
420.4 \\
375.6 \\
334.0 \\
297.0 \\
260.3 \\
222.8 \\
184.3 \\
148.3 \\
114.0 \\
86.3 \\
65.0\end{array}$ & $\begin{array}{l}S D \\
2.2 \\
2.2 \\
2.2 \\
2.7 \\
3.0 \\
3.1 \\
3.5 \\
3.7 \\
3.9 \\
3.9 \\
3.9 \\
4.0 \\
3.9 \\
3.7 \\
3.4 \\
3.1 \\
3.0 \\
2.8 \\
2.3 \\
2.1 \\
2.1 \\
1.8 \\
1.6 \\
1.5 \\
1.3 \\
1.6 \\
1.6 \\
1.2 \\
1.3\end{array}$ & $\begin{array}{c}\text { Int } \\
326.2 \\
376.2 \\
432.7 \\
490.8 \\
545.6 \\
601.1 \\
658.0 \\
710.0 \\
746.6 \\
769.9 \\
775.0 \\
763.8 \\
739.1 \\
698.0 \\
649.6 \\
602.2 \\
548.5 \\
493.1 \\
442.2 \\
392.9 \\
346.3 \\
299.1 \\
254.1 \\
211.8 \\
169.9 \\
132.0 \\
101.2 \\
78.2 \\
58.8\end{array}$ & $\begin{array}{l}S D \\
2.1 \\
2.4 \\
2.8 \\
2.9 \\
3.3 \\
3.4 \\
3.8 \\
3.9 \\
4.5 \\
4.4 \\
4.2 \\
4.4 \\
4.3 \\
4.2 \\
3.5 \\
3.2 \\
3.1 \\
3.0 \\
2.8 \\
2.4 \\
2.2 \\
2.0 \\
2.0 \\
2.2 \\
1.9 \\
1.7 \\
1.9 \\
2.1 \\
1.4\end{array}$ & $\begin{array}{c}\text { Int } \\
344.9 \\
400.2 \\
457.3 \\
518.8 \\
577.9 \\
631.6 \\
687.1 \\
732.8 \\
766.1 \\
785.0 \\
787.8 \\
774.1 \\
743.5 \\
699.0 \\
653.1 \\
602.9 \\
549.0 \\
495.6 \\
442.7 \\
393.1 \\
345.5 \\
298.5 \\
252.1 \\
207.5 \\
164.8 \\
128.8 \\
101.1 \\
77.9 \\
59.2\end{array}$ & $\begin{array}{l}\text { SD } \\
2.3 \\
2.5 \\
2.8 \\
2.9 \\
3.3 \\
3.7 \\
3.9 \\
4.0 \\
4.2 \\
4.3 \\
4.3 \\
4.4 \\
4.0 \\
3.9 \\
3.7 \\
3.3 \\
3.1 \\
3.1 \\
2.5 \\
2.2 \\
1.9 \\
1.9 \\
1.9 \\
1.5 \\
1.2 \\
1.1 \\
1.0 \\
1.1 \\
1.1\end{array}$ \\
\hline
\end{tabular}


Table 3 (continued).

\begin{tabular}{|c|c|c|c|c|c|c|c|c|c|c|}
\hline molality & \multicolumn{2}{|c|}{0.500} & \multicolumn{2}{|c|}{1.000} & \multicolumn{2}{|c|}{1.503} & \multicolumn{2}{|c|}{2.515} & \multicolumn{2}{|c|}{3.003} \\
\hline $\begin{array}{c}\text { C } 10-1 \\
2716.3 \\
2726.3 \\
2736.3 \\
2746.3 \\
2756.3 \\
2766.3 \\
2776.3 \\
2786.3 \\
2796.3\end{array}$ & $\begin{array}{l}\text { Int } \\
55.6 \\
41.0 \\
31.2 \\
21.9 \\
14.8 \\
10.2 \\
7.7 \\
4.8 \\
3.3\end{array}$ & $\begin{array}{l}\text { SD } \\
0.9 \\
1.1 \\
0.9 \\
0.8 \\
0.7 \\
0.8 \\
0.7 \\
0.4 \\
0.5\end{array}$ & $\begin{array}{l}\text { Int } \\
52.7 \\
39.7 \\
27.9 \\
21.4 \\
15.4 \\
9.8 \\
6.9 \\
5.3 \\
3.4\end{array}$ & $\begin{array}{l}\text { SD } \\
0.5 \\
0.7 \\
0.3 \\
0.4 \\
0.5 \\
0.6 \\
0.8 \\
0.2 \\
0.8\end{array}$ & $\begin{array}{l}\text { Int } \\
48.6 \\
36.1 \\
26.1 \\
18.2 \\
14.1 \\
9.4 \\
6.7 \\
5.1 \\
3.9\end{array}$ & $\begin{array}{l}\text { SD } \\
0.9 \\
1.2 \\
0.9 \\
0.4 \\
0.7 \\
0.7 \\
0.8 \\
0.8 \\
0.5\end{array}$ & $\begin{array}{l}\text { Int } \\
44.7 \\
34.9 \\
25.6 \\
18.0 \\
13.3 \\
10.0 \\
6.5 \\
5.5 \\
4.8\end{array}$ & $\begin{array}{l}5.0 \\
1.3 \\
1.2 \\
1.8 \\
1.9 \\
1.5 \\
1.6 \\
1.0 \\
1.8 \\
1.4\end{array}$ & $\begin{array}{l}\text { Int } \\
46.9 \\
35.7 \\
28.3 \\
23.0 \\
18.1 \\
14.2 \\
12.1 \\
10.3 \\
10.0\end{array}$ & $\begin{array}{l}\text { SD } \\
1.0 \\
1.0 \\
0.9 \\
0.9 \\
1.0 \\
1.2 \\
1.5 \\
1.6 \\
1.6\end{array}$ \\
\hline
\end{tabular}


Averages of the anisotropic intensities are tabulated in Table 4. The data for the first two concentrations are the results of two scans each, and the remaining concentrations were scanned three times each.2 $G \mathrm{dCl} 1_{3}-5 \mathrm{XC}_{2} \mathrm{O}$ and $5 \mathrm{KH}_{2} \mathrm{O}$.

Gadolinium was the only one of the three salts for which scans vere made of both the $O D$ and $O H$ bands. The results for the isotropic spectrum of the od vibration, which are the averages of $f$ ive scans made for each concentration, are listed in Table 5. The corresponding data for the anisotropic spectrum, averaged from two scans of each concentration, are tabulated in Table 6.2 Likewise, the averages of three scans for each concentration are listed in Table 7 for the isotropic $O H$ spectrua. Except for the most concentrated solution for which three scans were made, two data sets for each of the concentrations vere averaged for the anisotropic

Iscans were made only of five concentrations of IaCl $3-5 \% D_{2} 0$, and no cata yere discarded in the preparation of these rabies.

2 The resembling small backgrounds used for the anisotropic $\mathrm{LaCl}_{3}$ and $\mathrm{LuCl}_{3}$ data were used for the anisotropic $\mathrm{GdCl}_{3}-5 \mathrm{xI}_{2} \mathrm{O}^{3}$ bands. 
Table 4. Average intensities of the OD stretching frequencies of the anisotropic spectrum of $\mathrm{LaCl}_{3}-5 \% \mathrm{D}_{2} \mathrm{O}$.

\begin{tabular}{|c|c|c|c|c|c|c|c|c|c|c|}
\hline molality & \multicolumn{2}{|c|}{0.500} & \multicolumn{2}{|c|}{1.000} & \multicolumn{2}{|c|}{1.503} & \multicolumn{2}{|c|}{2.515} & \multicolumn{2}{|c|}{3.003} \\
\hline $\begin{array}{c}c \mathrm{~m}^{-1} \\
2146.6 \\
2156.6 \\
2166.6 \\
2176.6 \\
2186.6 \\
2196.6 \\
2206.6 \\
2216.6 \\
2226.6 \\
2236.6 \\
2246.6 \\
2256.6 \\
2266.6 \\
2276.5 \\
2286.5 \\
2296.5 \\
2306.5 \\
2316.5 \\
2326.5 \\
2336.5 \\
2346.5 \\
2356.5 \\
2366.5 \\
2376.5 \\
2386.5 \\
2396.5 \\
2406.5 \\
2416.5\end{array}$ & $\begin{array}{l}\text { Int } \\
0.9 \\
0.7 \\
0.9 \\
0.8 \\
1.4 \\
1.1 \\
1.2 \\
2.4 \\
2.1 \\
2.8 \\
3.2 \\
3.6 \\
3.4 \\
3.5 \\
5.1 \\
6.0 \\
6.3 \\
6.7 \\
8.0 \\
10.2 \\
10.8 \\
13.3 \\
14.1 \\
17.1 \\
19.8 \\
23.1 \\
27.6 \\
31.9\end{array}$ & $\begin{array}{l}\text { SD } \\
0.5 \\
0.6 \\
0.5 \\
0.4 \\
0.3 \\
0.1 \\
0.9 \\
1.0 \\
0.3 \\
0.4 \\
0.3 \\
0.1 \\
0.5 \\
0.6 \\
0.4 \\
0.7 \\
0.3 \\
0.5 \\
0.3 \\
0.2 \\
0.5 \\
0.4 \\
0.4 \\
0.2 \\
0.6 \\
0.4 \\
0.3 \\
0.4\end{array}$ & $\begin{array}{l}\text { Int } \\
-0.8 \\
-1.4 \\
-1.3 \\
0.6 \\
1.1 \\
1.5 \\
0.7 \\
-0.1 \\
1.0 \\
1.1 \\
1.7 \\
2.5 \\
2.9 \\
3.6 \\
5.2 \\
6.2 \\
7.6 \\
7.7 \\
10.2 \\
11.4 \\
12.7 \\
14.7 \\
17.2 \\
20.5 \\
23.7 \\
28.2 \\
32.3 \\
37.1\end{array}$ & $\begin{array}{l}S D \\
0.7 \\
0.5 \\
0.5 \\
0.2 \\
0.6 \\
0.3 \\
0.3 \\
0.7 \\
0.4 \\
0.3 \\
0.7 \\
0.8 \\
0.7 \\
0.8 \\
1.1 \\
1.3 \\
0.6 \\
0.6 \\
1.1 \\
1.3 \\
0.7 \\
0.5 \\
0.6 \\
1.1 \\
1.3 \\
1.5 \\
0.7 \\
0.3\end{array}$ & $\begin{array}{l}\text { Int } \\
1.8 \\
2.9 \\
3.4 \\
2.2 \\
1.2 \\
1.6 \\
0.1 \\
0.6 \\
3.2 \\
5.6 \\
4.8 \\
4.5 \\
6.5 \\
7.5 \\
8.2 \\
8.3 \\
8.9 \\
11.3 \\
11.4 \\
13.9 \\
16.1 \\
18.3 \\
21.8 \\
24.3 \\
27.7 \\
33.8 \\
39.9 \\
45.9\end{array}$ & $\begin{array}{l}\text { SD } \\
1.8 \\
1.3 \\
1.6 \\
1.2 \\
0.9 \\
0.7 \\
0.9 \\
0.9 \\
1.4 \\
1.2 \\
1.2 \\
0.9 \\
0.4 \\
0.9 \\
0.8 \\
1.0 \\
2.1 \\
1.0 \\
0.7 \\
1.0 \\
0.6 \\
0.2 \\
0.5 \\
0.5 \\
0.6 \\
0.7 \\
0.8 \\
0.6\end{array}$ & $\begin{array}{l}\text { Int } \\
0.4 \\
-0.4 \\
0.3 \\
-0.5 \\
0.3 \\
0.9 \\
1.2 \\
3.2 \\
4.1 \\
4.2 \\
6.2 \\
4.2 \\
5.5 \\
6.4 \\
7.9 \\
7.5 \\
9.2 \\
10.9 \\
14.4 \\
16.1 \\
19.9 \\
23.0 \\
25.6 \\
31.1 \\
36.9 \\
43.1 \\
50.8 \\
60.3\end{array}$ & $\begin{array}{l}S D \\
1.4 \\
1.2 \\
1.0 \\
1.1 \\
0.7 \\
0.7 \\
0.6 \\
1.1 \\
1.2 \\
1.5 \\
1.0 \\
1.1 \\
1.3 \\
0.7 \\
0.4 \\
0.9 \\
1.8 \\
1.2 \\
0.8 \\
0.7 \\
0.6 \\
0.7 \\
1.9 \\
1.7 \\
1.1 \\
0.9 \\
0.7 \\
1.3\end{array}$ & $\begin{array}{c}\text { Int } \\
0.9 \\
0.2 \\
0.8 \\
1.5 \\
1.3 \\
2.8 \\
5.9 \\
2.6 \\
5.2 \\
5.1 \\
7.2 \\
7.3 \\
8.9 \\
9.4 \\
11.6 \\
11.1 \\
12.8 \\
13.7 \\
16.5 \\
19.4 \\
22.8 \\
27.1 \\
31.0 \\
36.2 \\
43.8 \\
52.3 \\
60.4 \\
70.2\end{array}$ & $\begin{array}{l}S D \\
2.7 \\
2.0 \\
1.3 \\
0.9 \\
1.5 \\
1.5 \\
2.1 \\
1.1 \\
1.3 \\
1.9 \\
2.4 \\
2.6 \\
2.2 \\
1.3 \\
1.1 \\
0.9 \\
1.1 \\
1.8 \\
0.8 \\
0.7 \\
0.6 \\
0.6 \\
0.6 \\
1.4 \\
1.4 \\
1.4 \\
1.4 \\
1.3\end{array}$ \\
\hline
\end{tabular}


Table 4 (continued).

\begin{tabular}{|c|c|c|c|c|c|c|c|c|c|c|}
\hline molality & \multicolumn{2}{|c|}{0.500} & \multicolumn{2}{|c|}{1.000} & \multicolumn{2}{|c|}{1.503} & \multicolumn{2}{|c|}{2.515} & \multicolumn{2}{|c|}{3.003} \\
\hline $\begin{array}{c}\mathbb{A}^{1} \\
2426.5 \\
2436.5 \\
2446.5 \\
2456.4 \\
2466.4 \\
2476.4 \\
2486.4 \\
2496.4 \\
2506.4 \\
2516.4 \\
2526.4 \\
2536.4 \\
2546.4 \\
2556.4 \\
2566.4 \\
2576.4 \\
2586.4 \\
2596.4 \\
2606.4 \\
2616.4 \\
2626.4 \\
2636.3 \\
2646.3 \\
2656.3 \\
2666.3 \\
2676.3 \\
2686.3 \\
2696.3 \\
2706.3\end{array}$ & $\begin{array}{l}\text { Int } \\
37.7 \\
43.5 \\
50.4 \\
57.3 \\
64.7 \\
72.1 \\
78.3 \\
85.8 \\
89.9 \\
94.8 \\
95.5 \\
94.0 \\
90.6 \\
86.2 \\
79.6 \\
70.8 \\
63.8 \\
56.0 \\
48.6 \\
41.5 \\
36.1 \\
31.7 \\
27.0 \\
23.4 \\
19.7 \\
16.9 \\
14.1 \\
12.1 \\
9.4\end{array}$ & $\begin{array}{l}S D . \\
0.5 \\
0.5 \\
0.9 \\
0.4 \\
0.5 \\
0.4 \\
0.6 \\
1.4 \\
0.5 \\
1.0 \\
0.7 \\
0.6 \\
0.5 \\
0.5 \\
0.7 \\
0.6 \\
0.9 \\
1.0 \\
1.2 \\
0.3 \\
0.3 \\
0.6 \\
0.4 \\
0.3 \\
0.8 \\
0.2 \\
0.2 \\
0.2 \\
0.2\end{array}$ & $\begin{array}{l}\text { Int } \\
42.4 \\
49.4 \\
58.3 \\
67.3 \\
75.9 \\
84.0 \\
93.1 \\
100.2 \\
105.6 \\
111.5 \\
113.7 \\
111.3 \\
106.8 \\
101.5 \\
93.4 \\
84.0 \\
75.0 \\
65.2 \\
56.6 \\
48.2 \\
42.1 \\
36.2 \\
30.8 \\
26.7 \\
22.0 \\
18.7 \\
15.4 \\
12.6 \\
10.5\end{array}$ & $\begin{array}{l}S D \\
0.5 \\
0.4 \\
1.5 \\
0.8 \\
0.6 \\
0.9 \\
0.7 \\
0.7 \\
0.7 \\
0.9 \\
0.8 \\
0.9 \\
0.8 \\
1.0 \\
0.7 \\
0.6 \\
1.2 \\
1.1 \\
0.3 \\
0.4 \\
0.4 \\
1.2 \\
1.0 \\
0.9 \\
0.6 \\
0.7 \\
0.7 \\
0.2 \\
0.3\end{array}$ & $\begin{array}{c}\text { Int } \\
54.0 \\
62.6 \\
72.0 \\
79.8 \\
89.3 \\
100.4 \\
108.1 \\
117.2 \\
125.1 \\
130.5 \\
130.0 \\
131.0 \\
127.0 \\
115.8 \\
105.5 \\
94.3 \\
82.0 \\
70.7 \\
60.0 \\
50.8 \\
42.4 \\
36.4 \\
29.3 \\
23.4 \\
19.6 \\
16.2 \\
14.5 \\
11.3 \\
9.2\end{array}$ & $\begin{array}{l}\text { SD } \\
1.9 \\
1.4 \\
0.9 \\
0.8 \\
0.8 \\
1.1 \\
1.2 \\
1.5 \\
1.3 \\
1.1 \\
0.8 \\
1.3 \\
1.0 \\
1.0 \\
0.8 \\
1.1 \\
0.9 \\
1.2 \\
1.6 \\
1.7 \\
0.8 \\
0.8 \\
0.6 \\
1.0 \\
1.0 \\
0.8 \\
0.9 \\
1.0 \\
1.0\end{array}$ & $\begin{array}{r}69.6 \\
79.8 \\
93.2 \\
106.7 \\
119.7 \\
132.4 \\
146.5 \\
154.8 \\
160.5 \\
164.7 \\
162.3 \\
157.3 \\
149.6 \\
135.9 \\
122.8 \\
108.9 \\
95.2 \\
80.4 \\
68.0 \\
56.0 \\
47.6 \\
39.2 \\
31.7 \\
26.1 \\
22.5 \\
17.0 \\
13.9 \\
11.2 \\
9.5\end{array}$ & $\begin{array}{l}1.7 \\
2.0 \\
1.9 \\
1.8 \\
1.7 \\
1.8 \\
1.2 \\
1.5 \\
1.3 \\
1.5 \\
1.2 \\
1.0 \\
1.1 \\
1.2 \\
1.8 \\
1.0 \\
0.9 \\
0.8 \\
0.5 \\
1.3 \\
1.0 \\
0.9 \\
1.0 \\
1.1 \\
1.0 \\
1.8 \\
1.8 \\
1.1 \\
0.6\end{array}$ & $\begin{array}{r}80.9 \\
93.3 \\
109.4 \\
126.2 \\
139.7 \\
151.9 \\
167.3 \\
176.3 \\
182.0 \\
182.9 \\
181.5 \\
173.6 \\
162.0 \\
146.4 \\
132.7 \\
115.4 \\
101.0 \\
84.4 \\
70.4 \\
59.1 \\
48.3 \\
38.4 \\
30.2 \\
24.3 \\
19.5 \\
15.8 \\
13.5 \\
10.2 \\
7.2\end{array}$ & $\begin{array}{l}1.1 \\
1.7 \\
1.8 \\
2.1 \\
1.9 \\
1.5 \\
1.5 \\
1.2 \\
1.4 \\
1.4 \\
1.2 \\
1.2 \\
1.5 \\
1.6 \\
1.7 \\
1.5 \\
1.8 \\
1.6 \\
1.1 \\
1.3 \\
0.8 \\
0.5 \\
0.7 \\
1.6 \\
1.5 \\
1.4 \\
1.3 \\
0.8 \\
1.2\end{array}$ \\
\hline
\end{tabular}


Table 4 (continued).

\begin{tabular}{|c|c|c|c|c|c|c|c|c|c|c|}
\hline$\frac{\text { nolality }}{\text { ca- }}$ & \multicolumn{2}{|c|}{0.500} & \multicolumn{2}{|c|}{1.000} & \multicolumn{2}{|c|}{1.503} & \multicolumn{2}{|c|}{2.515} & \multicolumn{2}{|c|}{3.003} \\
\hline 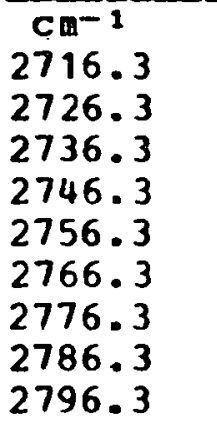 & $\begin{array}{l}\text { Int } \\
7.7 \\
6.4 \\
5.7 \\
4.7 \\
3.7 \\
3.0 \\
3.2 \\
3.4 \\
3.0\end{array}$ & $\begin{array}{l}S D \\
0.5 \\
0.1 \\
0.3 \\
0.1 \\
0.4 \\
0.2 \\
0.4 \\
0.6 \\
0.4\end{array}$ & $\begin{array}{l}\text { Int } \\
9.5 \\
8.0 \\
7.0 \\
6.6 \\
5.4 \\
4.5 \\
4.2 \\
4.7 \\
4.1\end{array}$ & $\begin{array}{l}\text { SD } \\
0.4 \\
0.3 \\
0.7 \\
0.8 \\
0.8 \\
0.0 \\
0.2 \\
0.5 \\
0.5\end{array}$ & $\begin{array}{l}\text { Int } \\
7.5 \\
6.4 \\
5.2 \\
3.8 \\
2.9 \\
2.7 \\
1.5 \\
1.4 \\
2.1\end{array}$ & $\begin{array}{l}\text { SD } \\
0.5 \\
1.0 \\
0.9 \\
0.8 \\
1.0 \\
0.8 \\
1.0 \\
1.9 \\
0.7\end{array}$ & $\begin{array}{l}8.4 \\
7.7 \\
6.2 \\
6.3 \\
5.6 \\
3.7 \\
3.3 \\
4.0 \\
4.9\end{array}$ & $\begin{array}{l}0.5 \\
0.3 \\
0.7 \\
0.8 \\
0.7 \\
0.6 \\
0.3 \\
0.5 \\
0.5\end{array}$ & $\begin{array}{l}5.3 \\
4.3 \\
3.1 \\
4.0 \\
2.8 \\
2.9 \\
1.8 \\
1.7 \\
1.4\end{array}$ & $\begin{array}{l}0.6 \\
0.6 \\
1.2 \\
1.2 \\
1.7 \\
2.1 \\
2.2 \\
1.5 \\
2.0\end{array}$ \\
\hline
\end{tabular}


THIS PAGE

\section{WAS INTENTIONALLY LEFT BLANK}


Table 5 (continued).

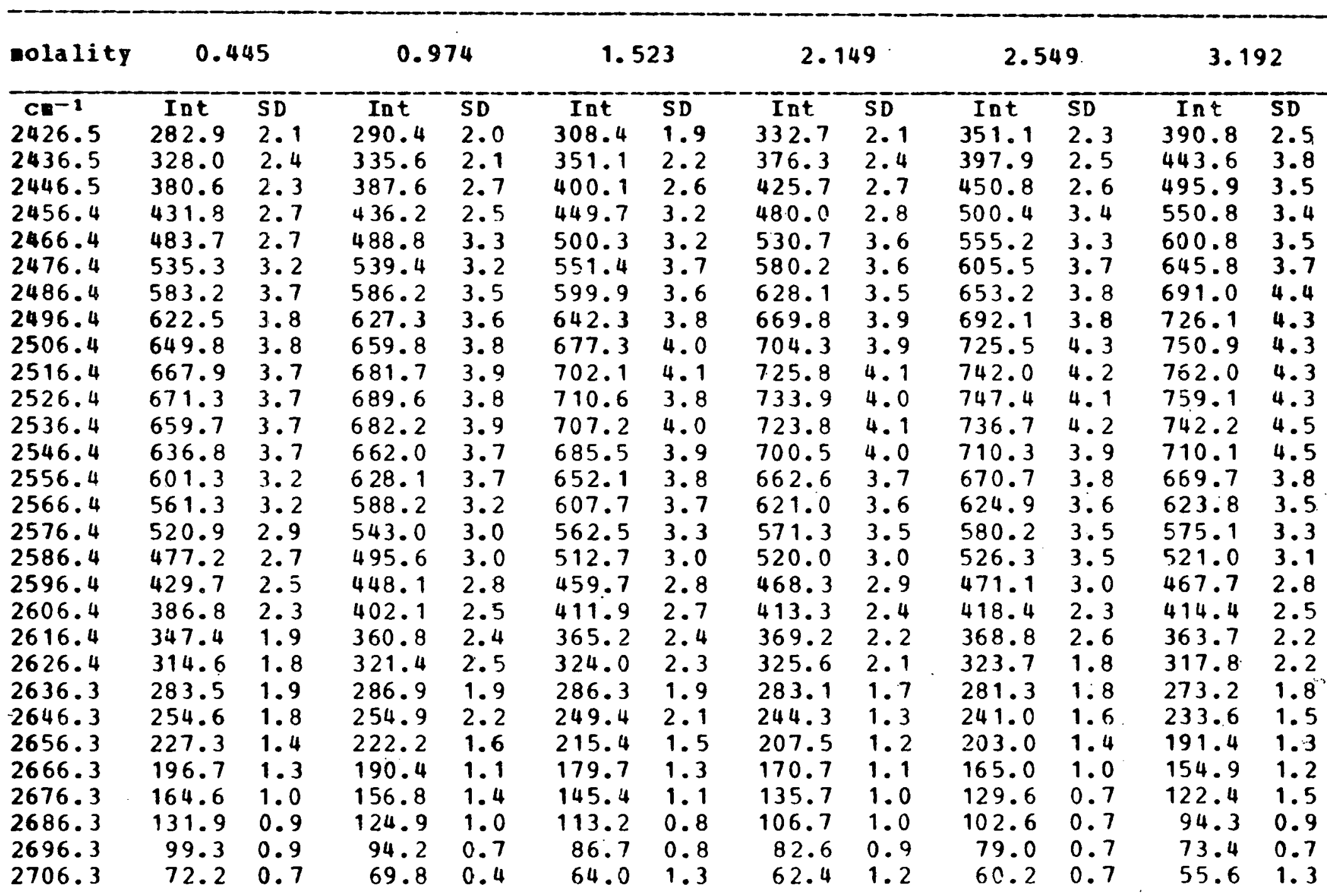


Table 5 (continued).

\begin{tabular}{|c|c|c|c|c|c|c|c|c|c|c|c|c|}
\hline molality & \multicolumn{2}{|c|}{0.445} & \multicolumn{2}{|c|}{0.974} & \multicolumn{2}{|c|}{1.523} & \multicolumn{2}{|c|}{2.149} & \multicolumn{2}{|c|}{2.549} & \multicolumn{2}{|c|}{3.192} \\
\hline $\begin{array}{c}C \cdot 1 \\
2716 \cdot 3 \\
2726.3 \\
2736 \cdot 3 \\
2746 \cdot 3 \\
2756 \cdot 3 \\
2766.3 \\
2776.3 \\
2786 \cdot 3 \\
2796.3\end{array}$ & $\begin{array}{l}\text { Int } \\
53.3 \\
38.6 \\
27.6 \\
19.2 \\
13.8 \\
10.0 \\
5.8 \\
4.9 \\
2.6\end{array}$ & $\begin{array}{l}S D \\
0.7 \\
0.7 \\
0.6 \\
0.8 \\
0.6 \\
0.2 \\
0.5 \\
0.6 \\
0.5\end{array}$ & $\begin{array}{l}\text { Int } \\
51.5 \\
38.1 \\
28.4 \\
20.3 \\
14.3 \\
10.9 \\
7.3 \\
5.6 \\
4.4\end{array}$ & $\begin{array}{l}\overline{S D} \\
0.9 \\
0.5 \\
0.8 \\
0.8 \\
0.5 \\
0.2 \\
1.2 \\
0.6 \\
0.9\end{array}$ & $\begin{array}{l}\text { Int } \\
47.7 \\
36.3 \\
25.2 \\
17.3 \\
11.6 \\
8.7 \\
6.5 \\
3.8 \\
4.7\end{array}$ & $\begin{array}{l}S D \\
0.9 \\
1.2 \\
1.7 \\
2.0 \\
2.0 \\
2.0 \\
0.4 \\
0.5 \\
0.7\end{array}$ & $\begin{array}{l}\operatorname{Int} \\
48.4 \\
35.7 \\
28.2 \\
21.3 \\
15.7 \\
9.2 \\
8.3 \\
6.5 \\
7.2\end{array}$ & $\begin{array}{l}5 \bar{D} \\
0.6 \\
0.9 \\
0.8 \\
1.4 \\
1.3 \\
0.9 \\
1.5 \\
0.9 \\
1.6\end{array}$ & $\begin{array}{l}\text { Int } \\
44.7 \\
34.5 \\
25.3 \\
19.4 \\
14.6 \\
11.5 \\
8.7 \\
6.3 \\
5.4\end{array}$ & $\begin{array}{l}\bar{S} \bar{D} \\
0.7 \\
0.4 \\
0.3 \\
0.6 \\
0.4 \\
1.0 \\
0.4 \\
0.7 \\
0.7\end{array}$ & $\begin{array}{l}\text { Int } \\
43.0 \\
32.6 \\
25.6 \\
17.6 \\
14.4 \\
10.3 \\
7.4 \\
6.1 \\
5.9\end{array}$ & $\begin{array}{l}S D \\
0.8 \\
0.7 \\
1.0 \\
1.0 \\
0.8 \\
0.8 \\
1.0 \\
0.7 \\
0.7\end{array}$ \\
\hline
\end{tabular}


Table 6. Average intensities of the OD stretching frequencies of the anisotropic spectrum of $\mathrm{GdCl}_{3}-5 \mathrm{KD}_{2} \mathrm{O}$.

\begin{tabular}{|c|c|c|c|c|c|c|c|c|c|c|c|c|}
\hline Dolality & \multicolumn{2}{|c|}{0.445} & \multicolumn{2}{|c|}{0.974} & \multicolumn{2}{|c|}{1.523} & \multicolumn{2}{|c|}{2.149} & \multicolumn{2}{|c|}{2.549} & \multicolumn{2}{|c|}{3.192} \\
\hline $\begin{array}{c}C^{-1} \\
2146.6 \\
2156.6 \\
2166.6 \\
2176.6 \\
2186.6 \\
2196.6 \\
2206.6 \\
2216.6 \\
2226.6 \\
2236.6 \\
2246.6 \\
2256.6 \\
2266.6 \\
2276.5 \\
2286.5 \\
2296.5 \\
2306.5 \\
2316.5 \\
2326.5 \\
2336.5 \\
2346.5 \\
2356.5 \\
2366.5 \\
2376.5 \\
2386.5 \\
2396.5 \\
2406.5 \\
2416.5\end{array}$ & $\begin{array}{l}\text { Int } \\
0.6 \\
0.7 \\
0.5 \\
0.3 \\
1.0 \\
0.8 \\
0.7 \\
1.8 \\
1.8 \\
1.9 \\
2.9 \\
3.6 \\
3.5 \\
3.8 \\
4.7 \\
5.2 \\
6.0 \\
7.8 \\
8.7 \\
10.1 \\
11.6 \\
13.6 \\
14.6 \\
16.8 \\
20.3 \\
23.9 \\
27.9 \\
32.5\end{array}$ & $\begin{array}{l}\text { SD } \\
0.3 \\
0.3 \\
0.4 \\
0.3 \\
0.3 \\
0.5 \\
0.1 \\
0.1 \\
0.5 \\
0.4 \\
0.8 \\
0.3 \\
0.3 \\
0.4 \\
0.4 \\
0.2 \\
0.1 \\
0.5 \\
0.4 \\
0.3 \\
0.1 \\
0.4 \\
0.1 \\
0.2 \\
0.4 \\
0.4 \\
0.3 \\
0.5\end{array}$ & $\begin{array}{l}\text { Int } \\
0.5 \\
1.1 \\
0.4 \\
0.4 \\
0.6 \\
0.7 \\
1.3 \\
1.7 \\
2.0 \\
3.1 \\
3.3 \\
4.1 \\
4.9 \\
5.7 \\
5.4 \\
7.2 \\
8.3 \\
8.9 \\
11.1 \\
12.4 \\
14.8 \\
16.1 \\
19.4 \\
22.4 \\
25.9 \\
30.3 \\
34.2 \\
39.5\end{array}$ & $\begin{array}{l}\text { SD } \\
0.6 \\
0.6 \\
0.6 \\
0.2 \\
0.5 \\
0.3 \\
0.6 \\
1.2 \\
0.9 \\
0.8 \\
0.9 \\
0.9 \\
0.7 \\
0.7 \\
0.1 \\
0.7 \\
0.2 . \\
0.2 \\
0.7 \\
0.7 \\
0.8 \\
0.8 \\
1.0 \\
0.9 \\
0.8 \\
1.1 \\
0.7 \\
0.8\end{array}$ & $\begin{array}{l}\text { Int } \\
2.5 \\
2.7 \\
3.3 \\
2.2 \\
2.0 \\
1.3 \\
0.9 \\
2.0 \\
3.5 \\
3.8 \\
5.1 \\
5.2 \\
6.0 \\
7.1 \\
8.0 \\
9.9 \\
10.7 \\
13.1 \\
14.8 \\
16.7 \\
18.6 \\
21.4 \\
23.8 \\
27.2 \\
31.4 \\
36.8 \\
42.4 \\
49.0\end{array}$ & $\begin{array}{l}\text { SD } \\
1.0 \\
0.7 \\
1.0 \\
1.1 \\
1.7 \\
2.0 \\
2.2 \\
2.3 \\
1.4 \\
0.5 \\
0.7 \\
1.1 \\
0.4 \\
0.3 \\
0.9 \\
0.5 \\
0.6 \\
1.5 \\
1.3 \\
1.3 \\
1.4 \\
1.3 \\
1.2 \\
0.8 \\
0.7 \\
1.1 \\
1.8 \\
1.8\end{array}$ & $\begin{array}{l}\text { Int } \\
7.7 \\
7.3 \\
7.8 \\
7.1 \\
8.0 \\
8.5 \\
7.6 \\
7.9 \\
8.2 \\
8.7 \\
9.2 \\
9.5 \\
11.1 \\
12.0 \\
13.1 \\
14.9 \\
14.8 \\
17.8 \\
19.3 \\
21.9 \\
25.4 \\
27.4 \\
31.6 \\
35.4 \\
41.1 \\
46.6 \\
52.1 \\
61.8\end{array}$ & $\begin{array}{l}S D \\
1.0 \\
0.2 \\
0.5 \\
0.4 \\
0.4 \\
0.3 \\
0.3 \\
1.0 \\
0.3 \\
0.8 \\
0.7 \\
0.7 \\
0.7 \\
0.4 \\
0.3 \\
0.1 \\
1.0 \\
0.5 \\
0.9 \\
0.2 \\
0.4 \\
0.7 \\
0.5 \\
0.4 \\
0.4 \\
1.6 \\
0.4 \\
0.7\end{array}$ & $\begin{array}{r}\text { Int } \\
7.1 \\
5.7 \\
6.9 \\
6.3 \\
6.0 \\
6.2 \\
6.9 \\
7.4 \\
8.3 \\
10.0 \\
10.6 \\
9.7 \\
10.1 \\
11.8 \\
14.1 \\
16.1 \\
16.3 \\
19.0 \\
21.7 \\
24.3 \\
28.3 \\
32.2 \\
36.5 \\
42.6 \\
49.6 \\
55.7 \\
63.2 \\
72.6\end{array}$ & $\begin{array}{l}\text { SD } \\
3.9 \\
4.7 \\
4.6 \\
4.9 \\
4.4 \\
3.6 \\
3.8 \\
2.7 \\
2.1 \\
1.4 \\
0.7 \\
1.1 \\
0.4 \\
0.8 \\
1.6 \\
0.7 \\
1.4 \\
1.5 \\
2.2 \\
2.2 \\
2.1 \\
2.3 \\
2.0 \\
2.8 \\
3.2 \\
3.2 \\
3.0 \\
3.5\end{array}$ & $\begin{array}{r}\text { Int } \\
10.2 \\
9.5 \\
9.3 \\
7.9 \\
8.5 \\
9.0 \\
13.6 \\
11.4 \\
14.1 \\
14.7 \\
18.0 \\
18.6 \\
20.9 \\
22.8 \\
25.1 \\
25.6 \\
28.0 \\
29.5 \\
32.5 \\
38.4 \\
42.7 \\
48.0 \\
52.7 \\
56.5 \\
66.7 \\
75.0 \\
83.4 \\
92.9\end{array}$ & $\begin{array}{l}\text { SD } \\
2.8 \\
1.9 \\
1.2 \\
1.1 \\
1.5 \\
1.6 \\
2.0 \\
1.0 \\
0.7 \\
1.6 \\
1.3 \\
1.8 \\
1.5 \\
0.3 \\
0.6 \\
0.4 \\
1.2 \\
1.6 \\
0.9 \\
0.7 \\
0.7 \\
1.0 \\
0.8 \\
0.9 \\
0.9 \\
1.0 \\
0.6 \\
0.7\end{array}$ \\
\hline
\end{tabular}


Table 6 (continued).

\begin{tabular}{|c|c|c|c|c|c|c|c|c|c|c|c|c|}
\hline molality & \multicolumn{2}{|c|}{0.445} & \multicolumn{2}{|c|}{0.974} & \multicolumn{2}{|c|}{ 1. 523} & \multicolumn{2}{|c|}{2.149} & \multicolumn{2}{|c|}{2.549} & \multicolumn{2}{|c|}{3.192} \\
\hline $\begin{array}{c}c m-1 \\
2426.5 \\
2436.5 \\
2446.5 \\
2456.4 \\
2466.4 \\
2476.4 \\
2486.4 \\
2496.4 \\
2506.4 \\
2516.4 \\
2526.4 \\
2536.4 \\
2546.4 \\
2556.4 \\
2566.4 \\
2576.4 \\
2586.4 \\
2596.4 \\
2606.4 \\
2616.4 \\
2626.4 \\
2636.3 \\
2646.3 \\
2656.3 \\
2666.3 \\
2676.3 \\
2686.3 \\
2696.3 \\
2706.3\end{array}$ & $\begin{array}{l}\text { Int } \\
38.2 \\
44.0 \\
51.5 \\
58.6 \\
65.9 \\
72.7 \\
79.6 \\
86.8 \\
92.6 \\
95.4 \\
97.2 \\
96.3 \\
92.8 \\
86.9 \\
79.8 \\
73.6 \\
65.8 \\
58.0 \\
49.5 \\
42.1 \\
36.5 \\
30.8 \\
26.7 \\
22.6 \\
18.7 \\
15.5 \\
13.0 \\
10.2 \\
8.3\end{array}$ & $\begin{array}{l}S D \\
0.7 \\
0.6 \\
0.6 \\
0.8 \\
1.0 \\
0.5 \\
0.5 \\
0.6 \\
0.6 \\
0.6 \\
0.6 \\
0.8 \\
0.6 \\
0.8 \\
0.7 \\
0.5 \\
0.4 \\
0.4 \\
0.4 \\
0.5 \\
0.4 .4 \\
0.4 \\
0.3 \\
0.3 \\
0.5 \\
0.2 \\
0.2 \\
0.4 \\
0.8\end{array}$ & $\begin{array}{c}\text { Int } \\
45.9 \\
52.7 \\
60.0 \\
68.4 \\
77.0 \\
86.0 \\
94.7 \\
103.0 \\
108.9 \\
112.8 \\
115.2 \\
114.7 \\
109.5 \\
102.3 \\
94.7 \\
84.7 \\
75.7 \\
65.3 \\
56.1 \\
47.0 \\
39.9 \\
33.2 \\
27.5 \\
23.4 \\
18.6 \\
15.5 \\
12.6 \\
9.9 \\
8.0\end{array}$ & $\begin{array}{l}\text { SD } \\
0.7 \\
0.7 \\
1.0 \\
0.7 \\
0.8 \\
1.0 \\
1.1 \\
1.1 \\
0.7 \\
0.8 \\
0.7 \\
0.7 \\
0.7 \\
0.7 \\
0.9 \\
0.7 \\
0.6 \\
0.7 \\
0.6 \\
0.8 \\
1.0 \\
0.5 \\
0.5 \\
0.4 \\
0.7 \\
1.0 \\
0.9 \\
0.7 \\
0.5\end{array}$ & $\begin{array}{l}\text { Int } \\
56.3 \\
64.3 \\
73.3 \\
82.6 \\
91.4 \\
101.7 \\
111.8 \\
120.9 \\
129.1 \\
132.6 \\
135.6 \\
132.7 \\
126.8 \\
116.1 \\
105.8 \\
95.0 \\
82.4 \\
70.7 \\
58.8 \\
49.4 \\
40.8 \\
33.6 \\
26.0 \\
21.6 \\
17.2 \\
13.2 \\
10.2 \\
7.6 \\
6.0\end{array}$ & $\begin{array}{l}\text { SD } \\
1.9 \\
2.0 \\
2.0 \\
1.5 \\
1.4 \\
1.2 \\
1.2 \\
1.2 \\
1.0 \\
1.0 \\
1.1 \\
1.1 \\
1.2 \\
1.1 \\
1.1 \\
1.7 \\
1.4 \\
1.1 \\
0.8 \\
1.2 \\
1.0 \\
0.9 \\
1.5 \\
1.4 \\
1.1 \\
0.4 \\
0.8 \\
0.5 \\
0.2\end{array}$ & $\begin{array}{c}\text { Int } \\
68.8 \\
79.1 \\
90.0 \\
101.8 \\
112.2 \\
125.2 \\
133.3 \\
143.3 \\
149.5 \\
154.3 \\
156.5 \\
152.5 \\
143.2 \\
132.3 \\
119.3 \\
106.0 \\
93.0 \\
80.1 \\
66.8 \\
54.7 \\
46.6 \\
37.4 \\
30.5 \\
24.7 \\
19.0 \\
15.9 \\
12.3 \\
10.2 \\
8.0\end{array}$ & $\begin{array}{l}\text { SD } \\
0.9 \\
1.1 \\
1.0 \\
1.0 \\
1.1 \\
1.0 \\
0.8 \\
1.4 \\
1.1 \\
1.3 \\
0.9 \\
1.3 \\
0.8 \\
1.1 \\
1.0 \\
0.8 \\
0.7 \\
0.5 \\
0.6 \\
0.3 \\
0.3 \\
0.3 \\
0.3 \\
0.3 \\
0.7 \\
0.8 \\
0.2 \\
0.1 \\
0.6\end{array}$ & $\begin{array}{l}\text { Int } \\
82.5 \\
93.1 \\
104.9 \\
119.1 \\
130.8 \\
143.0 \\
153.1 \\
161.8 \\
167.5 \\
168.5 \\
168.5 \\
161.5 \\
153.1 \\
139.5 \\
125.1 \\
110.8 \\
96.2 \\
79.8 \\
66.5 \\
54.6 \\
45.3 \\
36.8 \\
28.7 \\
22.8 \\
18.0 \\
13.7 \\
10.6 \\
7.0 \\
5.1\end{array}$ & $\begin{array}{l}S D \\
3.5 \\
2.7 \\
2.7 \\
2.7 \\
2.5 \\
2.5 \\
2.9 \\
1.6 \\
0.9 \\
1.7 \\
1.6 \\
1.2 \\
1.2 \\
1.4 \\
1.8 \\
1.8 \\
1.9 \\
2.9 \\
2.5 \\
2.5 \\
1.9 \\
1.9 \\
1.6 \\
1.5 \\
1.1 \\
1.3 \\
1.4 \\
1.1 \\
0.9\end{array}$ & $\begin{array}{c}\text { Int } \\
104.9 \\
115.5 \\
129.1 \\
143.6 \\
154.3 \\
165.7 \\
174.7 \\
180.9 \\
183.3 \\
182.0 \\
178.0 \\
169.5 \\
158.1 \\
142.3 \\
126.4 \\
111.6 \\
95.0 \\
79.1 \\
63.7 \\
53.0 \\
42.0 \\
32.6 \\
25.3 \\
19.0 \\
14.5 \\
11.5 \\
8.5 \\
5.9 \\
3.0\end{array}$ & $\begin{array}{l}S D \\
0.8 \\
1.6 \\
1.1 \\
1.4 \\
1.4 \\
1.3 \\
1.0 \\
1.2 \\
1.8 \\
1.4 \\
1.3 \\
1.1 \\
1.0 \\
0.9 \\
1.0 \\
0.9 \\
1.2 \\
1.0 \\
1.3 \\
1.1 \\
0.9 \\
0.3 \\
0.7 \\
1.6 \\
1.6 \\
1.5 \\
1.3 \\
0.9 \\
1.1\end{array}$ \\
\hline
\end{tabular}


Table 6 (continued).

\begin{tabular}{|c|c|c|c|c|c|c|c|c|c|c|c|c|}
\hline $\begin{array}{l}\text { molality } \\
-\overline{c n}=-1\end{array}$ & \multicolumn{2}{|c|}{0.445} & \multicolumn{2}{|c|}{0.974} & \multicolumn{2}{|c|}{1.523} & \multicolumn{2}{|c|}{2.149} & \multicolumn{2}{|c|}{2.549} & \multicolumn{2}{|c|}{3.192} \\
\hline $\begin{array}{l}c m=1 \\
2716.3 \\
2726.3 \\
2736.3 \\
2746.3 \\
2756.3 \\
2766.3 \\
2776.3 \\
2786.3 \\
2796.3\end{array}$ & $\begin{array}{l}\text { Int } \\
6.3 \\
4.8 \\
3.8 \\
2.8 \\
2.2 \\
1.5 \\
1.2 \\
0.9 \\
1.3\end{array}$ & $\begin{array}{l}S D \\
0.2 \\
0.4 \\
0.1 \\
0.3 \\
0.2 \\
0.2 \\
0.3 \\
0.5 \\
0.3\end{array}$ & $\begin{array}{l}\text { Int } \\
5.6 \\
4.6 \\
3.7 \\
3.2 \\
2.1 \\
1.3 \\
1.5 \\
1.9 \\
1.2\end{array}$ & $\begin{array}{l}S D \\
0.4 \\
0.4 \\
0.4 \\
0.1 \\
0.3 \\
0.7 \\
0.8 \\
1.1 \\
1.1\end{array}$ & $\begin{array}{r}\operatorname{Int} \\
4.0 \\
2.8 \\
1.6 \\
0.1 \\
0.2 \\
-0.1 \\
-0.6 \\
-0.6 \\
0.1\end{array}$ & $\begin{array}{l}S D \\
0.3 \\
0.3 \\
0.5 \\
0.4 \\
0.3 \\
0.6 \\
0.6 \\
0.8 \\
1.3\end{array}$ & $\begin{array}{l}\text { Int } \\
5.4 \\
4.1 \\
3.1 \\
1.9 \\
0.6 \\
0.5 \\
-0.6 \\
-0.3 \\
-0.5\end{array}$ & $\begin{array}{l}\text { SD } \\
0.0 \\
0.4 \\
0.7 \\
0.5 \\
0.7 \\
0.2 \\
0.5 \\
0.6 \\
0.8\end{array}$ & $\begin{array}{l}\text { Int } \\
3.8 \\
3.2 \\
2.0 \\
1.2 \\
1.3 \\
0.1 \\
0.0 \\
1.0 \\
1.4\end{array}$ & $\begin{array}{l}\overline{S D} \\
0.6 \\
0.1 \\
0.7 \\
0.9 \\
1.6 \\
1.1 \\
1.4 \\
2.7 \\
3.7\end{array}$ & $\begin{array}{r}\mathrm{I} \text { t } \\
2.0 \\
0.4 \\
-0.1 \\
2.1 \\
1.7 \\
2.7 \\
3.2 \\
2.7 \\
3.8\end{array}$ & $\begin{array}{l}\text { SD } \\
0.4 \\
0.3 \\
1.1 \\
1.1 \\
1.6 \\
2.1 \\
2.0 \\
0.9 \\
1.2\end{array}$ \\
\hline
\end{tabular}


Table 7. Average intensities of the or stretching frequencies of the isotropic spectrua of $\mathrm{GdCl}_{3}-5 \mathrm{x}_{2} \mathrm{O}$.

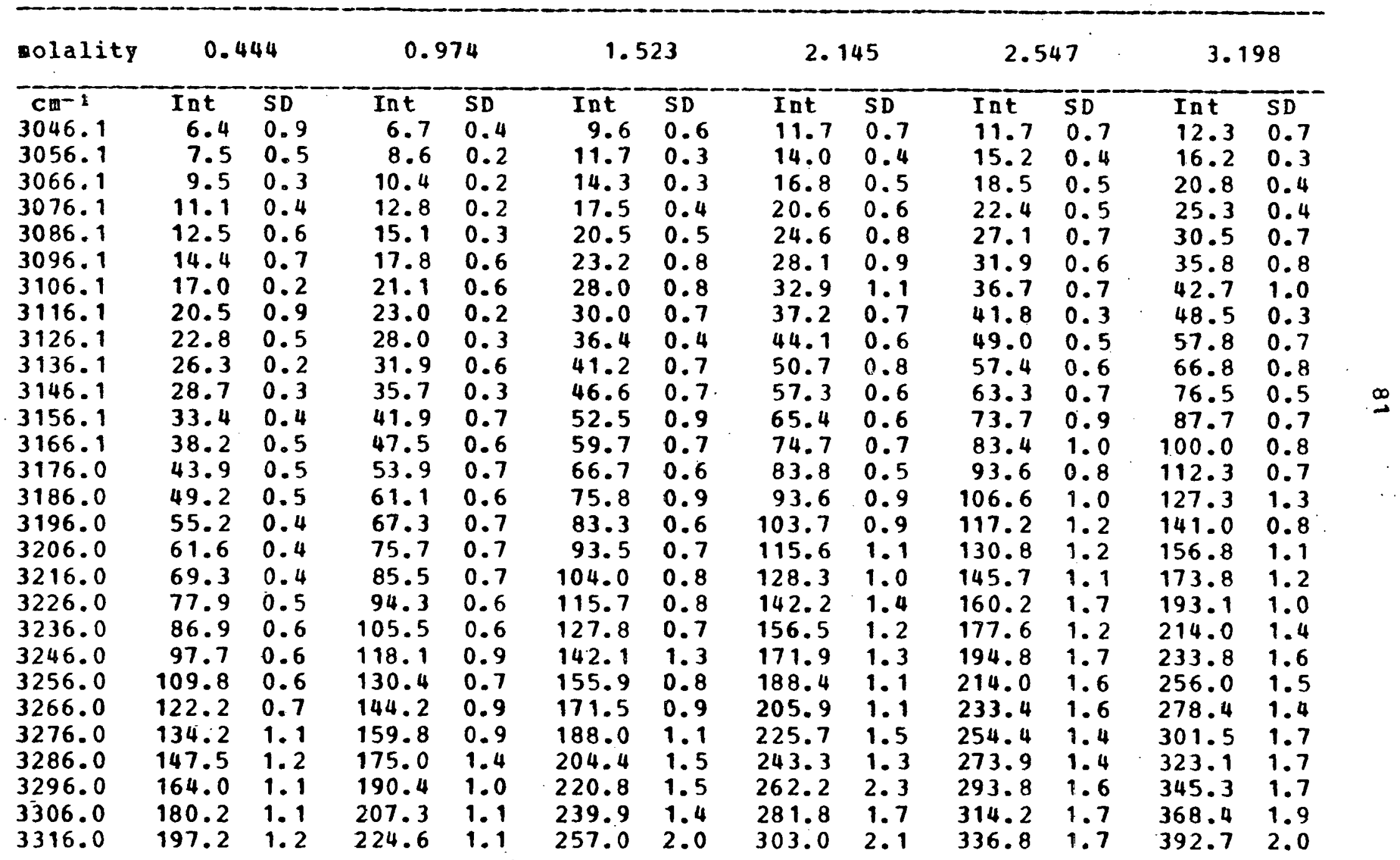


Table 7 (continued) .

\begin{tabular}{|c|c|c|c|c|c|c|c|c|c|c|c|c|}
\hline molality & \multicolumn{2}{|c|}{0.444} & \multicolumn{2}{|c|}{0.974} & \multicolumn{2}{|c|}{1.523} & \multicolumn{2}{|c|}{2.145} & \multicolumn{2}{|c|}{2.547} & \multicolumn{2}{|c|}{3.198} \\
\hline $\begin{array}{c}C B^{-1} \\
3326.0 \\
3336.0 \\
3346.0 \\
3355.9 \\
3365.9 \\
3375.9 \\
3385.9 \\
3395.9 \\
3405.9 \\
3415.9 \\
3425.9 \\
3435.9 \\
3445.9 \\
3455.9 \\
3465.9 \\
3475.9 \\
3485.9 \\
3495.9 \\
3505.9 \\
3515.9 \\
3525.9 \\
3535.8 \\
3545.8 \\
3555.8 \\
3565.8 \\
3575.8 \\
3585.8 \\
3595.8 \\
3605.8\end{array}$ & $\begin{array}{c}\text { Int } \\
216.1 \\
233.5 \\
250.6 \\
269.6 \\
287.2 \\
303.9 \\
316.8 \\
327.1 \\
337.4 \\
344.1 \\
347.1 \\
347.4 \\
345.5 \\
340.9 \\
332.5 \\
321.9 \\
310.7 \\
297.9 \\
283.9 \\
270.0 \\
254.1 \\
239.2 \\
225.2 \\
210.2 \\
196.4 \\
185.0 \\
175.0 \\
162.5 \\
150.9\end{array}$ & $\begin{array}{l}S D \\
1.3 \\
1.7 \\
1.7 \\
1.8 \\
1.6 \\
1.5 \\
1.8 \\
1.8 \\
2.3 \\
1.8 \\
2.2 \\
1.7 \\
1.7 \\
2.0 \\
1.7 \\
1.7 \\
2.0 \\
1.8 \\
1.8 \\
1.5 \\
1.4 \\
1.9 \\
1.4 \\
1.8 \\
1.4 \\
1.1 \\
1.4 \\
1.1 \\
1.2\end{array}$ & $\begin{array}{c}\text { Int } \\
246.0 \\
265.4 \\
283.5 \\
302.8 \\
321.0 \\
337.9 \\
354.0 \\
367.6 \\
376.1 \\
385.9 \\
389.9 \\
391.2 \\
386.2 \\
381.7 \\
373.9 \\
360.9 \\
347.7 \\
333.9 \\
316.5 \\
298.4 \\
279.7 \\
260.7 \\
243.9 \\
226.2 \\
210.5 \\
196.9 \\
183.5 \\
168.5 \\
156.1\end{array}$ & $\begin{array}{l}\text { SD } \\
1.2 \\
1.7 \\
1.7 \\
1.6 \\
1.6 \\
1.8 \\
1.9 \\
2.3 \\
2.0 \\
1.9 \\
2.0 \\
2.3 \\
2.0 \\
2.1 \\
2.1 \\
3.0 \\
2.4 \\
1.8 \\
2.3 \\
1.5 \\
1.7 \\
1.4 \\
1.5 \\
1.2 \\
1.3 \\
1.2 \\
1.2 \\
1.1 \\
1.0\end{array}$ & $\begin{array}{c}\text { Int } \\
278.7 \\
298.4 \\
320.7 \\
341.0 \\
360.6 \\
379.4 \\
393.4 \\
407.7 \\
418.0 \\
425.9 \\
430.6 \\
428.8 \\
423.7 \\
418.1 \\
405.2 \\
393.2 \\
376.9 \\
359.8 \\
341.9 \\
318.8 \\
298.6 \\
277.9 \\
258.9 \\
239.4 \\
220.7 \\
204.3 \\
188.1 \\
172.3 \\
156.4\end{array}$ & $\begin{array}{l}\text { SD } \\
1.6 \\
1.6 \\
1.9 \\
1.9 \\
2.1 \\
2.0 \\
2.0 \\
2.0 \\
2.4 \\
2.3 \\
2.3 \\
2.4 \\
2.2 \\
2.8 \\
2.2 \\
2.2 \\
2.1 \\
2.1 \\
1.8 \\
2.3 \\
1.5 \\
1.5 \\
1.3 \\
1.3 \\
1.2 \\
1.1 \\
1.3 \\
1.3 \\
1.2\end{array}$ & $\begin{array}{c}\text { Int } \\
324.7 \\
348.0 \\
369.7 \\
389.9 \\
410.5 \\
428.8 \\
444.1 \\
456.7 \\
466.0 \\
470.6 \\
471.1 \\
470.1 \\
462.9 \\
453.0 \\
439.3 \\
421.9 \\
403.8 \\
385.3 \\
364.3 \\
335.0 \\
314.9 \\
293.6 \\
272.3 \\
250.3 \\
233.0 \\
209.6 \\
191.8 \\
172.8 \\
153.6\end{array}$ & $\begin{array}{l}\text { SD } \\
1.9 \\
1.8 \\
2.1 \\
2.1 \\
2.1 \\
2.1 \\
2.2 \\
2.3 \\
3.1 \\
2.8 \\
2.5 \\
3.0 \\
2.5 \\
2.6 \\
2.3 \\
2.3 \\
2.3 \\
2.0 \\
2.0 \\
3.5 \\
2.0 \\
1.8 \\
1.8 \\
1.3 \\
3.5 \\
1.2 \\
1.3 \\
0.9 \\
1.0\end{array}$ & $\begin{array}{l}\text { Int } \\
361.0 \\
384.6 \\
407.1 \\
426.2 \\
445.3 \\
461.6 \\
477.0 \\
487.9 \\
494.5 \\
498.1 \\
497.8 \\
493.5 \\
485.3 \\
473.0 \\
458.7 \\
440.7 \\
419.9 \\
400.6 \\
374.1 \\
348.9 \\
323.7 \\
299.7 \\
276.9 \\
252.8 \\
231.5 \\
211.3 \\
191.2 \\
171.9 \\
151.2\end{array}$ & $\begin{array}{l}S D \\
1.9 \\
2.1 \\
2.5 \\
2.6 \\
2.4 \\
2.5 \\
2.6 \\
2.5 \\
2.9 \\
2.7 \\
3.0 \\
2.8 \\
3.1 \\
2.5 \\
2.8 \\
2.9 \\
2.9 \\
2.8 \\
2.1 \\
1.9 \\
1.9 \\
1.9 \\
1.5 \\
1.7 \\
1.4 \\
1.2 \\
1.0 \\
1.1 \\
1.0\end{array}$ & $\begin{array}{l}\text { Int } \\
417.1 \\
438.9 \\
462.6 \\
481.6 \\
501.1 \\
515.9 \\
527.0 \\
536.6 \\
540.1 \\
540.0 \\
535.3 \\
528.7 \\
517.0 \\
504.1 \\
486.9 \\
466.2 \\
441.4 \\
419.7 \\
394.7 \\
366.1 \\
340.7 \\
312.6 \\
287.0 \\
261.2 \\
236.8 \\
214.0 \\
192.7 \\
170.4 \\
148.1\end{array}$ & $\begin{array}{l}S D \\
2.2 \\
2.3 \\
2.3 \\
2.5 \\
2.7 \\
2.7 \\
2.8 \\
2.8 \\
2.9 \\
2.9 \\
2.8 \\
2.8 \\
3.0 \\
2.6 \\
2.7 \\
2.5 \\
2.4 \\
2.6 \\
2.1 \\
1.8 \\
1.8 \\
1.8 \\
1.7 \\
1.6 \\
1.3 \\
1.3 \\
1.3 \\
1.1 \\
1.0\end{array}$ \\
\hline
\end{tabular}


Table 7 (continued).

\begin{tabular}{|c|c|c|c|c|c|c|c|c|c|c|c|c|}
\hline molality & \multicolumn{2}{|c|}{0.444} & \multicolumn{2}{|c|}{0.974} & \multicolumn{2}{|c|}{1.523} & \multicolumn{2}{|c|}{2.145} & \multicolumn{2}{|c|}{2.547} & \multicolumn{2}{|c|}{3.198} \\
\hline $\begin{array}{c}C D-1 \\
3615.8 \\
3625.8 \\
3635.8 \\
3645.8 \\
3655.8 \\
3665.8 \\
3675.8 \\
3685.8 \\
3695.8 \\
3705.8 \\
3715.8 \\
3725.8 \\
3735.7 \\
3745.7 \\
3755.7 \\
3765.7 \\
3775.7 \\
3785.7 \\
3795.7\end{array}$ & $\begin{array}{r}\text { Int } \\
139.0 \\
126.0 \\
109.3 \\
90.6 \\
69.1 \\
49.4 \\
36.0 \\
24.8 \\
17.5 \\
12.3 \\
8.3 \\
5.9 \\
4.3 \\
3.4 \\
2.4 \\
1.2 \\
1.0 \\
0.6 \\
0.8\end{array}$ & $\begin{array}{l}S D \\
1.1 \\
1.0 \\
1.2 \\
0.6 \\
0.6 \\
0.4 \\
0.4 \\
0.4 \\
0.4 \\
0.4 \\
0.4 \\
0.5 \\
0.2 \\
0.1 \\
0.2 \\
0.2 \\
0.1 \\
0.1 \\
0.1\end{array}$ & $\begin{array}{c}\text { Int } \\
140.2 \\
124.2 \\
105.4 \\
84.7 \\
63.5 \\
45.8 \\
33.1 \\
22.8 \\
17.4 \\
11.2 \\
8.4 \\
6.1 \\
4.1 \\
3.5 \\
2.1 \\
1.7 \\
1.2 \\
0.7 \\
0.6\end{array}$ & $\begin{array}{l}\text { SD } \\
1.2 \\
0.7 \\
0.6 \\
0.7 \\
0.4 \\
0.4 \\
0.5 \\
0.4 \\
0.6 \\
0.4 \\
0.3 \\
0.3 \\
0.2 \\
0.2 \\
0.2 \\
0.2 \\
0.2 \\
0.3 \\
0.3\end{array}$ & $\begin{array}{c}\text { Int } \\
137.5 \\
119.0 \\
99.2 \\
77.8 \\
58.4 \\
42.6 \\
31.1 \\
22.3 \\
16.4 \\
11.6 \\
8.7 \\
6.5 \\
4.5 \\
3.4 \\
2.5 \\
1.9 \\
1.4 \\
1.4 \\
1.0\end{array}$ & $\begin{array}{l}S D \\
1.2 \\
1.2 \\
0.7 \\
0.6 \\
0.4 \\
0.6 \\
0.4 \\
0.4 \\
0.5 \\
0.2 \\
0.3 \\
0.4 \\
0.2 \\
0.4 \\
0.1 \\
0.3 \\
0.5 \\
0.2 \\
0.3\end{array}$ & $\begin{array}{c}\text { Int } \\
133.4 \\
113.2 \\
91.9 \\
71.0 \\
52.4 \\
38.5 \\
28.4 \\
2.0 .8 \\
15.6 \\
11.2 \\
8.8 \\
6.7 \\
4.8 \\
3.8 \\
2.9 \\
2.4 \\
1.9 \\
1.9 \\
1.5\end{array}$ & $\begin{array}{l}S D \\
1.1 \\
0.9 \\
1.5 \\
0.4 \\
0.4 \\
0.5 \\
0.6 \\
0.4 \\
0.6 \\
0.4 \\
0.3 \\
0.4 \\
0.2 \\
0.3 \\
0.1 \\
0.3 \\
0.2 \\
0.4 \\
0.4\end{array}$ & $\begin{array}{r}\text { Int } \\
129.6 \\
107.7 \\
85.6 \\
66.2 \\
48.5 \\
35.5 \\
26.8 \\
19.5 \\
14.9 \\
10.8 \\
7.8 \\
6.1 \\
4.7 \\
3.6 \\
2.5 \\
1.8 \\
1.3 \\
1.1 \\
0.4\end{array}$ & $\begin{array}{l}\text { SD } \\
2.0 \\
0.6 \\
0.6 \\
0.4 \\
0.4 \\
0.5 \\
0.4 \\
0.6 \\
0.8 \\
0.3 \\
0.4 \\
0.4 \\
0.2 \\
0.3 \\
0.4 \\
0.3 \\
0.2 \\
0.1 \\
0.4\end{array}$ & $\begin{array}{r}\text { Int } \\
123.5 \\
100.8 \\
79.6 \\
59.9 \\
43.5 \\
32.3 \\
25.3 \\
17.6 \\
13.8 \\
9.9 \\
7.5 \\
5.6 \\
4.4 \\
3.0 \\
2.1 \\
1.5 \\
1.0 \\
0.9 \\
0.3\end{array}$ & $\begin{array}{l}S D \\
0.9 \\
0.6 \\
0.6 \\
0.7 \\
0.3 \\
0.5 \\
0.4 \\
0.4 \\
0.6 \\
0.2 \\
0.4 \\
0.4 \\
0.2 \\
0.3 \\
0.1 \\
0.1 \\
0.3 \\
0.2 \\
0.3\end{array}$ \\
\hline
\end{tabular}


Table 8. Average intensities of the of stretching frequencies of the anisotropic spectrum of $\mathrm{GdCl}_{3}-5 \mathrm{KH}_{2} \mathrm{O}$.

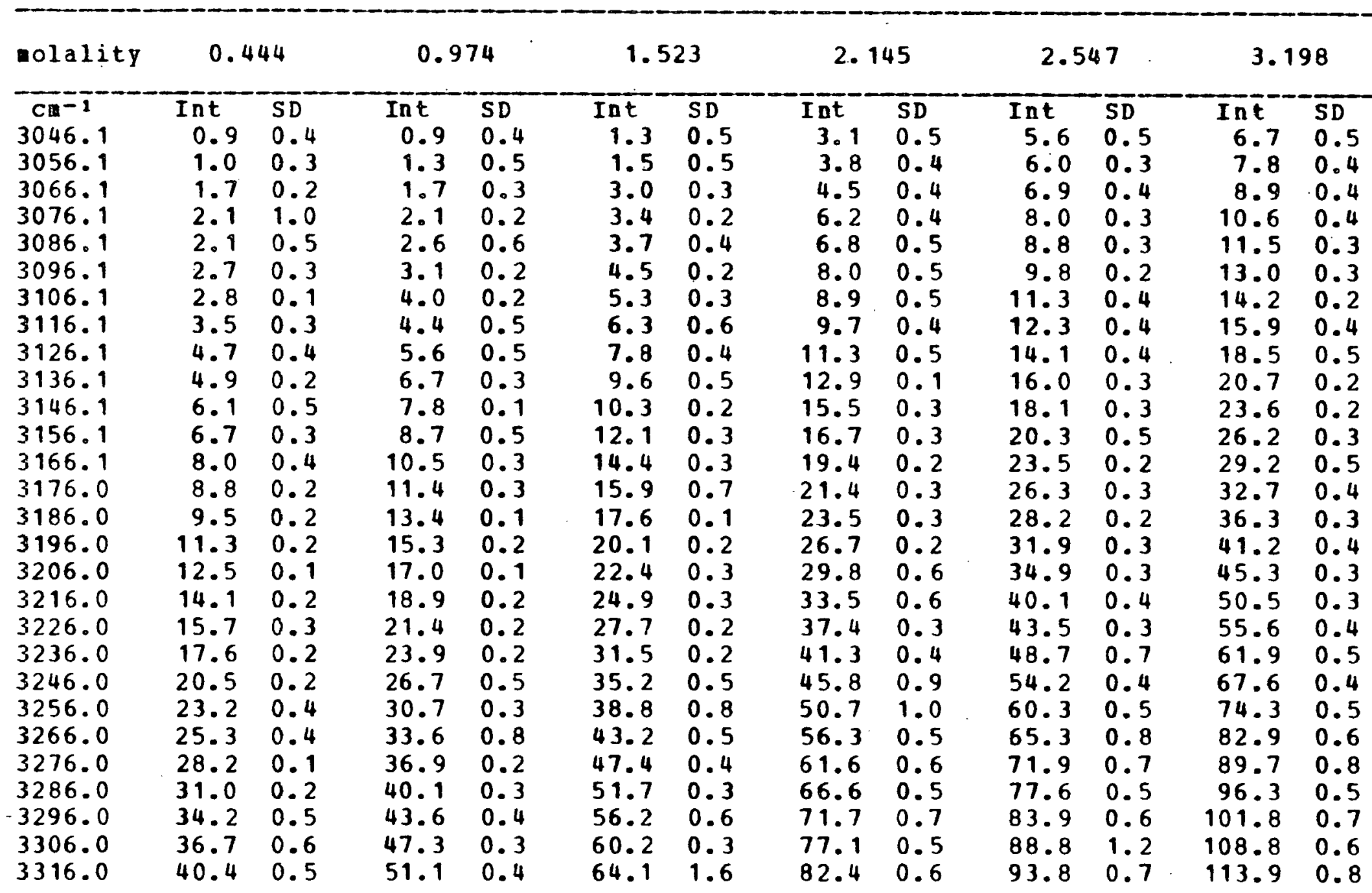


Table 8 (continued).

\begin{tabular}{|c|c|c|c|c|c|c|c|c|c|c|c|c|}
\hline wolality & \multicolumn{2}{|c|}{0.444} & \multicolumn{2}{|c|}{0.974} & \multicolumn{2}{|c|}{1.523} & \multicolumn{2}{|c|}{2.145} & \multicolumn{2}{|c|}{2.547} & \multicolumn{2}{|c|}{3.198} \\
\hline $\begin{array}{l}\text { C1 } 1 \text {-1 } \\
3326.0 \\
3336.0 \\
3346.0 \\
3355.9 \\
3365.9 \\
3375.9 \\
3385.9 \\
3395.9 \\
3405.9 \\
3415.9 \\
3425.9 \\
3435.9 \\
3445.9 \\
3455.9 \\
3465.9 \\
3475.9 \\
3485.9 \\
3495.9 \\
3505.9 \\
3515.9 \\
3525.9 \\
3535.8 \\
3545.8 \\
3555.8 \\
3565.8 \\
3575.8 \\
3585.8 \\
3595.8 \\
3605.8\end{array}$ & $\begin{array}{l}\text { Int } \\
44.0 \\
47.3 \\
51.5 \\
55.0 \\
58.9 \\
61.6 \\
64.5 \\
65.8 \\
69.2 \\
69.5 \\
69.4 \\
69.2 \\
67.8 \\
66.8 \\
64.7 \\
61.8 \\
59.2 \\
55.9 \\
52.6 \\
48.1 \\
44.8 \\
41.1 \\
37.6 \\
34.2 \\
30.5 \\
28.5 \\
25.0 \\
22.9 \\
20.2\end{array}$ & $\begin{array}{l}S D \\
0.3 \\
0.4 \\
0.3 \\
0.6 \\
0.6 \\
0.5 \\
0.3 \\
0.4 \\
0.4 \\
0.5 \\
0.5 \\
1.2 \\
0.8 \\
0.5 \\
0.4 \\
0.4 \\
0.5 \\
0.3 \\
0.5 \\
0.4 \\
0.4 \\
0.5 \\
0.4 \\
0.4 \\
0.2 \\
0.3 \\
0.5 \\
0.2 \\
0.2\end{array}$ & $\begin{array}{l}\text { Int } \\
56.1 \\
60.5 \\
64.9 \\
69.9 \\
73.3 \\
76.6 \\
79.8 \\
83.4 \\
85.3 \\
86.2 \\
85.9 \\
86.8 \\
85.0 \\
82.3 \\
79.0 \\
76.2 \\
72.0 \\
68.1 \\
62.6 \\
58.0 \\
53.1 \\
48.0 \\
43.8 \\
39.7 \\
34.7 \\
31.7 \\
28.4 \\
25.1 \\
22.0\end{array}$ & $\begin{array}{l}S D \\
0.4 \\
0.7 \\
0.3 \\
0.6 \\
0.6 \\
0.7 \\
0.8 \\
0.6 \\
0.6 \\
0.5 \\
0.5 \\
1.2 \\
0.4 \\
0.5 \\
0.6 \\
0.4 \\
0.6 \\
0.4 \\
0.4 \\
0.4 \\
0.5 \\
0.4 \\
0.3 \\
0.4 \\
0.5 \\
0.8 \\
0.2 \\
0.3 \\
0.2\end{array}$ & $\begin{array}{l}\text { Int } \\
70.2 \\
74.3 \\
80.3 \\
84.5 \\
89.0 \\
93.2 \\
96.3 \\
98.8 \\
100.4 \\
102.1 \\
101.2 \\
101.6 \\
98.7 \\
96.3 \\
91.3 \\
87.1 \\
83.0 \\
78.2 \\
72.1 \\
65.9 \\
60.7 \\
54.0 \\
48.6 \\
43.8 \\
37.2 \\
33.8 \\
29.8 \\
25.9 \\
22.2\end{array}$ & $\begin{array}{l}\text { SD } \\
0.4 \\
0.7 \\
0.9 \\
0.5 \\
0.6 \\
0.8 \\
0.6 \\
0.6 \\
0.6 \\
0.7 \\
0.7 \\
0.9 \\
1.2 \\
0.5 \\
1.1 \\
0.8 \\
0.5 \\
0.4 \\
1.0 \\
0.7 \\
0.4 \\
0.8 \\
0.6 \\
0.4 \\
0.7 \\
0.4 \\
0.9 \\
0.4 \\
0.5\end{array}$ & $\begin{array}{l}\text { Int } \\
87.9 \\
93.7 \\
98.1 \\
103.4 \\
108.0 \\
112.2 \\
114.4 \\
116.5 \\
117.9 \\
119.0 \\
118.0 \\
116.1 \\
112.8 \\
109.6 \\
104.0 \\
98.6 \\
92.7 \\
86.6 \\
79.1 \\
71.6 \\
64.5 \\
57.9 \\
52.1 \\
46.0 \\
40.2 \\
35.2 \\
31.2 \\
26.2 \\
22.5\end{array}$ & $\begin{array}{l}\text { SD } \\
0.5 \\
0.6 \\
1.1 \\
1.0 \\
0.7 \\
0.9 \\
0.9 \\
0.8 \\
1.3 \\
0.6 \\
0.7 \\
0.7 \\
0.7 \\
0.6 \\
0.6 \\
0.5 \\
1.1 \\
0.7 \\
0.7 \\
1.3 \\
0.5 \\
0.5 \\
0.4 \\
0.5 \\
0.4 \\
0.7 \\
0.3 \\
0.3 \\
0.3\end{array}$ & $\begin{array}{c}\text { Int } \\
100.1 \\
104.9 \\
111.6 \\
116.5 \\
119.7 \\
123.8 \\
125.3 \\
126.9 \\
127.6 \\
126.9 \\
125.2 \\
122.9 \\
119.7 \\
114.4 \\
108.7 \\
102.5 \\
96.3 \\
90.6 \\
82.4 \\
75.3 \\
67.7 \\
59.5 \\
52.5 \\
46.8 \\
40.4 \\
35.1 \\
30.0 \\
26.2 \\
22.0\end{array}$ & $\begin{array}{l}S D \\
0.7 \\
0.6 \\
0.8 \\
0.7 \\
0.7 \\
0.9 \\
0.7 \\
0.7 \\
0.8 \\
0.8 \\
0.7 \\
0.6 \\
1.0 \\
0.8 \\
0.7 \\
0.8 \\
0.5 \\
0.5 \\
0.8 \\
0.8 \\
0.7 \\
0.5 \\
0.7 \\
0.4 \\
0.3 \\
0.7 \\
0.2 \\
0.4 \\
0.8\end{array}$ & $\begin{array}{c}\text { Int } \\
120.5 \\
126.0 \\
131.6 \\
136.7 \\
139.8 \\
142.3 \\
144.5 \\
143.6 \\
143.1 \\
141.8 \\
137.8 \\
134.3 \\
130.4 \\
123.5 \\
116.6 \\
110.0 \\
103.0 \\
95.1 \\
87.3 \\
78.5 \\
71.2 \\
62.6 \\
55.3 \\
48.8 \\
40.9 \\
36.0 \\
31.0 \\
26.5 \\
22.0\end{array}$ & $\begin{array}{l}S D \\
0.7 \\
0.7 \\
0.8 \\
0.9 \\
0.8 \\
0.8 \\
0.9 \\
0.9 \\
0.8 \\
0.8 \\
0.8 \\
0.7 \\
0.8 \\
0.9 \\
0.9 \\
0.8 \\
0.9 \\
0.6 \\
0.6 \\
0.5 \\
0.5 \\
0.4 \\
0.6 \\
0.4 \\
0.5 \\
0.3 \\
0.5 \\
0.2 \\
0.2\end{array}$ \\
\hline
\end{tabular}


Table 8 (continued).

\begin{tabular}{|c|c|c|c|c|c|c|c|c|c|c|c|c|}
\hline molality & \multicolumn{2}{|c|}{0.444} & \multicolumn{2}{|c|}{0.974} & \multicolumn{2}{|c|}{1.523} & \multicolumn{2}{|c|}{2.145} & \multicolumn{2}{|c|}{2.547} & \multicolumn{2}{|c|}{3.198} \\
\hline $\begin{array}{c}\mathrm{Cm}^{-1} \\
3615.8 \\
3625.8 \\
3635.8 \\
3645.8 \\
3655.8 \\
3665.8 \\
3675.8 \\
3685.8 \\
3695.8 \\
3705.8 \\
3715.8 \\
3725.8 \\
3735.7 \\
3745.7 \\
3755.7 \\
3765.7 \\
3775.7 \\
3785.7 \\
3795.7\end{array}$ & $\begin{array}{l}\text { Int } \\
17.3 \\
15.4 \\
12.5 \\
9.9 \\
8.1 \\
5.6 \\
4.3 \\
3.5 \\
2.4 \\
2.1 \\
1.6 \\
1.1 \\
0.9 \\
1.1 \\
0.1 \\
0.3 \\
0.4 \\
-0.1 \\
0.2\end{array}$ & $\begin{array}{l}\text { SD } \\
0.3 \\
0.2 \\
0.1 \\
0.2 \\
0.3 \\
0.1 \\
0.5 \\
0.2 \\
0.1 \\
0.2 \\
0.1 \\
0.2 \\
0.5 \\
0.4 \\
0.3 \\
0.2 \\
0.6 \\
0.2 \\
0.3\end{array}$ & $\begin{array}{l}\text { Int } \\
18.5 \\
15.7 \\
12.7 \\
10.1 \\
8.4 \\
5.7 \\
4.3 \\
3.6 \\
2.1 \\
2.2 \\
1.1 \\
1.0 \\
1.1 \\
0.6 \\
0.3 \\
0.2 \\
-0.1 \\
0.2 \\
0.1\end{array}$ & $\begin{array}{l}S D \\
0.2 \\
0.1 \\
0.1 \\
0.3 \\
0.3 \\
0.2 \\
0.2 \\
0.4 \\
0.2 \\
0.2 \\
0.1 \\
0.4 \\
0.3 \\
0.2 \\
0.3 \\
0.2 \\
0.3 \\
0.3 \\
0.3\end{array}$ & $\begin{array}{l}\text { Int } \\
19.2 \\
16.3 \\
13.1 \\
10.4 \\
8.0 \\
5.6 \\
4.4 \\
3.4 \\
2.4 \\
2.1 \\
1.8 \\
1.1 \\
1.6 \\
0.3 \\
0.6 \\
-0.1 \\
0.6 \\
0.2 \\
0.3\end{array}$ & $\begin{array}{l}S D \\
0.4 \\
0.2 \\
0.2 \\
0.3 \\
0.3 \\
0.2 \\
0.4 \\
0.2 \\
0.3 \\
0.3 \\
0.2 \\
0.2 \\
0.3 \\
0.2 \\
0.2 \\
0.2 \\
0.3 \\
0.3 \\
0.4\end{array}$ & $\begin{array}{l}\text { Int } \\
18.8 \\
15.0 \\
12.2 \\
9.6 \\
7.0 \\
4.8 \\
4.2 \\
2.8 \\
2.1 \\
1.7 \\
1.2 \\
0.9 \\
0.9 \\
0.4 \\
-0.0 \\
-0.2 \\
0.3 \\
-0.2 \\
0.0\end{array}$ & $\begin{array}{l}S D \\
0.3 \\
0.1 \\
0.4 \\
0.4 \\
0.2 \\
0.1 \\
0.4 \\
0.5 \\
0.1 \\
0.4 \\
0.2 \\
0.3 \\
0.3 \\
0.3 \\
0.4 \\
0.3 \\
0.3 \\
0.2 \\
0.3\end{array}$ & $\begin{array}{l}\text { Int } \\
18.1 \\
14.7 \\
11.3 \\
9.0 \\
6.7 \\
5.0 \\
4.1 \\
2.8 \\
2.1 \\
1.7 \\
1.2 \\
0.5 \\
1.0 \\
0.4 \\
0.4 \\
-0.1 \\
-0.0 \\
0.1 \\
-0.3\end{array}$ & $\begin{array}{l}\text { SD } \\
0.2 \\
0.1 \\
0.3 \\
0.2 \\
0.2 \\
0.3 \\
0.5 \\
0.2 \\
0.1 \\
0.4 \\
0.1 \\
0.2 \\
0.3 \\
0.4 \\
0.2 \\
0.3 \\
0.3 \\
0.3 \\
0.3\end{array}$ & $\begin{array}{l}\text { Int } \\
18.1 \\
14.4 \\
11.1 \\
8.4 \\
6.3 \\
4.8 \\
3.6 \\
2.9 \\
2.1 \\
2.2 \\
1.0 \\
0.8 \\
0.9 \\
0.5 \\
0.5 \\
-0.0 \\
0.2 \\
-0.4 \\
-0.1\end{array}$ & $\begin{array}{l}\text { SD } \\
0.2 \\
0.1 \\
0.2 \\
0.2 \\
0.3 \\
0.2 \\
0.3 \\
0.3 \\
0.2 \\
0.3 \\
0.2 \\
0.3 \\
0.3 \\
0.3 \\
0.3 \\
0.4 \\
0.4 \\
0.2 \\
0.3\end{array}$ \\
\hline
\end{tabular}


OH spectra listed in Table 8.1

$\operatorname{LuCl}_{3}-5 \times \mathrm{D}_{2} \mathrm{O}$

Three spectral scans were made and averaged for both polarizations of the solutions listed in Tables 9 and 10. But for the isotropic spectra of the 2.0 molal solution and the anisotropic band of the 0.5 molal solution only two runs vere nade. 2

The first feature to notice in Figs. $9-13$ is that though no dramatic changes are apparent as the concentrations

1 There was difficulty in preparing GdCl ${ }_{3}$ aqueous solutions, in which all of the water was deuteriun, to be used as backgrounds for the corresponding solutions used to obtain 0 H spectral data. In spite of precautions taken during the preparation of these background solutions, sufficient $\mathrm{H}_{2} \mathrm{O}$ was absorbed to give a Raman signal. Because there rere no ${ }^{2}$ overtone or combination bands in this spectral region, all that kept the background from being constant was the bigh frequency tail of the $D_{2} O$ spectral band. Hence, guided by the corrected $100 \times D_{2} O$ background used for the vater data and taking into account the end points of the $\mathrm{GdCl}_{3}-5 \mathrm{xH}_{2} \mathrm{O}$ solution data. curves were obtained to be used as backgrounds for this data. The use cf this adjusted background along with the uncertaintg about the amount of $\mathrm{H}_{2} \mathrm{O}$ in the band solutions way introduce systematic errors as large as $10 \%$ in the $O H$ spectral intensities. In spite of this possible inaccuracy. the analysis of this data was consistent with that of the $5 \% \mathrm{D}_{2} \mathrm{O}$ solutions.

20riginally six concentrations of this rare earth were used. However, the data for the 1.5 aolal solution was inconsistent with all the other concentrations and also with the data. for the other salts. This was the only data that was discarded in the preparation of this report. It is assumed that impurities or optical misalignaent may bave been at fault. 
Table 9. Average intensities of the OD stretching frequencies of the isotropic spectrum of $\mathrm{LaCl}_{3}-5 \% \mathrm{D}_{2} \mathrm{O}$.

\begin{tabular}{|c|c|c|c|c|c|c|c|c|c|c|}
\hline Bolality & \multicolumn{2}{|c|}{0.504} & \multicolumn{2}{|c|}{1.002} & \multicolumn{2}{|c|}{1.999} & \multicolumn{2}{|c|}{2.571} & \multicolumn{2}{|c|}{2.916} \\
\hline $\begin{array}{c}C-1 \\
2146.6 \\
2156.6 \\
2166.6 \\
2176.6 \\
2186.6 \\
2196.6 \\
2206.6 \\
2216.6 \\
2226.6 \\
2236.6 \\
2246.6 \\
2256.6 \\
2266.6 \\
2276.5 \\
2286.5 \\
2296.5 \\
2306.5 \\
2316.5 \\
2326.5 \\
2336.5 \\
2346.5 \\
2356.5 \\
2366.5 \\
2376.5 \\
2386.5 \\
2396.5 \\
2406.5 \\
2416.5\end{array}$ & $\begin{array}{r}\text { Int } \\
6.8 \\
7.0 \\
9.1 \\
9.6 \\
11.3 \\
12.5 \\
15.0 \\
15.3 \\
18.6 \\
20.6 \\
22.6 \\
25.5 \\
27.5 \\
32.5 \\
37.2 \\
42.0 \\
48.8 \\
56.4 \\
64.3 \\
73.4 \\
84.5 \\
96.1 \\
110.3 \\
128.5 \\
151.8 \\
176.0 \\
206.6 \\
241.0\end{array}$ & $\begin{array}{l}S D \\
0.4 \\
0.3 \\
0.5 \\
0.4 \\
0.4 \\
0.7 \\
0.3 \\
0.7 \\
0.3 \\
0.2 \\
0.4 \\
0.8 \\
0.7 \\
0.5 \\
0.5 \\
0.5 \\
0.5 \\
0.7 \\
0.5 \\
0.5 \\
1.0 \\
0.9 \\
0.8 \\
1.3 \\
1.3 \\
1.1 \\
1.3 \\
1.4\end{array}$ & $\begin{array}{r}\text { Int } \\
5.4 \\
7.0 \\
8.4 \\
8.8 \\
10.2 \\
12.7 \\
13.8 \\
16.9 \\
18.9 \\
21.7 \\
24.1 \\
28.3 \\
31.8 \\
37.4 \\
42.6 \\
47.7 \\
54.7 \\
63.0 \\
73.6 \\
84.3 \\
96.6 \\
110.6 \\
125.2 \\
144.8 \\
167.3 \\
193.6 \\
222.7 \\
257.7\end{array}$ & $\begin{array}{l}5 D \\
0.7 \\
0.7 \\
0.7 \\
0.4 \\
0.5 \\
0.6 \\
0.6 \\
0.3 \\
0.2 \\
0.6 \\
0.6 \\
0.8 \\
1.0 \\
0.8 \\
0.5 \\
0.8 \\
0.6 \\
0.6 \\
0.7 \\
0.7 \\
0.9 \\
0.7 \\
1.0 \\
1.1 \\
1.3 \\
1.4 \\
1.5 \\
1.5\end{array}$ & $\begin{array}{r}\text { Int } \\
7.7 \\
9.3 \\
11.6 \\
12.0 \\
13.1 \\
15.9 \\
18.4 \\
21.5 \\
24.6 \\
27.2 \\
31.0 \\
36.0 \\
41.0 \\
47.6 \\
53.9 \\
62.1 \\
70.5 \\
80.7 \\
93.2 \\
106.5 \\
121.8 \\
139.0 \\
157.0 \\
177.0 \\
202.4 \\
229.8 \\
259.9 \\
295.4\end{array}$ & $\begin{array}{l}S D \\
1.5 \\
2.0 \\
1.7 \\
1.0 \\
2.1 \\
0.3 \\
0.6 \\
0.7 \\
0.8 \\
1.4 \\
0.6 \\
0.9 \\
0.6 \\
0.6 \\
0.4 \\
0.7 \\
0.5 \\
0.7 \\
1.1 \\
0.7 \\
0.8 \\
2.0 \\
0.9 \\
2.4 \\
1.8 \\
1.6 \\
1.5 \\
1.7\end{array}$ & $\begin{array}{r}\text { Int } \\
6.6 \\
8.9 \\
12.6 \\
12.4 \\
14.8 \\
16.2 \\
19.9 \\
22.7 \\
26.0 \\
30.7 \\
34.0 \\
39.3 \\
44.3 \\
52.6 \\
60.0 \\
68.2 \\
79.7 \\
92.4 \\
105.3 \\
120.3 \\
137.0 \\
154.1 \\
176.7 \\
202.1 \\
231.0 \\
259.5 \\
292.0 \\
327.9\end{array}$ & $\begin{array}{l}\text { SD } \\
1.3 \\
1.0 \\
1.0 \\
0.8 \\
1.6 \\
1.0 \\
1.5 \\
1.1 \\
0.5 \\
0.8 \\
0.6 \\
0.4 \\
0.6 \\
0.9 \\
1.0 \\
1.3 \\
1.0 \\
0.8 \\
1.4 \\
1.5 \\
1.5 \\
1.6 \\
2.0 \\
1.8 \\
2.1 \\
2.1 \\
2.0 \\
2.5\end{array}$ & $\begin{array}{r}\text { Int } \\
6.1 \\
7.1 \\
8.8 \\
10.3 \\
12.0 \\
15.2 \\
16.4 \\
20.1 \\
24.5 \\
27.1 \\
32.9 \\
36.6 \\
43.6 \\
50.8 \\
60.2 \\
70.1 \\
79.7 \\
93.3 \\
107.9 \\
126.5 \\
145.6 \\
165.8 \\
188.4 \\
212.1 \\
242.5 \\
274.7 \\
308.6 \\
349.5\end{array}$ & $\begin{array}{l}5 D \\
0.7 \\
0.5 \\
0.9 \\
1.8 \\
1.2 \\
0.7 \\
0.8 \\
0.7 \\
1.0 \\
0.9 \\
0.6 \\
0.8 \\
0.5 \\
1.2 \\
0.6 \\
1.0 \\
0.5 \\
0.8 \\
1.1 \\
0.8 \\
0.9 \\
1.1 \\
1.4 \\
1.5 \\
1.5 \\
2.1 \\
2.2 \\
2.2\end{array}$ \\
\hline
\end{tabular}


Table 9 (continued).

\begin{tabular}{|c|c|c|c|c|c|c|c|c|c|c|}
\hline molality & \multicolumn{2}{|c|}{0.504} & \multicolumn{2}{|c|}{1.002} & \multicolumn{2}{|c|}{1.999} & \multicolumn{2}{|c|}{2.571} & \multicolumn{2}{|c|}{2.916} \\
\hline $\begin{array}{c}c \mathrm{~m}^{-} \\
2426.5 \\
2436.5 \\
2446.5 \\
2456.4 \\
2466.4 \\
2476.4 \\
2486.4 \\
2496.4 \\
2506.4 \\
2516.4 \\
2526.4 \\
2536.4 \\
2546.4 \\
2556.4 \\
2566.4 \\
2576.4 \\
2586.4 \\
2596.4 \\
2606.4 \\
2616.4 \\
2626.4 \\
2636.3 \\
2646.3 \\
2656.3 \\
2666.3 \\
2676.3 \\
2686.3 \\
2696.3 \\
2706.3\end{array}$ & $\begin{array}{c}\text { Int } \\
281.7 \\
327.3 \\
379.3 \\
428.6 \\
478.1 \\
526.9 \\
574.2 \\
614.2 \\
642.1 \\
657.8 \\
662.1 \\
650.1 \\
628.5 \\
595.7 \\
555.6 \\
518.0 \\
474.0 \\
431.5 \\
386.5 \\
347.6 \\
311.0 \\
282.3 \\
252.8 \\
226.5 \\
194.6 \\
162.2 \\
130.2 \\
99.4 \\
74.3\end{array}$ & $\begin{array}{l}\text { SD } \\
1.8 \\
1.9 \\
2.2 \\
2.4 \\
2.8 \\
3.0 \\
3.1 \\
3.8 \\
3.7 \\
3.6 \\
3.8 \\
3.8 \\
3.4 \\
3.4 \\
3.4 \\
2.8 \\
2.6 \\
2.4 \\
2.1 \\
2.0 \\
1.9 \\
1.8 \\
1.7 \\
1.3 \\
1.1 \\
1.1 \\
1.1 \\
0.6 \\
0.5\end{array}$ & $\begin{array}{c}\text { Int } \\
296.9 \\
341.6 \\
389.2 \\
435.5 \\
486.3 \\
529.8 \\
579.3 \\
624.3 \\
655.7 \\
676.7 \\
686.7 \\
678.2 \\
656.2 \\
621.6 \\
583.0 \\
539.2 \\
493.0 \\
443.2 \\
398.5 \\
357.4 \\
317.4 \\
281.8 \\
250.2 \\
219.1 \\
185.9 \\
152.2 \\
122.1 \\
93.3 \\
68.5\end{array}$ & $\begin{array}{l}\text { SD } \\
2.3 \\
1.9 \\
2.2 \\
2.8 \\
2.8 \\
2.9 \\
3.4 \\
3.5 \\
3.6 \\
3.7 \\
4.4 \\
3.7 \\
3.7 \\
3.5 \\
3.2 \\
3.7 \\
2.7 \\
2.5 \\
2.2 \\
2.0 \\
1.9 \\
1.5 \\
1.6 \\
1.2 \\
1.2 \\
1.2 \\
0.8 \\
0.5 \\
0.7\end{array}$ & $\begin{array}{c}\text { Int } \\
336.0 \\
378.5 \\
427.3 \\
475.2 \\
523.3 \\
571.2 \\
616.1 \\
659.7 \\
688.3 \\
709.3 \\
717.8 \\
710.0 \\
686.2 \\
648.1 \\
606.0 \\
557.2 \\
508.7 \\
454.8 \\
404.5 \\
354.2 \\
312.4 \\
273.2 \\
236.5 \\
199.7 \\
165.2 \\
133.1 \\
104.7 \\
80.8 \\
60.7\end{array}$ & $\begin{array}{l}\text { SD } \\
2.0 \\
2.3 \\
2.5 \\
2.6 \\
2.9 \\
3.6 \\
3.4 \\
3.6 \\
3.9 \\
3.9 \\
3.9 \\
4.2 \\
3.8 \\
4.0 \\
3.2 \\
3.8 \\
3.0 \\
5.2 \\
2.1 \\
2.1 \\
3.4 \\
3.0 \\
3.0 \\
2.2 \\
0.9 \\
0.9 \\
1.0 \\
0.9 \\
0.8\end{array}$ & $\begin{array}{c}\text { Tnt } \\
372.4 \\
418.4 \\
467.6 \\
516.0 \\
563.1 \\
605.1 \\
646.8 \\
683.0 \\
710.9 \\
726.3 \\
726.8 \\
716.7 \\
686.4 \\
645.4 \\
601.8 \\
553.8 \\
502.3 \\
446.1 \\
393.9 \\
345.7 \\
302.2 \\
261.6 \\
223.6 \\
187.2 \\
154.6 \\
122.1 \\
96.8 \\
75.1 \\
57.2\end{array}$ & $\begin{array}{l}\text { SD } \\
2.6 \\
2.8 \\
3.8 \\
3.5 \\
3.6 \\
4.2 \\
3.6 \\
4.2 \\
3.9 \\
4.0 \\
4.0 \\
3.9 \\
3.7 \\
3.4 \\
3.6 \\
3.3 \\
2.9 \\
3.7 \\
3.3 \\
3.0 \\
2.1 \\
2.6 \\
2.2 \\
1.7 \\
1.7 \\
1.7 \\
1.5 \\
1.7 \\
1.7\end{array}$ & $\begin{array}{c}\text { Int } \\
392.6 \\
441.1 \\
489.5 \\
540.4 \\
585.3 \\
628.5 \\
668.8 \\
700.2 \\
722.9 \\
734.9 \\
732.0 \\
718.9 \\
689.2 \\
650.6 \\
604.0 \\
555.0 \\
503.7 \\
448.6 \\
396.8 \\
348.8 \\
305.0 \\
262.9 \\
226.4 \\
187.7 \\
151.2 \\
118.2 \\
92.8 \\
72.4 \\
54.9\end{array}$ & $\begin{array}{l}S D \\
2.6 \\
2.5 \\
2.7 \\
3.0 \\
4.0 \\
3.6 \\
3.9 \\
4.0 \\
4.0 \\
4.0 \\
4.0 \\
3.9 \\
3.8 \\
3.6 \\
3.4 \\
3.0 \\
2.7 \\
2.4 \\
2.6 \\
2.1 \\
1.7 \\
1.4 \\
1.5 \\
1.6 \\
1.1 \\
1.7 \\
1.0 \\
0.9 \\
0.6\end{array}$ \\
\hline
\end{tabular}


Table 9 (continued).

\begin{tabular}{|c|c|c|c|c|c|c|c|c|c|c|}
\hline$\frac{\text { volality }}{\mathrm{CB}^{-1}}$ & \multicolumn{2}{|c|}{0.504} & \multicolumn{2}{|c|}{1.002} & \multicolumn{2}{|c|}{1.999} & \multicolumn{2}{|c|}{2.571} & \multicolumn{2}{|c|}{2.916} \\
\hline $\begin{array}{c}\mathrm{CB}-\mathrm{I} \\
2716 \cdot 3 \\
2726 \cdot 3 \\
2736 \cdot 3 \\
2746 \cdot 3 \\
2756 \cdot 3 \\
2766 \cdot 3 \\
2776 \cdot 3 \\
2786 \cdot 3 \\
2796 \cdot 3\end{array}$ & $\begin{array}{l}\text { Int } \\
54.0 \\
39.9 \\
29.8 \\
21.5 \\
16.0 \\
11.0 \\
8.1 \\
4.4 \\
3.7\end{array}$ & $\begin{array}{l}\text { SD } \\
0.6 \\
0.8 \\
0.6 \\
0.5 \\
0.2 \\
0.9 \\
0.2 \\
0.3 \\
0.4\end{array}$ & $\begin{array}{l}\text { Int } \\
52.1 \\
38.0 \\
28.2 \\
20.7 \\
16.6 \\
11.4 \\
7.7 \\
5.5 \\
4.9\end{array}$ & $\begin{array}{l}5.0 \\
0.6 \\
0.7 \\
0.4 \\
0.2 \\
0.3 \\
0.3 \\
1.0 \\
0.4 \\
0.9\end{array}$ & $\begin{array}{l}\text { Int } \\
45.1 \\
34.3 \\
24.0 \\
18.8 \\
14.2 \\
10.3 \\
9.3 \\
5.9 \\
2.6\end{array}$ & $\begin{array}{l}S D \\
1.7 \\
1.4 \\
0.5 \\
0.8 \\
1.1 \\
0.5 \\
2.5 \\
2.0 \\
1.9\end{array}$ & $\begin{array}{l}\text { Int } \\
43.3 \\
33.4 \\
23.9 \\
18.4 \\
12.7 \\
9.5 \\
6.6 \\
5.4 \\
4.5\end{array}$ & $\begin{array}{l}\text { SD } \\
1.4 \\
1.3 \\
1.2 \\
0.9 \\
1.3 \\
1.3 \\
1.3 \\
0.8 \\
2.0\end{array}$ & $\begin{array}{l}\text { Int } \\
41.8 \\
32.1 \\
24.1 \\
18.0 \\
11.8 \\
8.8 \\
6.1 \\
4.1 \\
2.4\end{array}$ & $\begin{array}{l}\text { SD } \\
0.4 \\
0.7 \\
0.8 \\
0.7 \\
1.1 \\
1.3 \\
0.7 \\
0.7 \\
1.8\end{array}$ \\
\hline
\end{tabular}


Table 10. Average intensities of the OD stretching frequencies of the anisotropic spectrum of $\mathrm{LuCl}_{3}-5 \times \mathrm{D}_{2} \mathrm{O}$.

\begin{tabular}{|c|c|c|c|c|c|c|c|c|c|c|}
\hline solality & \multicolumn{2}{|c|}{0.504} & \multicolumn{2}{|c|}{1.002} & \multicolumn{2}{|c|}{1.999} & \multicolumn{2}{|c|}{2.571} & \multicolumn{2}{|c|}{2.916} \\
\hline $\begin{array}{c}\mathrm{Cg}^{-1} \\
2146.6 \\
2156.6 \\
2166.6 \\
2176.6 \\
2186.6 \\
2196.6 \\
2206.6 \\
2216.6 \\
2226.6 \\
2236.6 \\
2246.6 \\
2256.6 \\
2266.6 \\
2276.5 \\
2286.5 \\
2296.5 \\
2306.5 \\
2316.5 \\
2326.5 \\
2336.5 \\
2346.5 \\
2356.5 \\
2366.5 \\
2376.5 \\
2386.5 \\
2396.5 \\
2406.5 \\
2416.5\end{array}$ & $\begin{array}{l}\text { Int } \\
1.2 \\
2.2 \\
1.4 \\
1.9 \\
2.7 \\
3.6 \\
2.9 \\
4.3 \\
4.1 \\
4.8 \\
5.5 \\
4.7 \\
5.6 \\
5.8 \\
6.5 \\
7.5 \\
8.6 \\
9.9 \\
10.2 \\
11.4 \\
12.7 \\
15.0 \\
16.7 \\
18.9 \\
21.2 \\
24.9 \\
27.9 \\
32.0\end{array}$ & $\begin{array}{l}S D \\
0.2 \\
0.3 \\
0.3 \\
0.2 \\
0.4 \\
0.4 \\
0.2 \\
0.3 \\
0.4 \\
0.5 \\
0.2 \\
0.4 \\
0.5 \\
0.4 \\
0.4 \\
0.5 \\
0.2 \\
0.5 \\
0.6 \\
0.7 \\
0.7 \\
1.0 \\
0.8 \\
0.6 \\
0.3 \\
0.8 \\
0.4 \\
0.3\end{array}$ & $\begin{array}{l}\text { Int } \\
-0.2 \\
0.7 \\
0.4 \\
0.8 \\
1.2 \\
1.4 \\
2.8 \\
2.8 \\
2.8 \\
3.6 \\
4.2 \\
4.9 \\
5.2 \\
5.8 \\
6.7 \\
8.2 \\
9.3 \\
10.9 \\
11.5 \\
14.1 \\
15.7 \\
17.8 \\
20.0 \\
23.6 \\
27.7 \\
30.9 \\
34.9 \\
40.4\end{array}$ & $\begin{array}{l}S D \\
0.4 \\
0.2 \\
0.4 \\
0.3 \\
0.4 \\
0.6 \\
1.1 \\
0.5 \\
0.5 \\
0.4 \\
0.5 \\
0.6 \\
0.6 \\
0.3 \\
0.2 \\
0.4 \\
0.7 \\
0.4 \\
0.4 \\
0.2 \\
0.3 \\
0.2 \\
0.5 \\
0.6 \\
0.3 \\
0.5 \\
0.3 \\
0.4\end{array}$ & $\begin{array}{l}\text { Int } \\
2.4 \\
2.0 \\
3.6 \\
3.7 \\
4.6 \\
5.3 \\
5.0 \\
6.0 \\
6.2 \\
6.5 \\
7.8 \\
8.9 \\
9.9 \\
11.4 \\
12.9 \\
14.5 \\
15.8 \\
18.2 \\
20.3 \\
23.4 \\
25.7 \\
28.2 \\
31.6 \\
34.3 \\
39.8 \\
44.1 \\
49.6 \\
57.2\end{array}$ & $\begin{array}{l}S D \\
0.7 \\
0.1 \\
0.1 \\
0.1 \\
0.4 \\
0.3 \\
0.3 \\
0.8 \\
0.3 \\
0.6 \\
0.6 \\
0.8 \\
0.6 \\
0.6 \\
0.3 \\
0.2 \\
0.8 \\
0.5 \\
0.3 \\
0.3 \\
0.4 \\
0.4 \\
0.6 \\
0.6 \\
0.4 \\
0.6 \\
0.3 \\
0.5\end{array}$ & $\begin{array}{l}\text { Int } \\
0.5 \\
0.4 \\
1.3 \\
2.2 \\
2.4 \\
2.8 \\
3.5 \\
4.2 \\
4.4 \\
5.7 \\
6.7 \\
7.4 \\
9.1 \\
10.1 \\
12.2 \\
15.4 \\
16.3 \\
18.7 \\
22.3 \\
25.3 \\
28.7 \\
32.2 \\
37.7 \\
42.4 \\
48.1 \\
55.0 \\
62.8 \\
70.5\end{array}$ & $\begin{array}{l}S D \\
0.5 \\
0.4 \\
0.4 \\
0.5 \\
0.5 \\
0.9 \\
0.9 \\
0.2 \\
0.4 \\
0.3 \\
0.4 \\
0.6 \\
0.3 \\
0.3 \\
0.4 \\
0.7 \\
0.3 \\
0.6 \\
1.0 \\
0.4 \\
0.2 \\
0.4 \\
0.4 \\
0.4 \\
0.3 \\
0.5 \\
0.5 \\
0.7\end{array}$ & $\begin{array}{l}\text { Int } \\
-0.1 \\
-0.0 \\
0.3 \\
0.9 \\
1.4 \\
1.0 \\
2.1 \\
2.1 \\
3.7 \\
4.0 \\
4.9 \\
6.9 \\
7.7 \\
9.5 \\
11.6 \\
14.4 \\
17.3 \\
20.8 \\
24.3 \\
27.2 \\
32.9 \\
37.9 \\
42.8 \\
49.6 \\
57.5 \\
64.5 \\
72.8 \\
82.6\end{array}$ & $\begin{array}{l}S D \\
0.6 \\
0.5 \\
0.7 \\
0.5 \\
0.6 \\
0.6 \\
0.5 \\
0.5 \\
0.4 \\
0.5 \\
0.5 \\
0.3 \\
0.6 \\
0.4 \\
0.3 \\
0.6 \\
0.5 \\
0.7 \\
0.4 \\
0.6 \\
0.3 \\
0.5 \\
0.4 \\
0.5 \\
0.6 \\
0.6 \\
0.7 \\
0.7\end{array}$ \\
\hline
\end{tabular}


Table 10 (continued).

\begin{tabular}{|c|c|c|c|c|c|c|c|c|c|c|}
\hline nolality & \multicolumn{2}{|c|}{0.504} & \multicolumn{2}{|c|}{1.002} & \multicolumn{2}{|c|}{1.999} & \multicolumn{2}{|c|}{2.571} & \multicolumn{2}{|c|}{2.916} \\
\hline $\begin{array}{c}c D^{-} \\
2426.5 \\
2436.5 \\
2446.5 \\
2456.4 \\
2466.4 \\
2476.4 \\
2486.4 \\
2496.4 \\
2506.4 \\
2516.4 \\
2526.4 \\
2536.4 \\
2546.4 \\
2556.4 \\
2566.4 \\
2576.4 \\
2586.4 \\
2596.4 \\
2606.4 \\
2616.4 \\
2626.4 \\
2636.3 \\
2646.3 \\
2656.3 \\
2666.3 \\
2676.3 \\
2686.3 \\
2696.3 \\
2706.3\end{array}$ & $\begin{array}{l}\text { Int } \\
37.2 \\
42.8 \\
49.2 \\
55.7 \\
62.2 \\
69.2 \\
75.4 \\
81.4 \\
86.0 \\
89.4 \\
90.3 \\
89.5 \\
85.6 \\
80.1 \\
74.5 \\
68.9 \\
61.1 \\
54.0 \\
47.1 \\
40.3 \\
34.7 \\
30.1 \\
25.9 \\
22.6 \\
19.1 \\
15.9 \\
13.2 \\
11.7 \\
9.8\end{array}$ & $\begin{array}{l}S D \\
0.3 \\
1.0 \\
0.5 \\
0.5 \\
0.5 \\
0.5 \\
0.7 \\
0.7 \\
0.5 \\
0.6 \\
0.7 \\
0.6 \\
1.0 \\
0.6 \\
0.5 \\
0.5 \\
0.7 \\
0.6 \\
0.4 \\
0.4 \\
0.3 \\
0.4 \\
0.3 \\
0.5 \\
0.3 \\
0.4 \\
0.1 \\
0.2 \\
0.2\end{array}$ & $\begin{array}{l}\text { Int } \\
46.5 \\
52.7 \\
59.7 \\
67.7 \\
74.8 \\
83.3 \\
89.3 \\
97.8 \\
104.6 \\
107.7 \\
110.5 \\
109.4 \\
104.3 \\
97.7 \\
90.1 \\
81.5 \\
72.2 \\
62.8 \\
54.3 \\
45.6 \\
39.1 \\
33.3 \\
28.2 \\
24.3 \\
20.0 \\
17.5 \\
14.4 \\
12.4 \\
10.3\end{array}$ & $\begin{array}{l}\text { SD } \\
0.4 \\
0.6 \\
0.5 \\
0.8 \\
0.8 \\
0.6 \\
0.6 \\
0.7 \\
0.9 \\
0.7 \\
0.8 \\
0.9 \\
1.0 \\
0.6 \\
0.6 \\
0.8 \\
0.4 \\
0.5 \\
0.8 \\
0.6 \\
0.6 \\
0.3 \\
0.7 \\
0.6 \\
0.2 \\
0.3 \\
0.3 \\
0.1 \\
0.5\end{array}$ & $\begin{array}{c}\text { Int } \\
63.0 \\
70.9 \\
80.3 \\
88.7 \\
97.1 \\
105.3 \\
113.4 \\
122.0 \\
126.0 \\
130.1 \\
130.0 \\
126.8 \\
121.4 \\
112.1 \\
102.3 \\
90.9 \\
80.7 \\
69.1 \\
58.4 \\
49.7 \\
41.9 \\
35.4 \\
30.0 \\
25.3 \\
21.4 \\
18.4 \\
15.6 \\
13.6 \\
11.5\end{array}$ & $\begin{array}{l}\text { SD } \\
1.0 \\
0.9 \\
0.7 \\
1.0 \\
1.0 \\
1.1 \\
0.8 \\
0.9 \\
1.0 \\
0.9 \\
0.8 \\
0.9 \\
0.8 \\
0.6 \\
0.9 \\
0.7 \\
0.5 \\
0.7 \\
0.7 \\
0.5 \\
0.3 \\
0.2 \\
0.2 \\
0.4 \\
0.5 \\
0.7 \\
0.2 \\
0.3 \\
0.4\end{array}$ & $\begin{array}{l}\text { Int } \\
79.2 \\
89.0 \\
98.1 \\
108.3 \\
118.7 \\
126.2 \\
133.5 \\
140.4 \\
144.2 \\
145.7 \\
143.4 \\
138.3 \\
129.9 \\
119.3 \\
108.0 \\
96.3 \\
83.5 \\
71.3 \\
60.2 \\
50.3 \\
42.0 \\
35.3 \\
29.3 \\
24.3 \\
20.4 \\
16.9 \\
14.7 \\
12.3 \\
10.8\end{array}$ & $\begin{array}{l}\text { SD } \\
0.7 \\
0.7 \\
0.9 \\
1.2 \\
0.8 \\
0.7 \\
0.9 \\
0.9 \\
1.0 \\
0.9 \\
0.8 \\
0.9 \\
0.7 \\
0.7 \\
0.6 \\
0.6 \\
0.8 \\
0.6 \\
0.8 \\
0.8 \\
0.7 \\
0.4 \\
0.3 \\
0.3 \\
0.2 \\
0.2 \\
0.3 \\
0.3 \\
0.4\end{array}$ & $\begin{array}{c}\text { Int } \\
94.5 \\
106.5 \\
117.7 \\
127.7 \\
137.2 \\
146.3 \\
152.2 \\
158.0 \\
160.0 \\
160.7 \\
156.8 \\
150.0 \\
140.1 \\
127.6 \\
115.2 \\
102.9 \\
88.1 \\
74.8 \\
61.8 \\
52.5 \\
44.1 \\
35.5 \\
29.2 \\
24.3 \\
19.2 \\
15.2 \\
13.0 \\
10.4 \\
9.7\end{array}$ & $\begin{array}{l}\text { SD } \\
0.9 \\
1.0 \\
0.8 \\
0.9 \\
0.9 \\
1.0 \\
0.9 \\
1.1 \\
1.0 \\
2.0 \\
1.5 \\
0.9 \\
0.9 \\
0.8 \\
0.8 \\
0.7 \\
0.6 \\
0.7 \\
0.5 \\
0.3 \\
0.7 \\
0.4 \\
0.2 \\
0.6 \\
0.5 \\
0.6 \\
0.2 \\
0.2 \\
0.7\end{array}$ \\
\hline
\end{tabular}


Table 10 (continued).

\begin{tabular}{|c|c|c|c|c|c|c|c|c|c|c|}
\hline \multirow[b]{2}{*}{$\begin{array}{l}\text { molality } \\
\text { CR-1 }^{-1} \\
2716.3 \\
2726.3 \\
2736.3 \\
2746.3 \\
2756.3 \\
2766.3 \\
2776.3 \\
2786.3 \\
2796.3\end{array}$} & \multicolumn{2}{|c|}{0.504} & \multicolumn{2}{|c|}{1.002} & \multicolumn{2}{|c|}{1.999} & \multicolumn{2}{|c|}{2.571} & \multicolumn{2}{|c|}{2.916} \\
\hline & $\begin{array}{c}\text { Int } \\
8.4 \\
6.8 \\
5.7 \\
4.7 \\
4.5 \\
4.0 \\
4.0 \\
3.6 \\
4.2\end{array}$ & $\begin{array}{l}\text { SD } \\
0.2 \\
0.4 \\
0.4 \\
0.1 \\
0.6 \\
0.1 \\
0.2 \\
0.1 \\
0.7\end{array}$ & $\begin{array}{l}\text { Int } \\
8.4 \\
7.3 \\
6.2 \\
5.4 \\
4.3 \\
4.0 \\
4.4 \\
4.2 \\
3.2\end{array}$ & $\begin{array}{l}\text { SD } \\
0.5 \\
0.5 \\
0.3 \\
0.5 \\
0.4 \\
0.3 \\
0.4 \\
0.3 \\
0.2\end{array}$ & $\begin{array}{l}\text { Int } \\
10.1 \\
8.9 \\
8.1 \\
7.3 \\
6.2 \\
6.0 \\
5.5 \\
5.8 \\
5.6\end{array}$ & $\begin{array}{l}\text { SD } \\
0.1 \\
0.1 \\
0.6 \\
0.5 \\
0.6 \\
0.7 \\
0.5 \\
0.5 \\
0.6\end{array}$ & $\begin{array}{c}\text { Int } \\
9.1 \\
8.2 \\
7.2 \\
6.9 \\
5.5 \\
5.8 \\
6.0 \\
5.7 \\
4.9\end{array}$ & $\begin{array}{l}S D \\
0.2 \\
0.2 \\
0.3 \\
0.5 \\
0.3 \\
0.3 \\
0.3 \\
0.2 \\
0.8\end{array}$ & $\begin{array}{r}\text { Int } \\
8.0 \\
5.9 \\
5.0 \\
4.2 \\
3.7 \\
4.1 \\
3.6 \\
3.0 \\
2.0\end{array}$ & $\begin{array}{l}\text { SD } \\
0.3 \\
0.7 \\
0.2 \\
0.4 . \\
0.7 \\
0.1 \\
0.3 \\
0.4 \\
0.2\end{array}$ \\
\hline
\end{tabular}




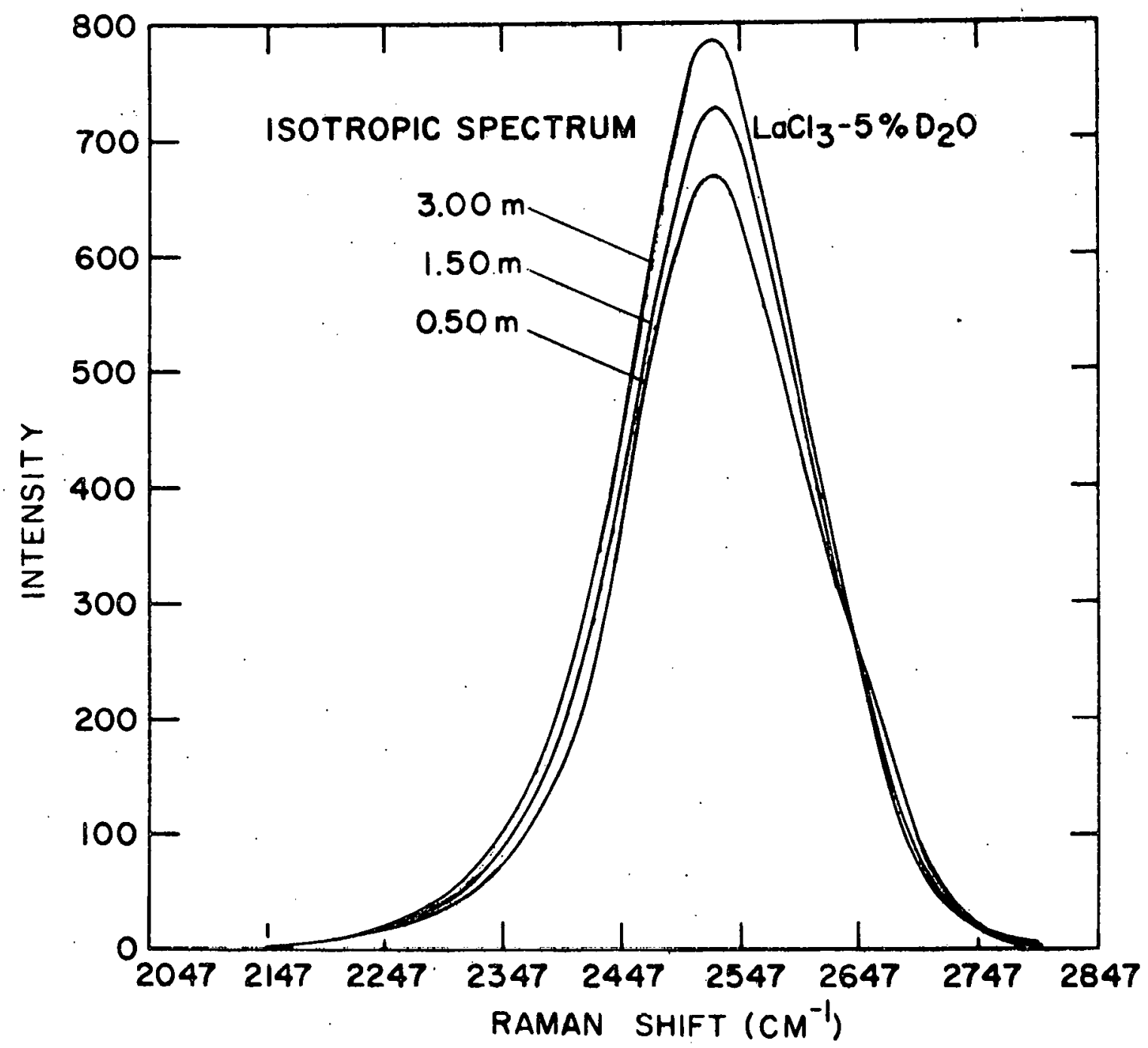

Fig. 9. Intensities of the isotropic Ranan bands of the $O D$ stretching vibrations of HDO in aqueous solutions of $\mathrm{LaCl}_{3}$ for several concentrations. 


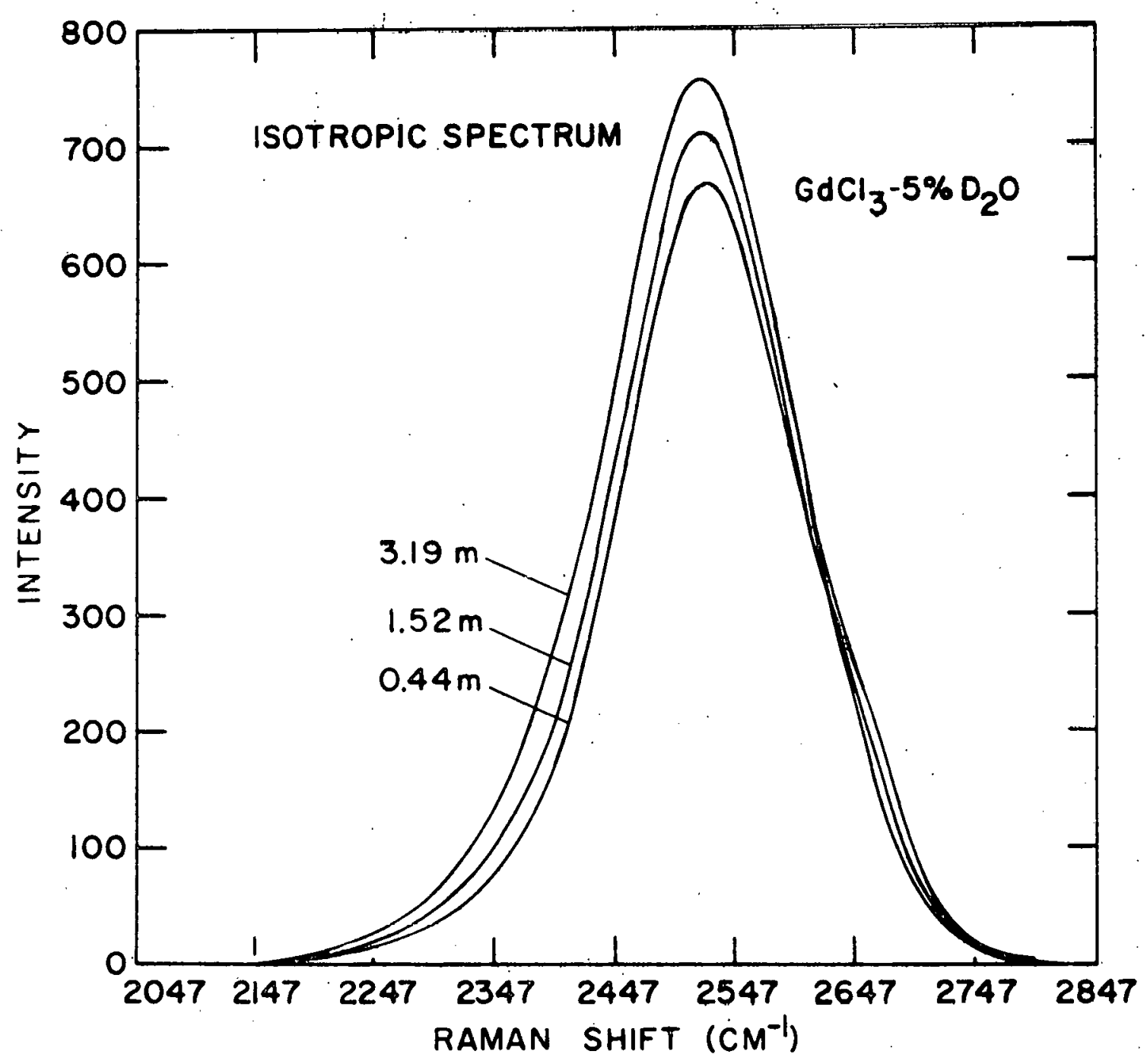

Fiq. 10. Intensities of the isotropic Raman bands of the OD stretching vibrations of $\mathrm{HDO}$ in aqueous solutions of $\mathrm{GdCl}_{3}$ for several concentrations. 


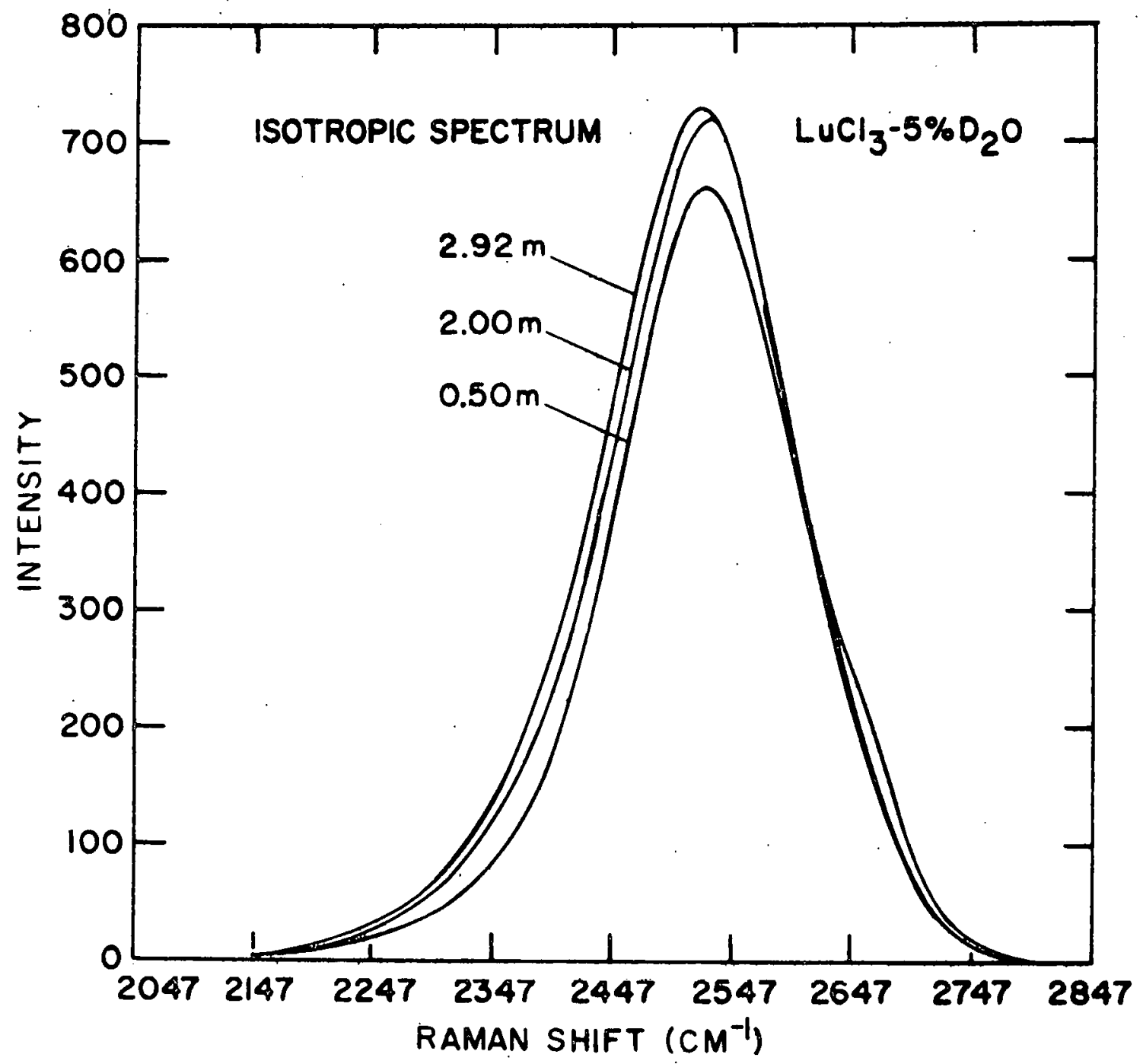

Fig. 11. Intensities of the isotropic Raman bands of the oD stretching vibrations of HDO in aqueous solutions of $\mathrm{IuCl}_{3}$ for several concentrations. 


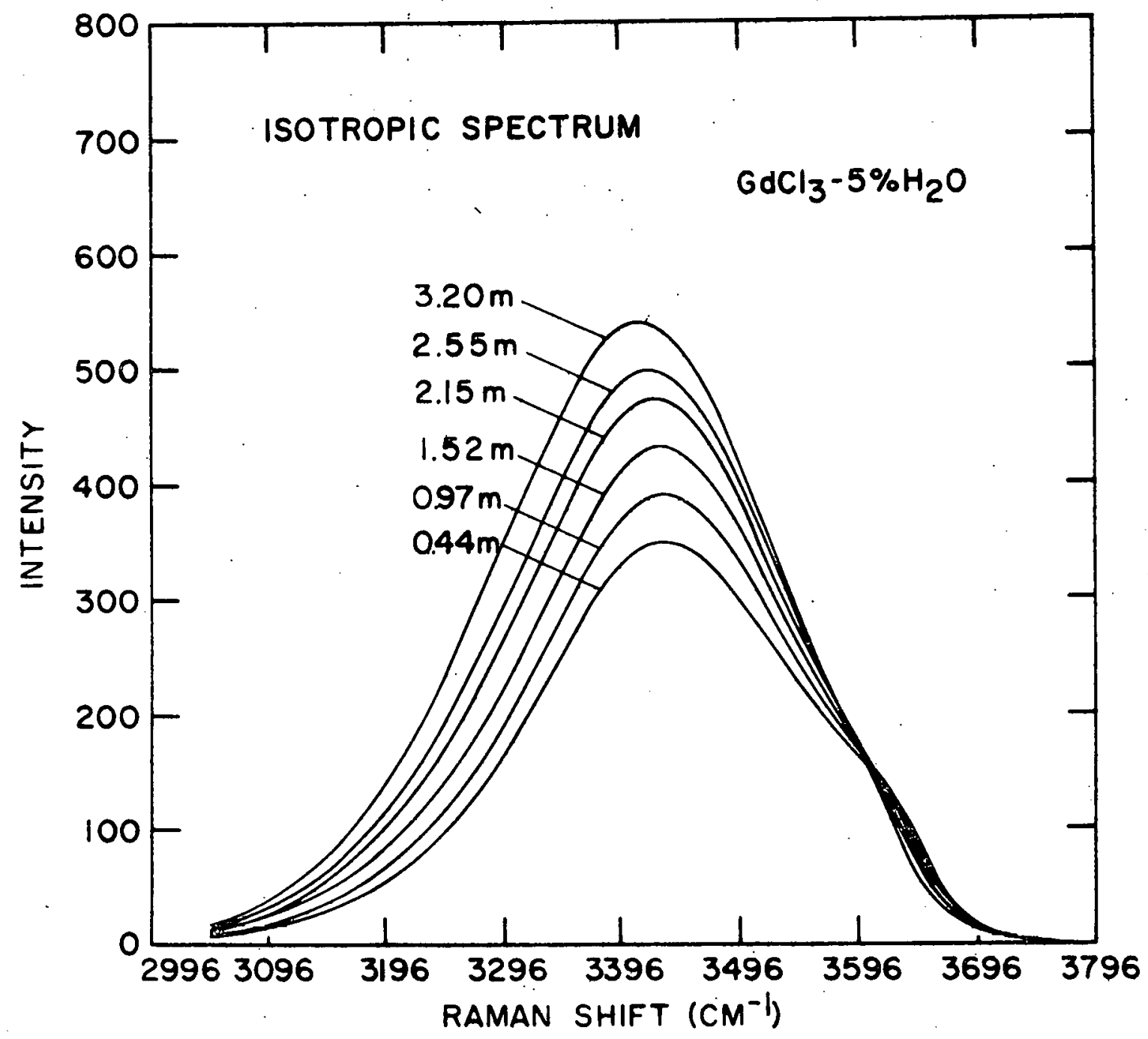

Fig. 12. Intensities of all the isotropic Raman bands of the OH stretching vibrations of HDO in aqueous solutions of $\mathrm{GdCl}_{3}$. 


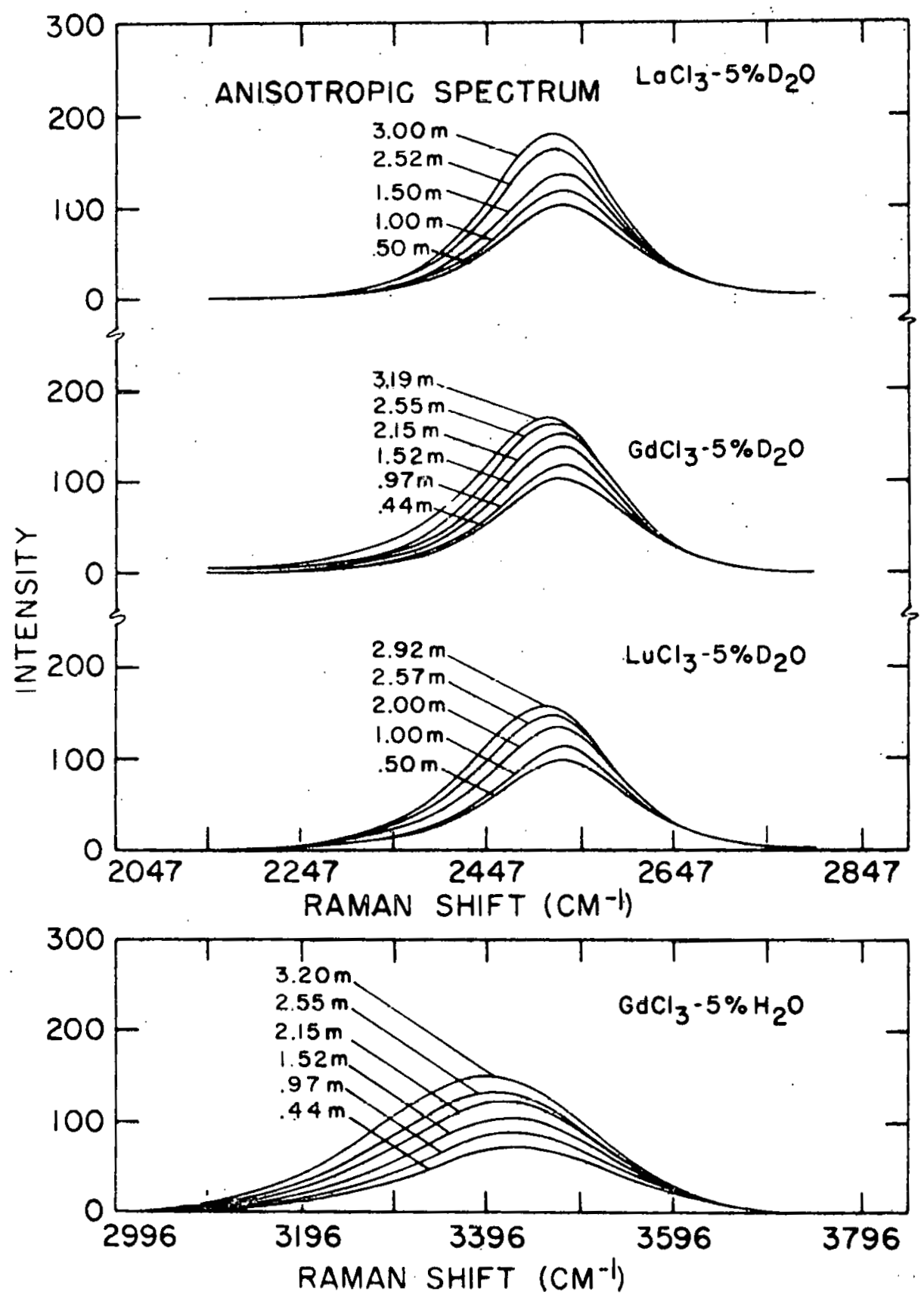

Fig. 13. Intensities of the anisotropic Raman bands of the $O D$ stretching vibrations of HDO in aqueous solutions of $\mathrm{LaCl}_{3}, \mathrm{GdCl}_{3}$ and $\mathrm{LuCl}_{3}$ and of the $\mathrm{OH}$ stretching vibrations of HDO in aqueous solutions of $\mathrm{GdCl}_{3}$ 
of the samples are increased, the shoulder, which appears on the high freguency side of the isotropic water band, qradually disappears for both the OD and $O H$ spectral bands. a closer inspection reveals that in general, for both polarizations of all solutions, the Raman shifts of the peak intensities first increase as anticipated, then unexpectedly decrease at higher concentrations. These results are graphed along with error bars in Figs. 14 - 17. The connecting lines are simfly a visual aid. Plots of the half-widths as a function of wolality in Figs. 18 - 21 demonstrate how initially both the $O D$ and $O H$ bands become narrower, for both polarizations of all solutions, and then broaden again at high concentrations. Such "complicated" beharior had not been anticipated.

In addition to these unexpected results, the positions of peak intensities and the vreadths of the half-widths differ for the three rare earth solutions in a consistent manner at high concentrations. This is apparently a significant, though small cation effect.

\section{Analysis}

Though the differeaces in the spectral data among the three salts and the changes in band shape, with changes in concentration, are swall, they are outside of experinental error. As an aid to analyzing the data, the following wethod was developed: A graph was flotted of the average intensity 


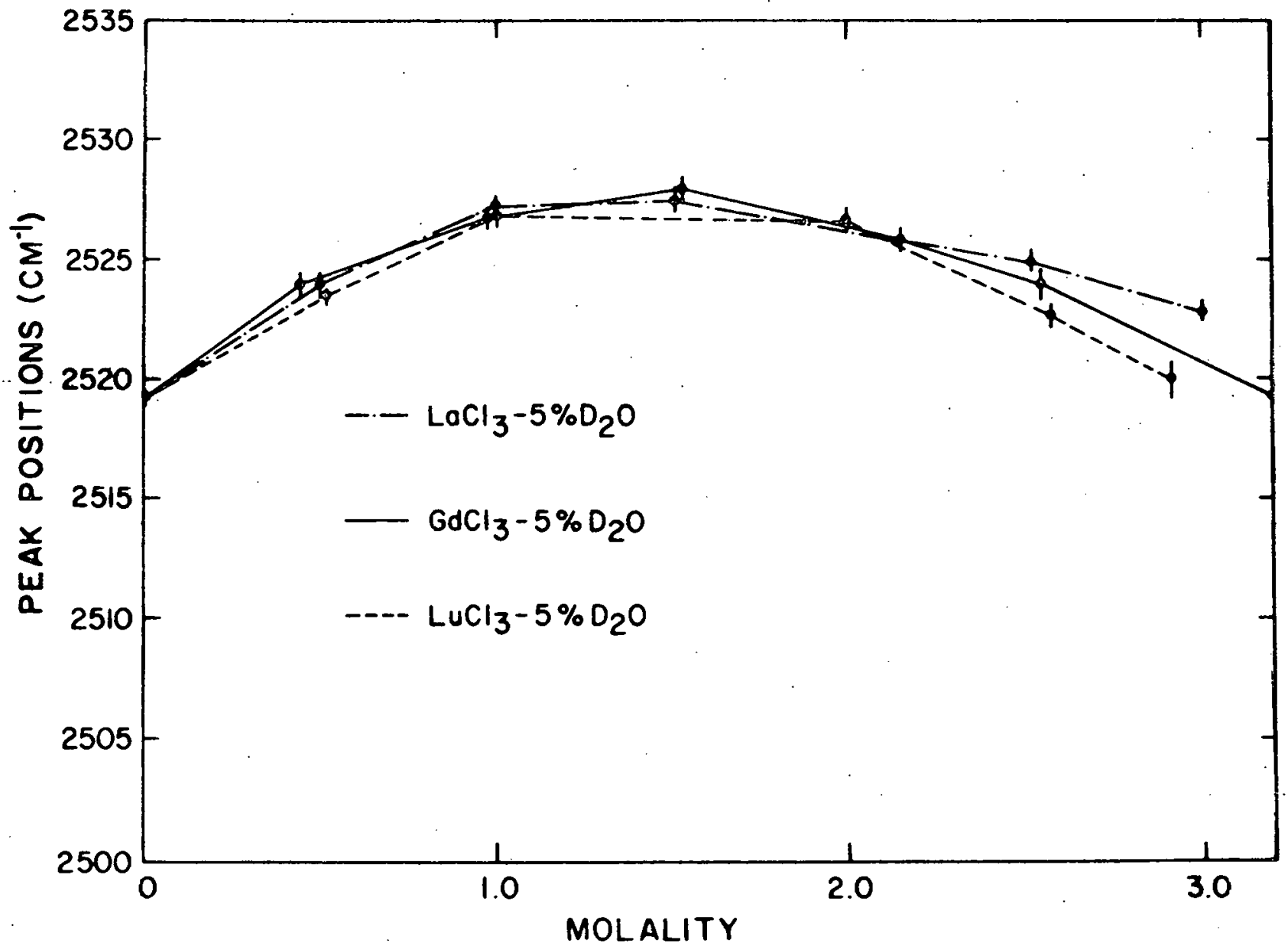

Fig. 14. Peak positions of the isotropic Raman bands of the $O D$ stretching vibrations of $H D O$ in water and aqueous solutions of $\mathrm{LaCl}_{3}, \mathrm{GdCl}_{3}$ and $\mathrm{LuCl}_{3}$. 


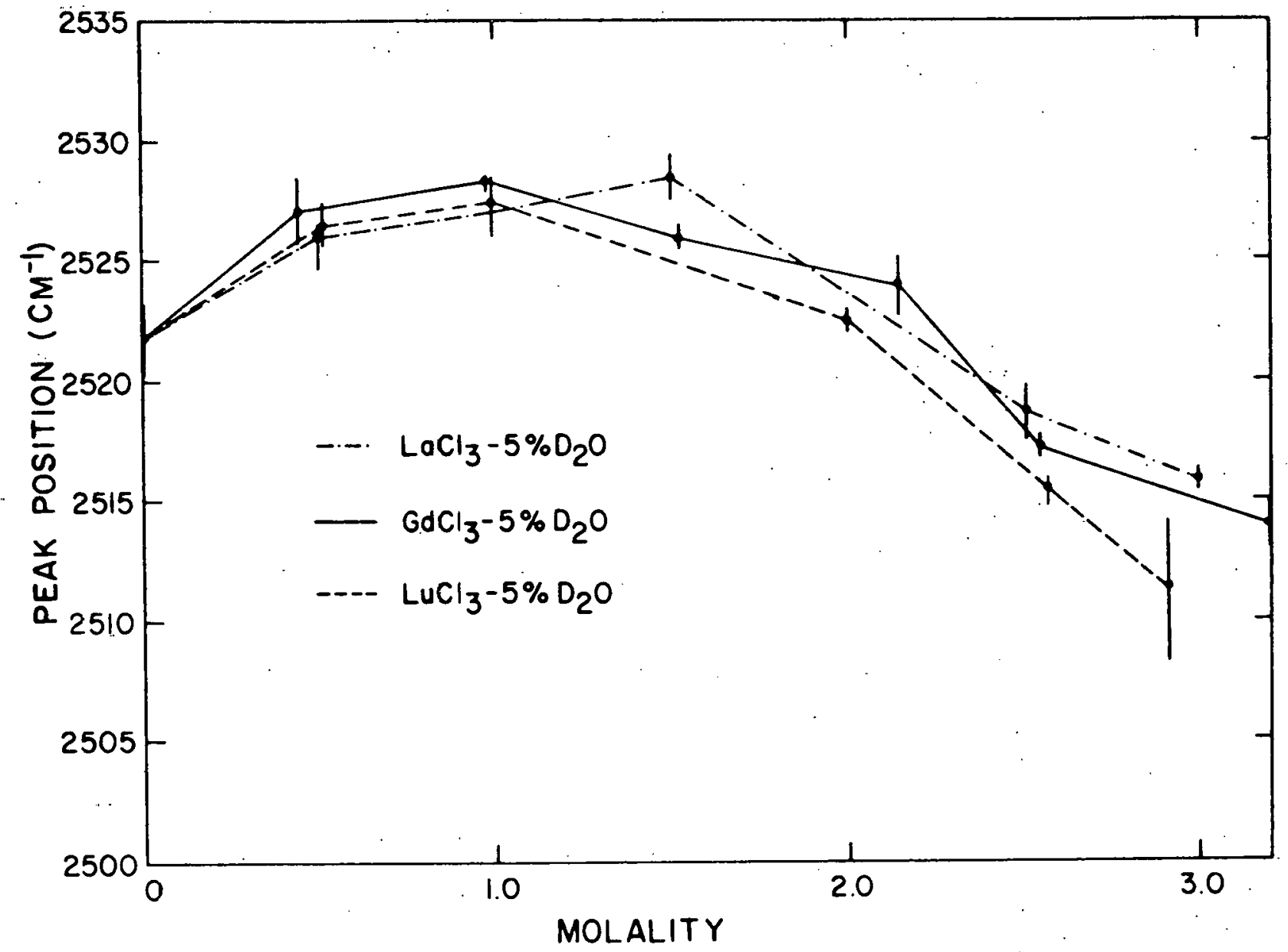

Pig. 15. Peak positions of the anisotropic Raman bands of the OD stretching vibration of $\mathrm{HDO}$ in water and aqueous solutions of $\mathrm{LaCl}_{3}, \mathrm{GdCl}_{3}$ and $\mathrm{LuCl}_{3}$. 


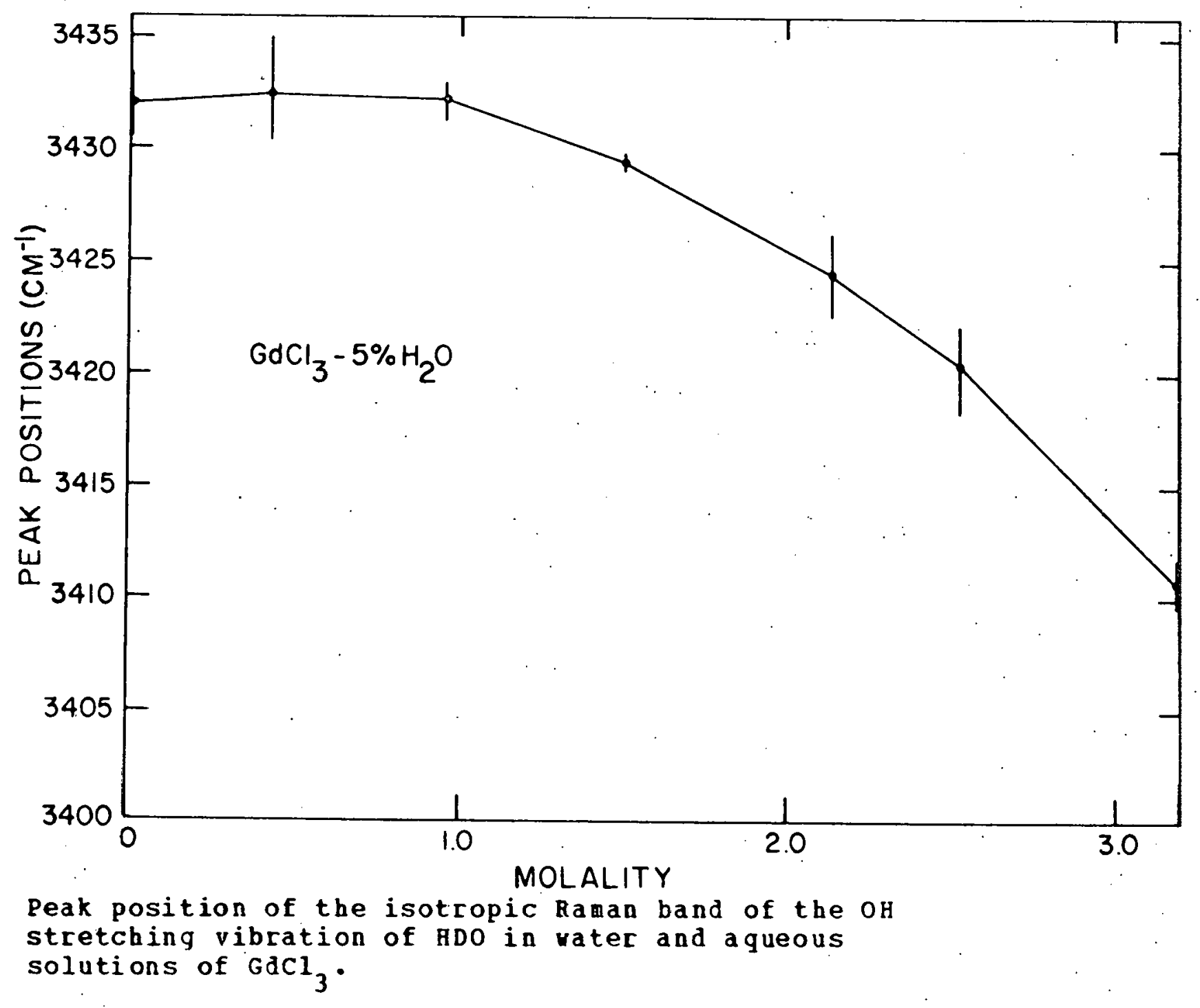

은

Pig. 16. Peak position of the isotropic Ratnan band of the $O H$ stretching vibration of HDO in vater and aqueous solutions of $\mathrm{GdCl}_{3}$ 


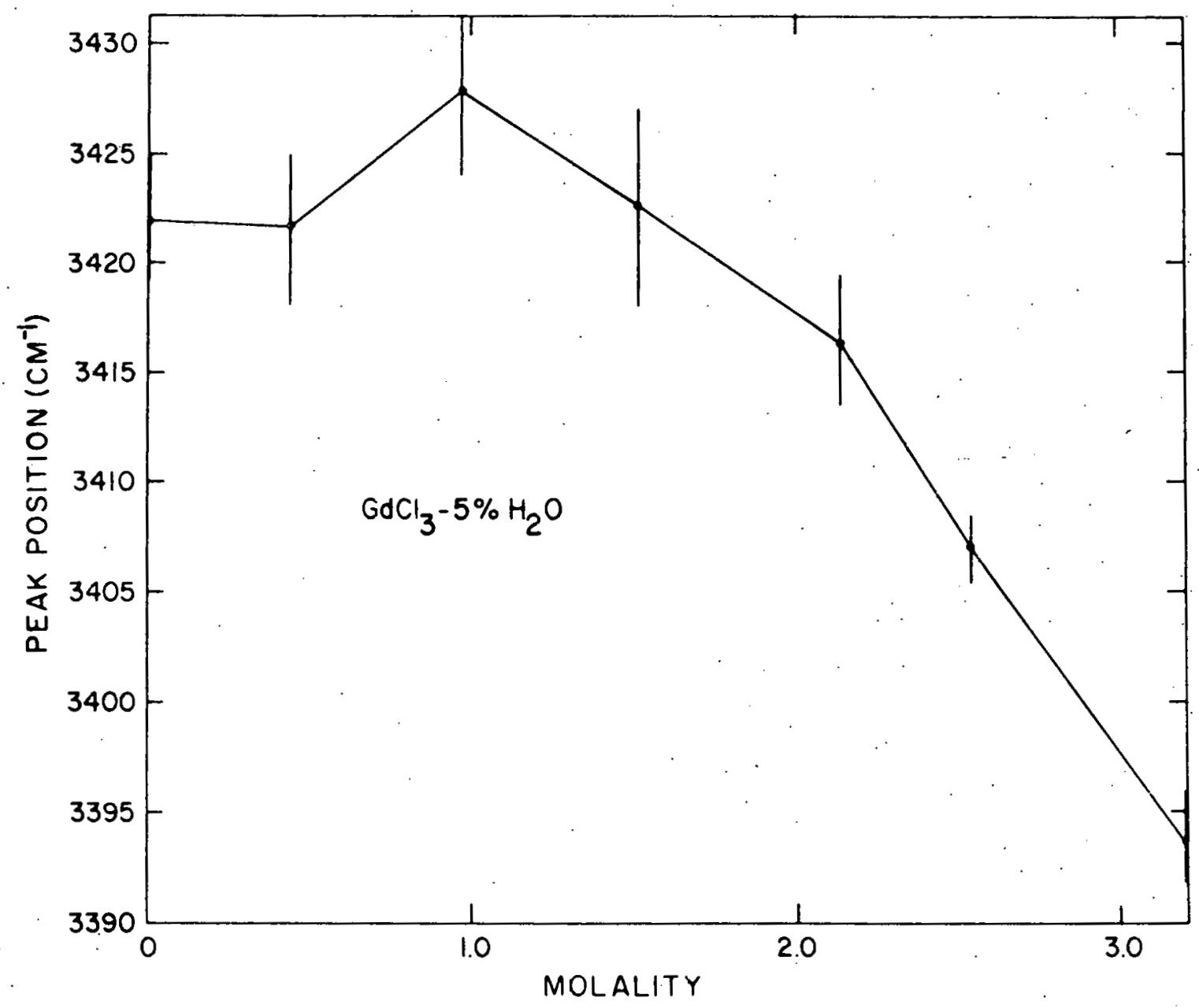

Pig. 17. Peak position of the anisotropic Raman band of the $O H$ stretching vibration of $H D O$ in water and aqueous solutions of $\mathrm{GdCl}_{3}$. 


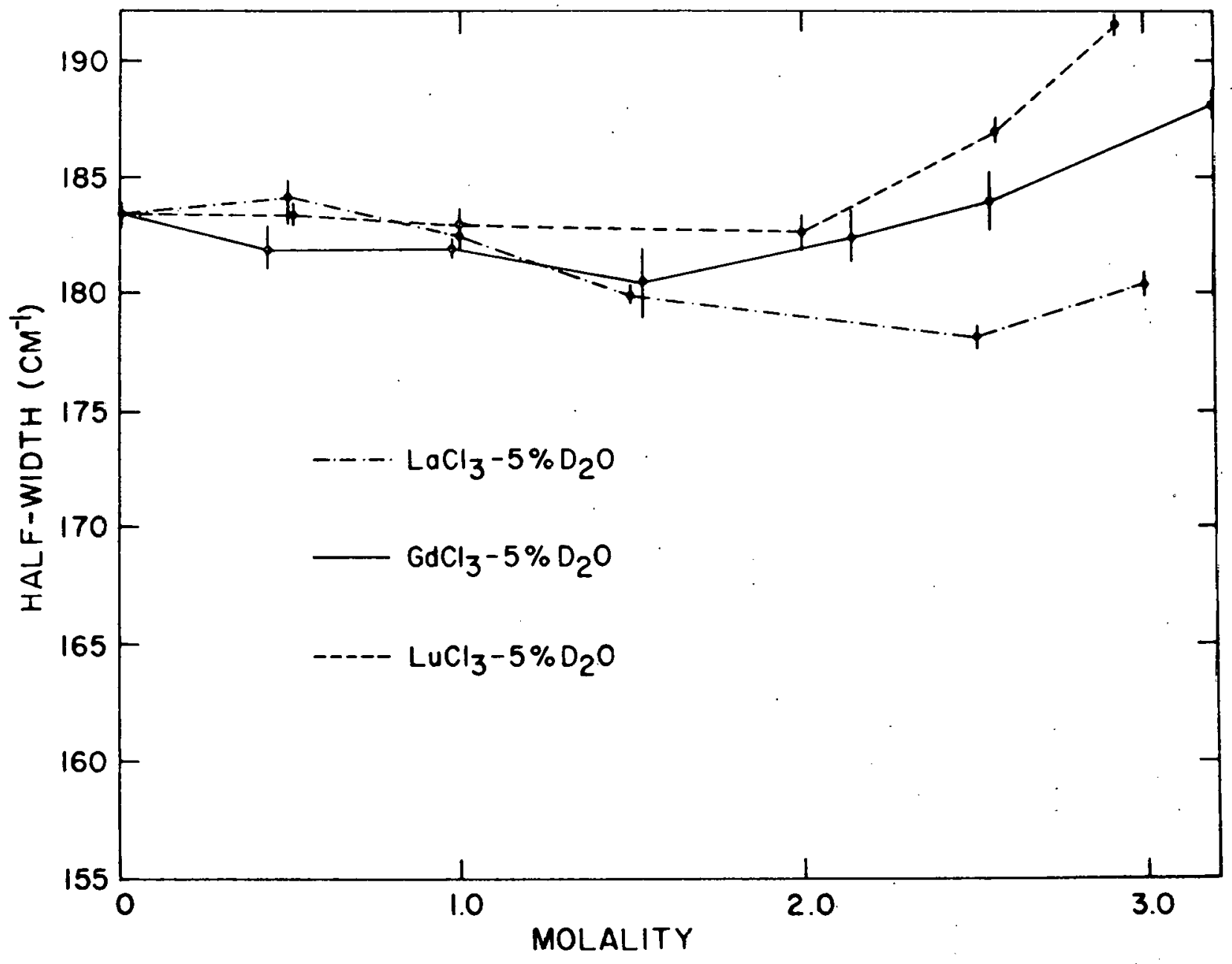

Pig. 18. Half-widths of the isotropic Raman bands of the OD stretching vibrations of HDO in water and aqueous solutions of $\mathrm{LaCl}_{3}, \mathrm{GdCl}_{3}$ and $\mathrm{LuCl}_{3}$. 


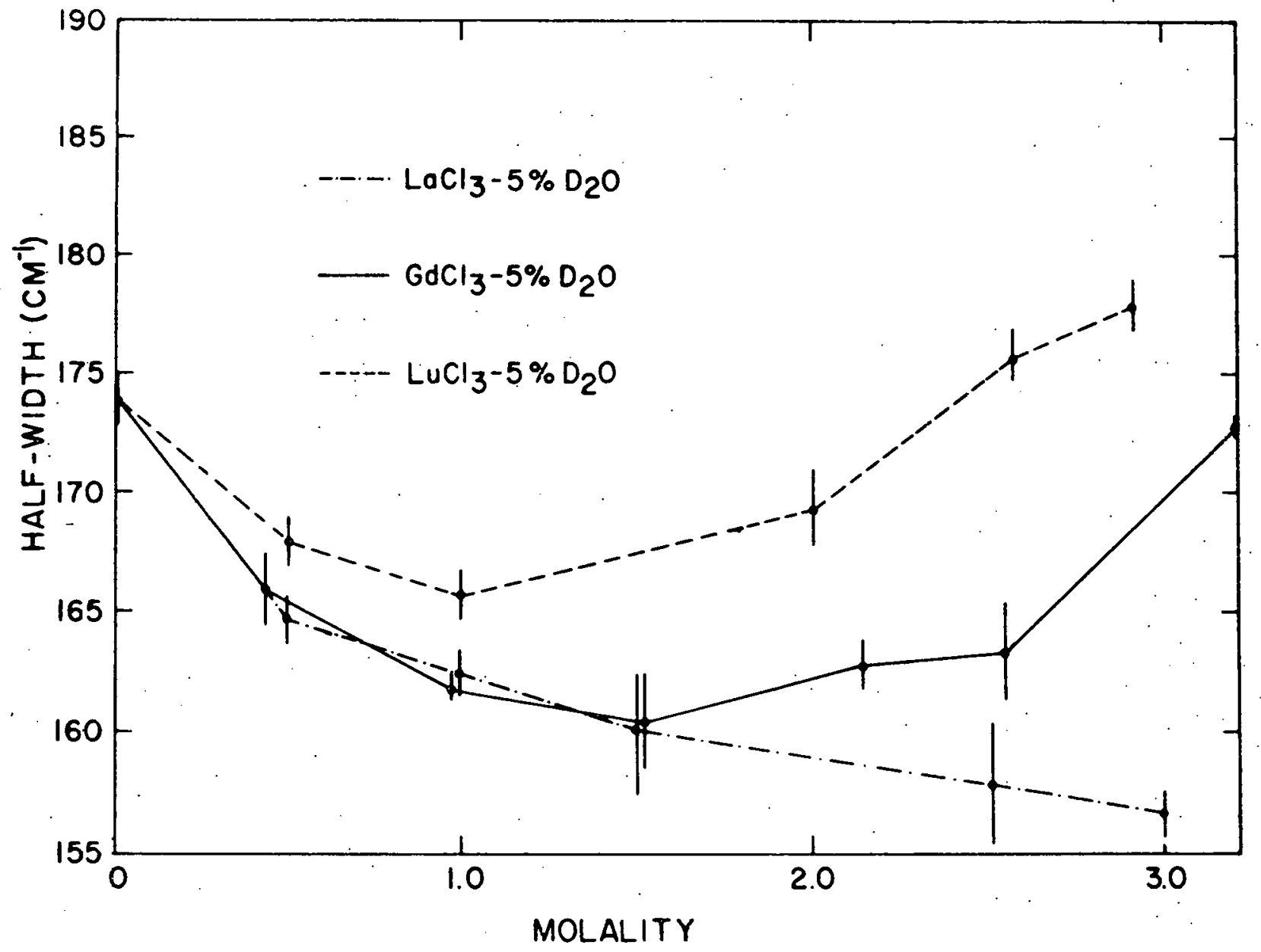

i

Fig. 19. Half-widths of the anisotropic Raman bands of the

$O D$ stretching vibrations of $H D O$ in vater and

aqueous solutions of $\mathrm{LaCl}_{3}, \mathrm{GdCl}_{3}$ and $\mathrm{LuCl}_{3}$ : 


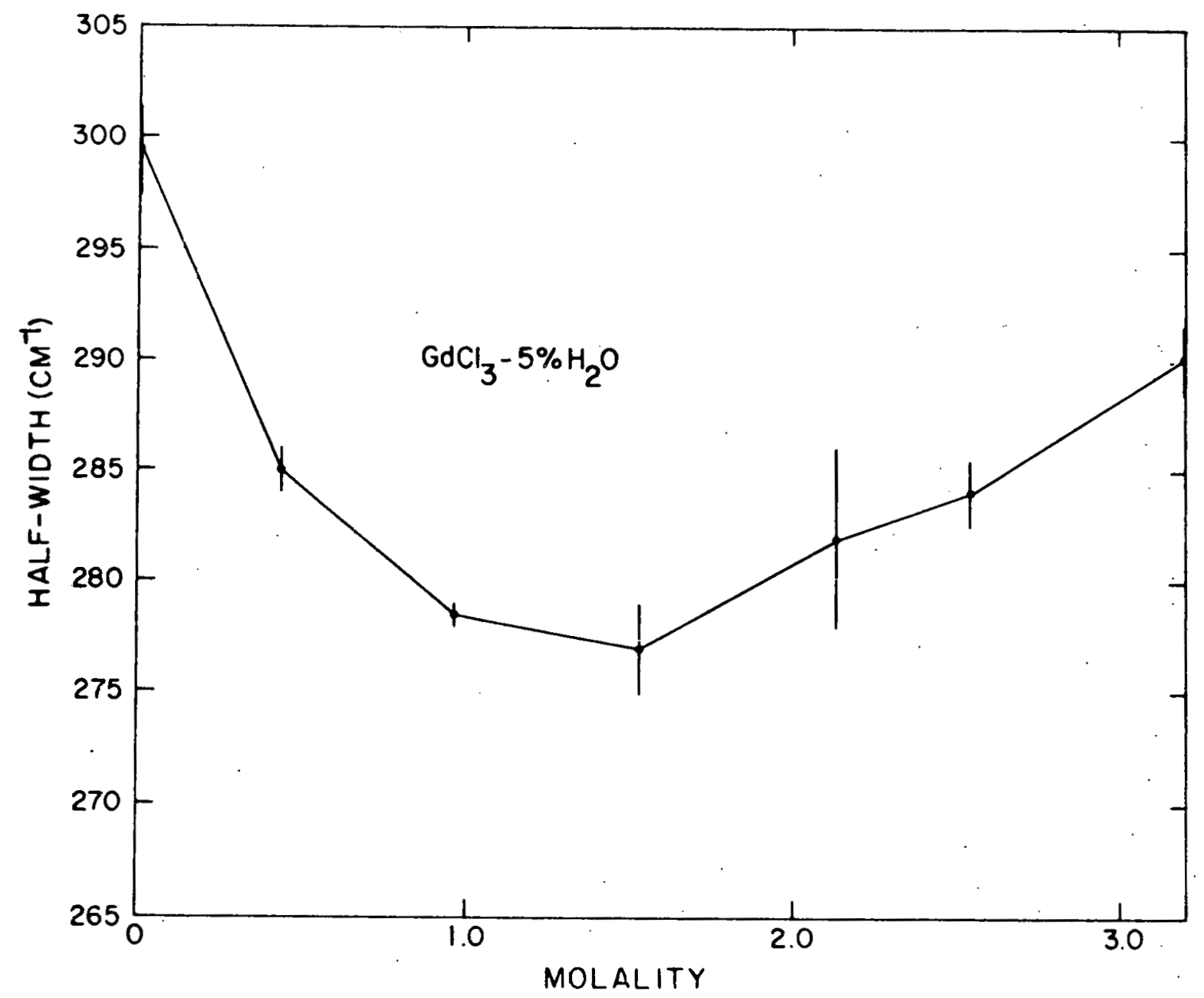

$\vec{\circ}$

Fig. 20. Half-width of the isotropic Baman band of the $O H$ stretching vibration of $H D O$ in water and aqueous solutions of $\mathrm{GdCl}_{3}$. 


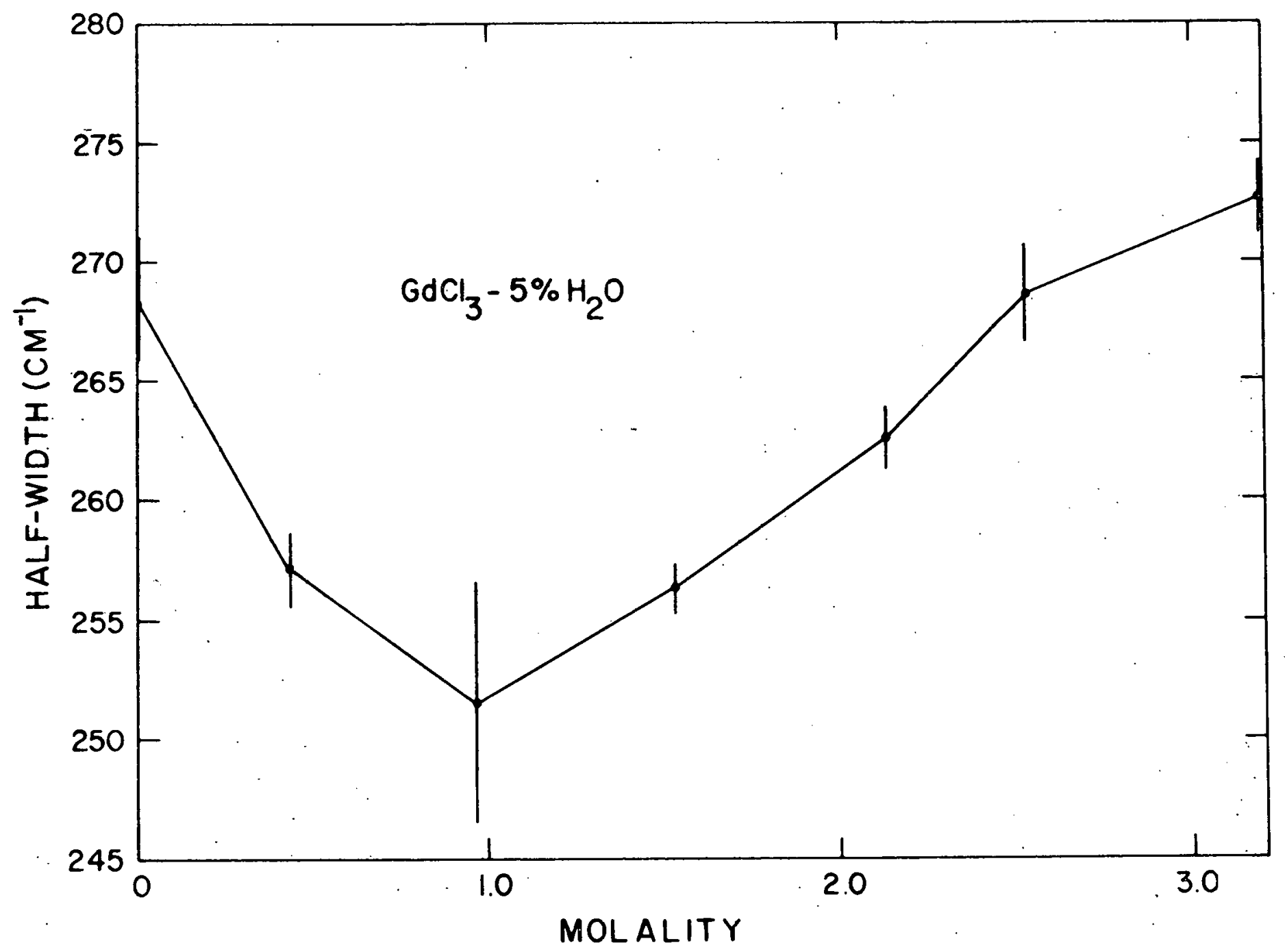

$\overrightarrow{0}$

Fig. 21. Half-uidth of the anisotropic Raman band of the of stretching vibration of HDO in water and aqueous solutions of $\mathrm{GdCl}_{3}$. 
as a function of concentration for a fixed Raman shift. For $G \mathrm{dCl} l_{3}-5 \% \mathrm{D}_{2} \mathrm{O}$. for instance, seven intensities, including water for zero concentration, vere plotted for each of the 66 wave numbers for which isotropic data yas taken. The results are illustratal for several Raman frequencies in Fig. 22. Subseguently, a least-squares quadratic fit was made to each of these plots. Statistical analysis indicated that a quadratic equation was suitable for this data. Then the slopes, or tangents, of these intensity curves vere determined at each concentration by taking the analytic derivative of the guadratic equations. The numerical value of this derivative, at a qiven concentration and Raman shift, corresponds to the average change in the molar intensity of the OD oscillator, as the fraction of water molecules in contact with the electrolytic ions increases. This number, hereafter called a differential of intensity with respect to concentration, is a Eunction cf concentration and the Raman frequency. Fig. 23 illustrates the differential plotted as a function of wave number for each GdCl${ }_{3}-5 \mathrm{D}_{2} 0$ concentration including water for $\mathrm{GdCl}_{3}-5 \mathrm{XD}_{2} \mathrm{O}$ at infinite dilution). These plots are to be interpreted in terms of the Raman stretching Erequencies of HDO molecules which are affected by the cations or anions in the soluticn.

It is qenerally believed that in dilute solutions $\mathrm{GdCl}_{3}$ ionizes completely into $\mathrm{Gd}^{3}+$ and $\mathrm{Cl}^{-}$. But as the concentra- 


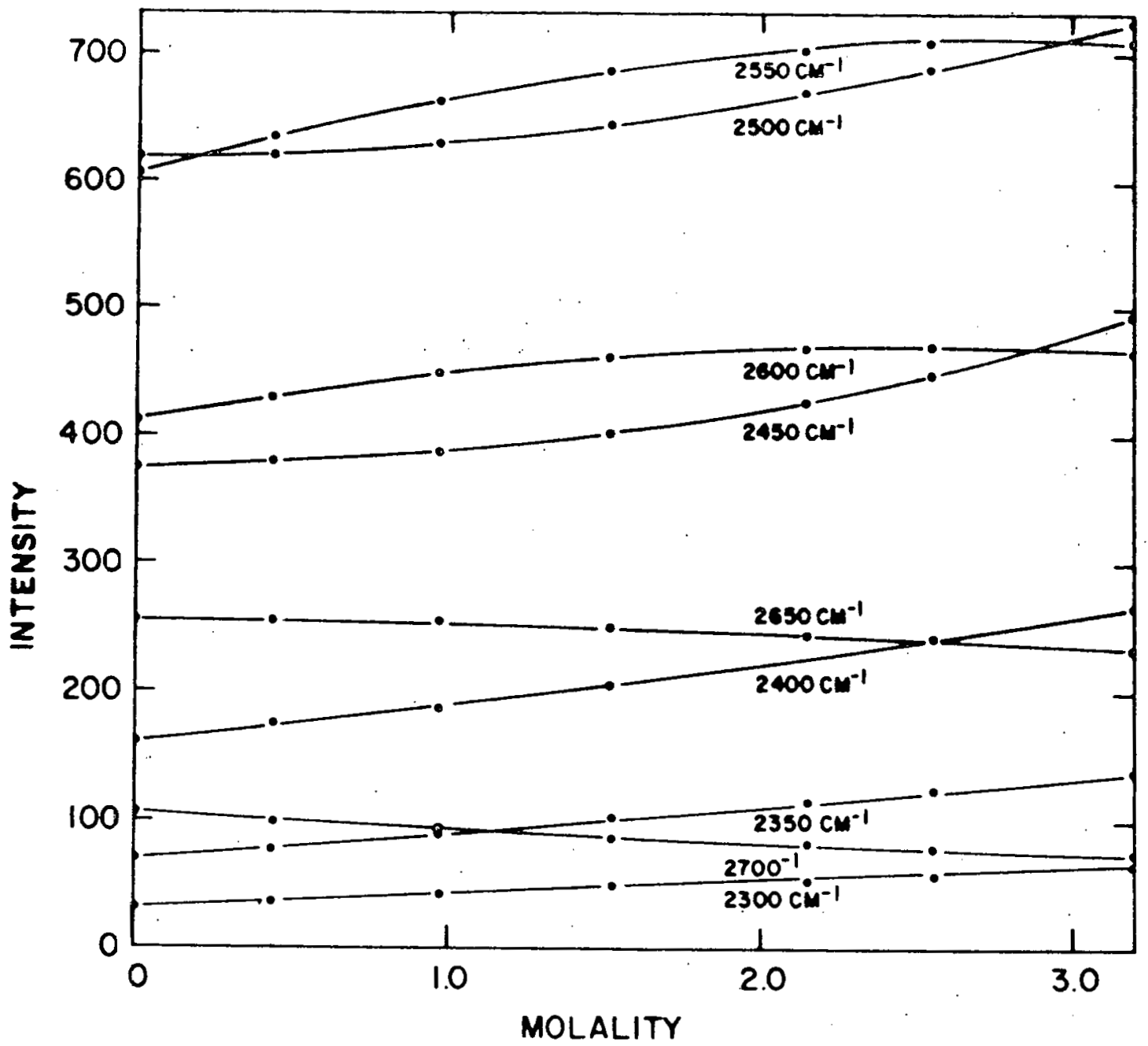

Fig. 22. The intensity as a function of concentration at several Raman frequencies across the isotropic Ranan band of the OD stretching vibration of HDO in water and aqueous solutions of $\mathrm{GdCl}_{3}$. 


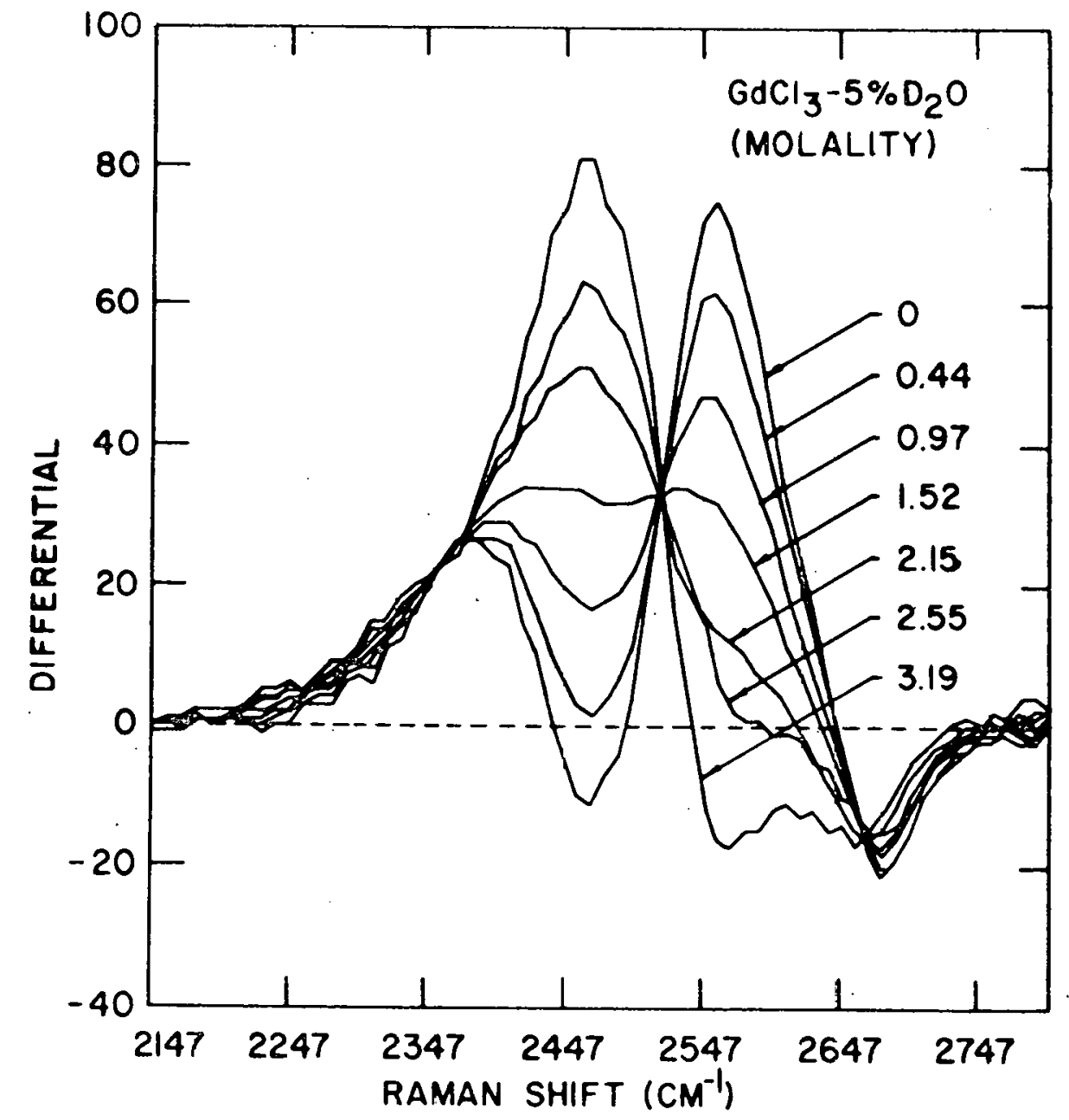

$\overrightarrow{0}$

Pig. 23. The differentials of intensity vith respect to molality of the isotropic Raman band of the $O D$ stretching vibration of HDO in vater and aqueous solutions of $\mathrm{GdCl}_{3}$. 
THIS PAGE

\section{WAS INTENTIONALLY LEFT BLANK}


have been made in this laboratory on aqueous solutions of Gd $\left(\mathrm{ClO}_{4}\right)_{3^{-}}$The differential analysis of this data uncovers a peak at virtually the same frequency as the one that has been associated with the cation above, while the high frequency different: 1 band is much different in shape and position than the above anion band. The fact that the two resolved differential bands disappear and one emerges for higher concentrations, is attributed to scatter which occurs from water molecules which are adjacent to cations and anions at the same time. This is in agreement yitb the generally conceived behavior of ionic solutions.

To establish that these results vere not just an artifact of the guadratic fits, cords were draun between the intensities of adjacent concentrations of $\mathrm{GdCl}_{3}-5 \mathrm{XD}_{2} \mathrm{O}$ and their slopes used to plot a "difference" curve for the isotropic data. Comparison of Fig. 24 with Fig. 23 demonstrates that the features which are being discussed are clearly discernible.

Analogous results obtained for the isotropic spectrum of the $O H$ stretching vitration are displayed in Fig. 25. AIthough the differential bands are much broader so that two differential bands are not resolved at lcu concentration, their identity is established by the shoulder and associated inflection on the low frequency side of the curve. At high concentrations, only one band is obvious as before, and the 


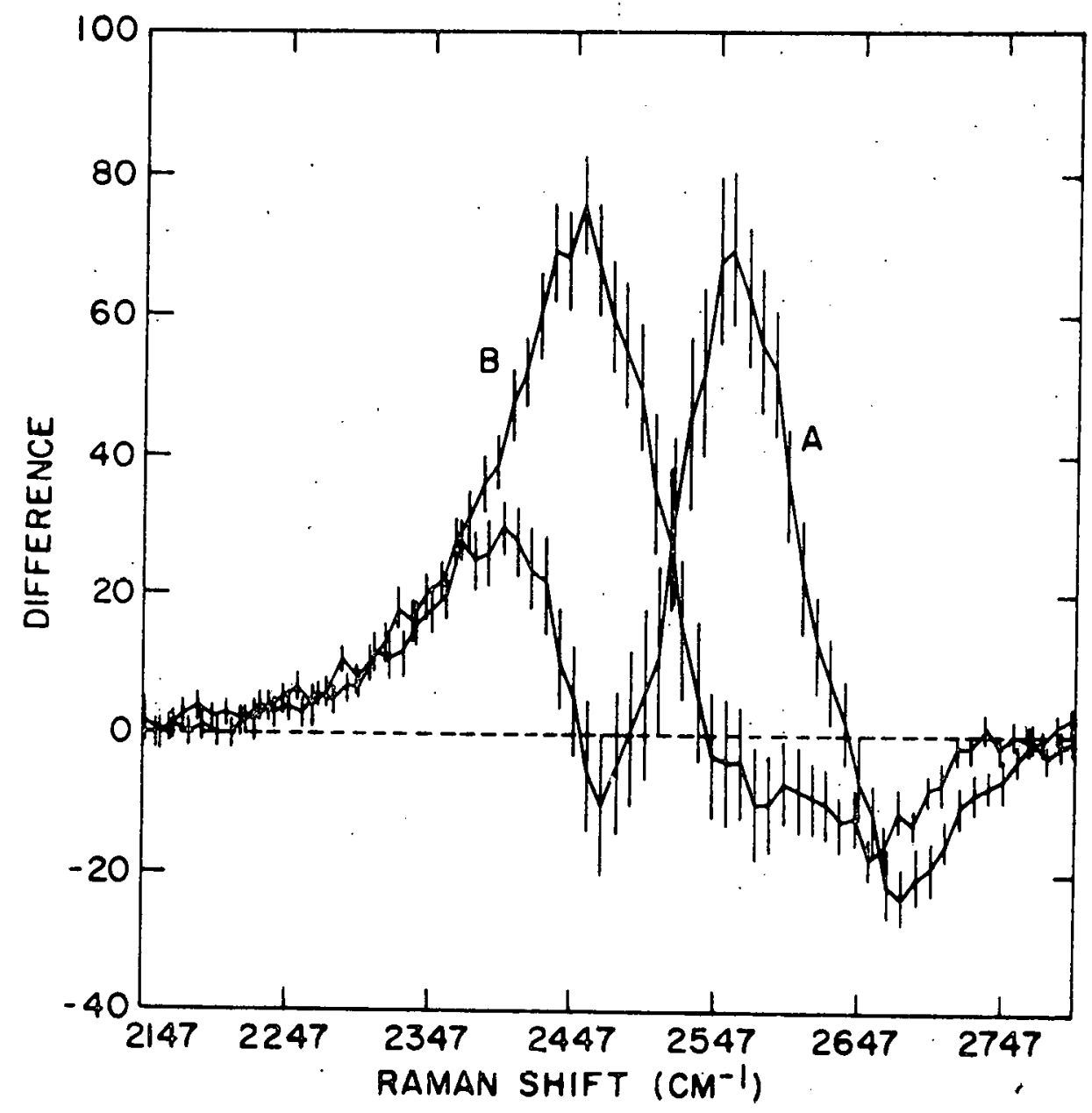

Biq. 24. The differences between the intensities of the $O D$ stretching vibration of HDO in $0.44 \mathrm{~m} \mathrm{GdCl} 3$ and water (A): the difference between 3.19 a $\mathrm{GdCl}_{3}$ and $2.55 \mathrm{GdCl}_{3}(\mathrm{~B})$. 


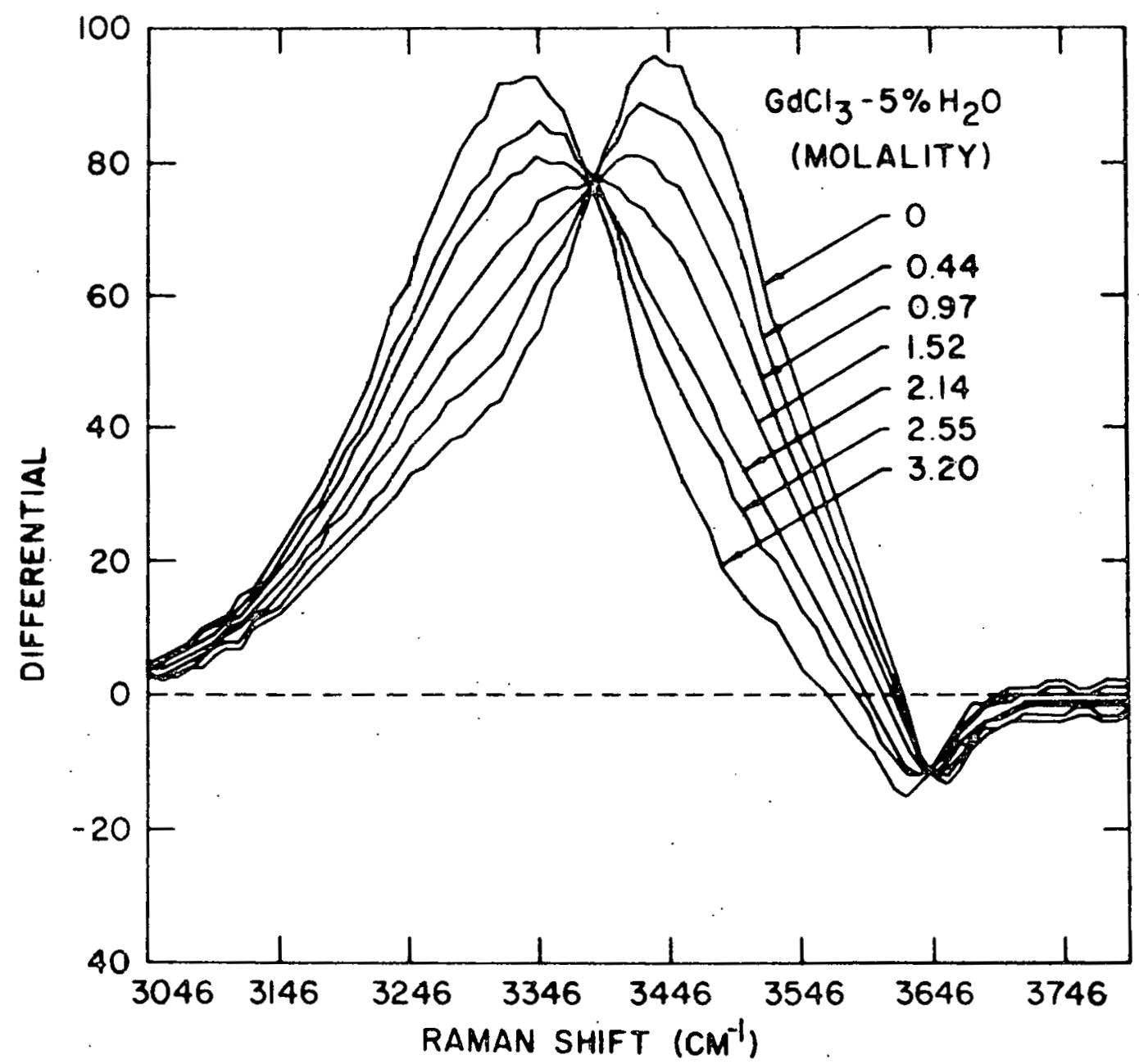

$\overrightarrow{\vec{E}}$

Fig. 25. The differentials of intensity vith respect to

nolality of the isotropic Ram an band of the $O H$ stretching vibration of $\mathrm{HDO}$ in water and aqueous solutions of $\mathrm{GdCl}_{3}$. 
frequency of the peak is again between the frequency of the two unresolved bands ottained at lower concentrations. When a similar analysis is made of the anisotropic spectrum of the OD stretching frequency of $\mathrm{GdCl}_{3}$, only one differential band is apparent at loy concentrations, which corresponds with the band having the higher frequency in the analysis of the isotropic spectrum. Mith further addition of $\mathrm{GdCl}_{3}$ to the solution, the frequency of this band decreases till. near saturated concentrations, it is located at a similar frequency as the corresponding differential band of the isotropic spectrum, as demonstrated in Fig. 26. As seen in Fig. 27. parallel effects are obtained for the differential analysis of the spectrum of the $O H$ stretching frequency in the aqueous anisotropic $\mathrm{GdCl}_{3}$ soluticns.

The same analysis was done for both polarizations of the OD stretching frequency of the aqueous solutions of $\mathrm{LaCl}_{3}$ and $\mathrm{IuCl}_{3}$, and very similar results were acquired as seen in Figs. 28 - 31. It is instructive to superimpose the resulting curves for the three salts at infinite dilution and at a concentrated solution, as is done in Figs. 32 and 33 . This makes it clear that while the results for $\mathrm{GdCl}_{3}$ and $\mathrm{LuCl}_{3}$ are nearly the same, the results for $\mathrm{LaCl}_{3}$ is measurably different. And the difference at infinite dilution occurs in the band at low frequency wich has been tentatively assigned to water molecules yhich are affected by the rare earth ions. 


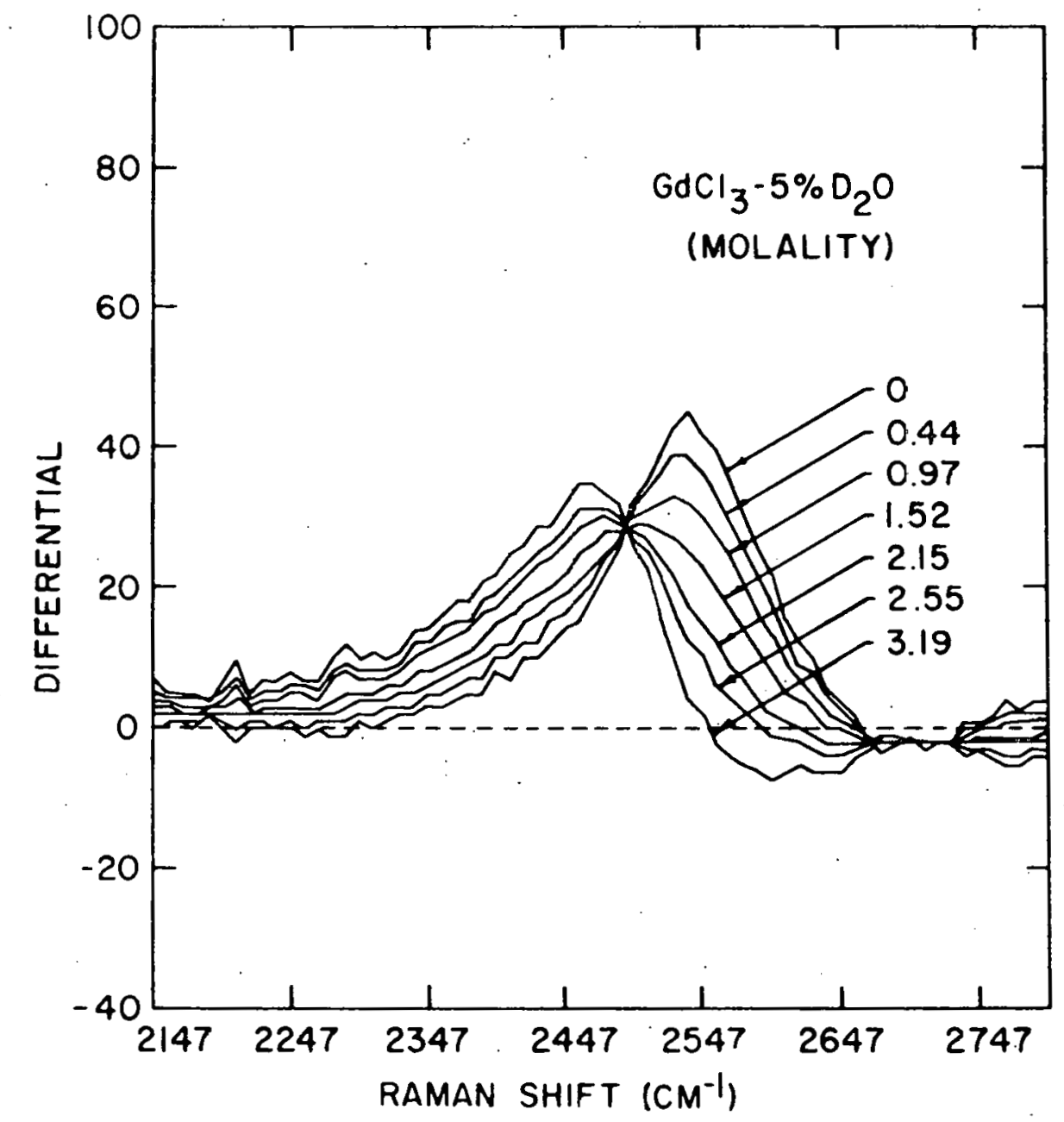

Fig. 26. The differentials of intensity with respect to molality of the anisotropic Raman band of the OD stretching vibration of HDO in vater and aqueous solutions of $\mathrm{GdCl}_{3}$. 


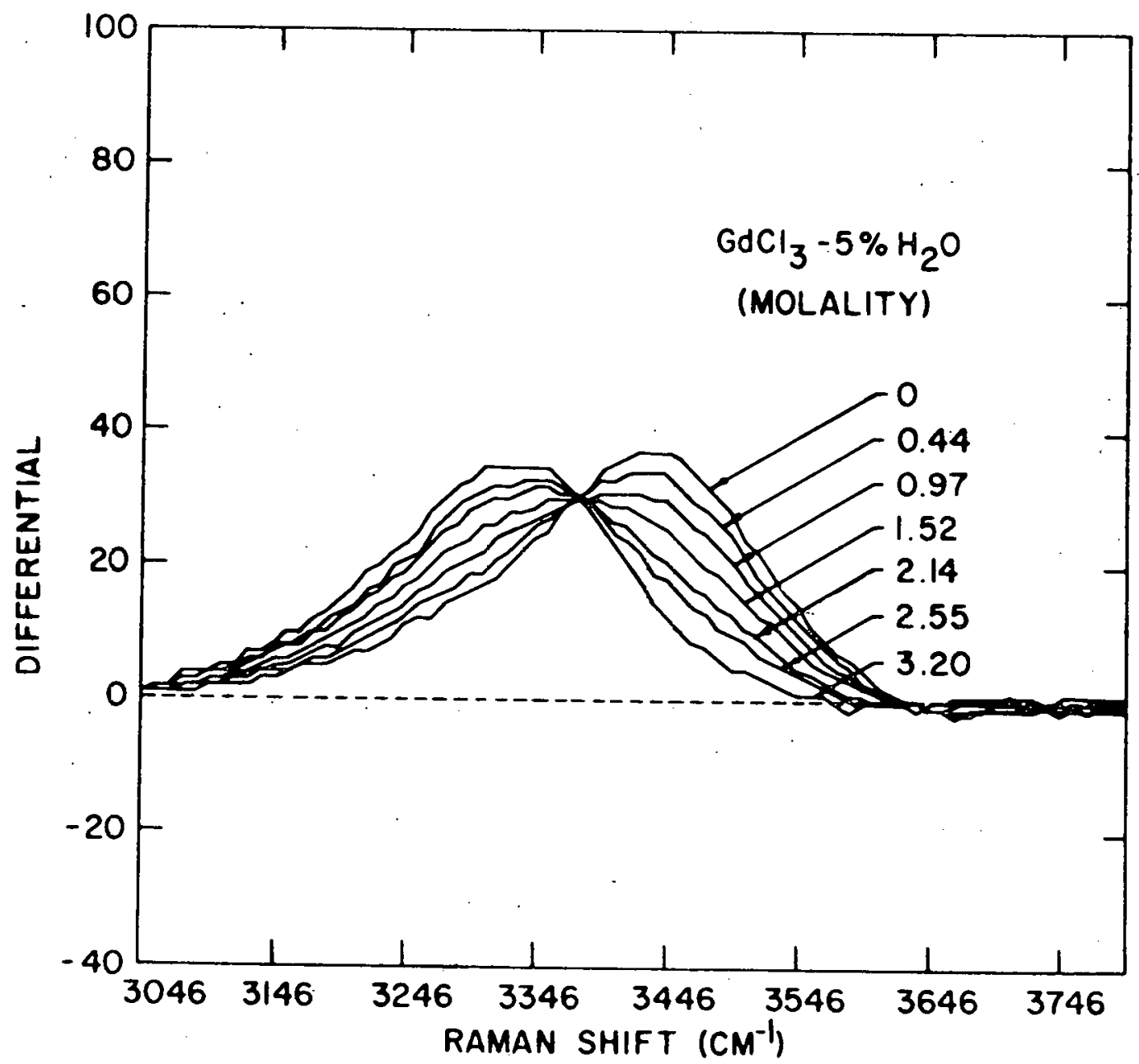

Fig. 27. The differentials of intensity with respect to -olality of the anisotropic Raman band of the $\mathrm{OH}$ stretching vibration of HDO in water and aqueous solutions of $\mathrm{GdCl}_{3}$. 


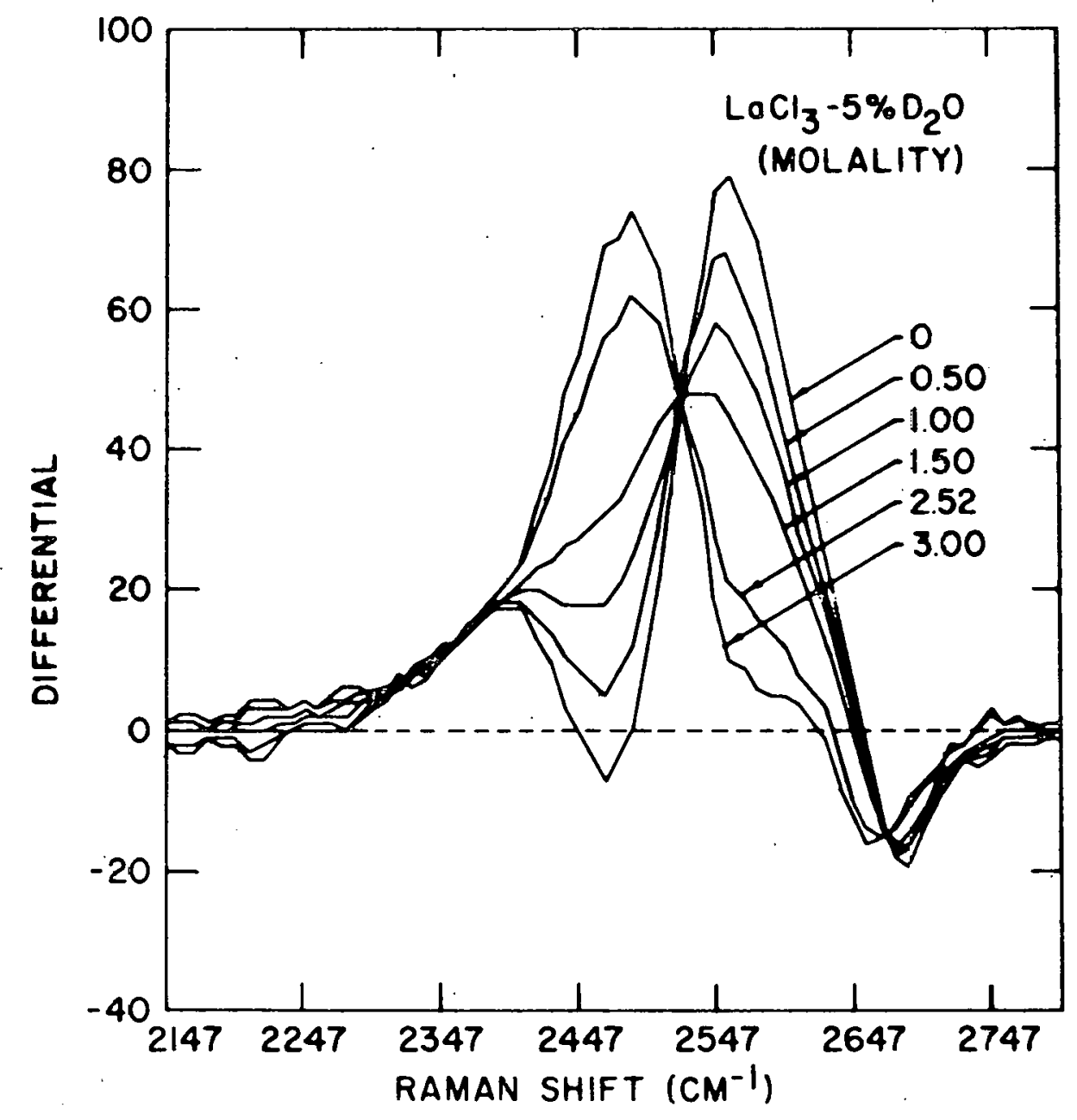

$\vec{\infty}$

Fig. 28. The differentials of intensity vith respect to molality of the isotropic Raman band of the $O D$ stretching vibration of $\mathrm{HDO}$ in water and aqueous solutions of $\mathrm{LaCl}_{3}$. 


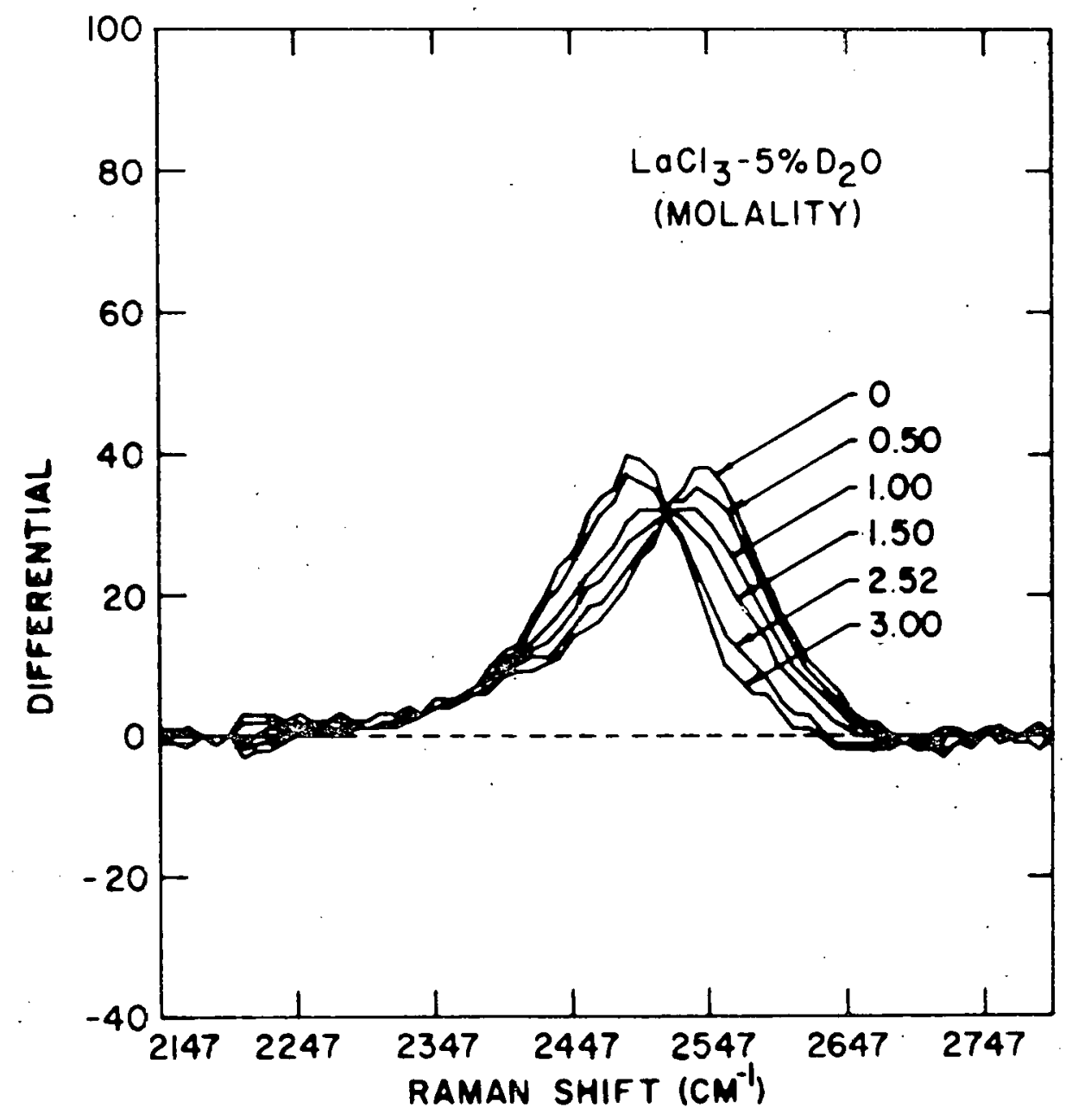

Fig. 29. The differentials of intensity with respect to molality of the anisotropic Raman band of the $O H$ stretching vibration of HDO in vater and aqueous solutions of $\mathrm{LaCl}_{3}$. 


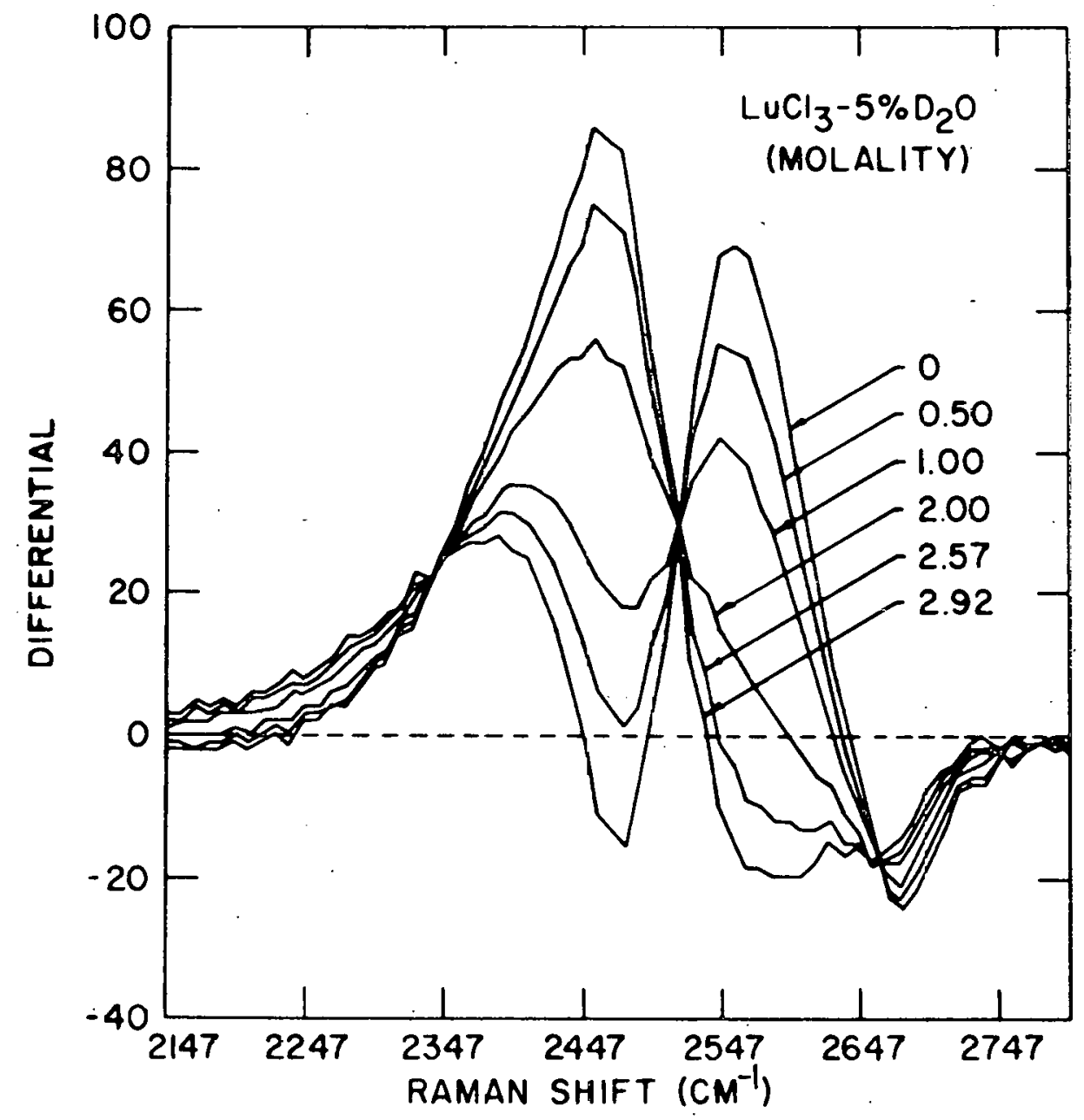

Pig. 30. The differentials of intensity vith respect to molality of the isotropic Raman band of the OD stretching vibration of $\mathrm{HDO}$ in vater and aqueous solutions of $\mathrm{LuCl}_{3}$. 


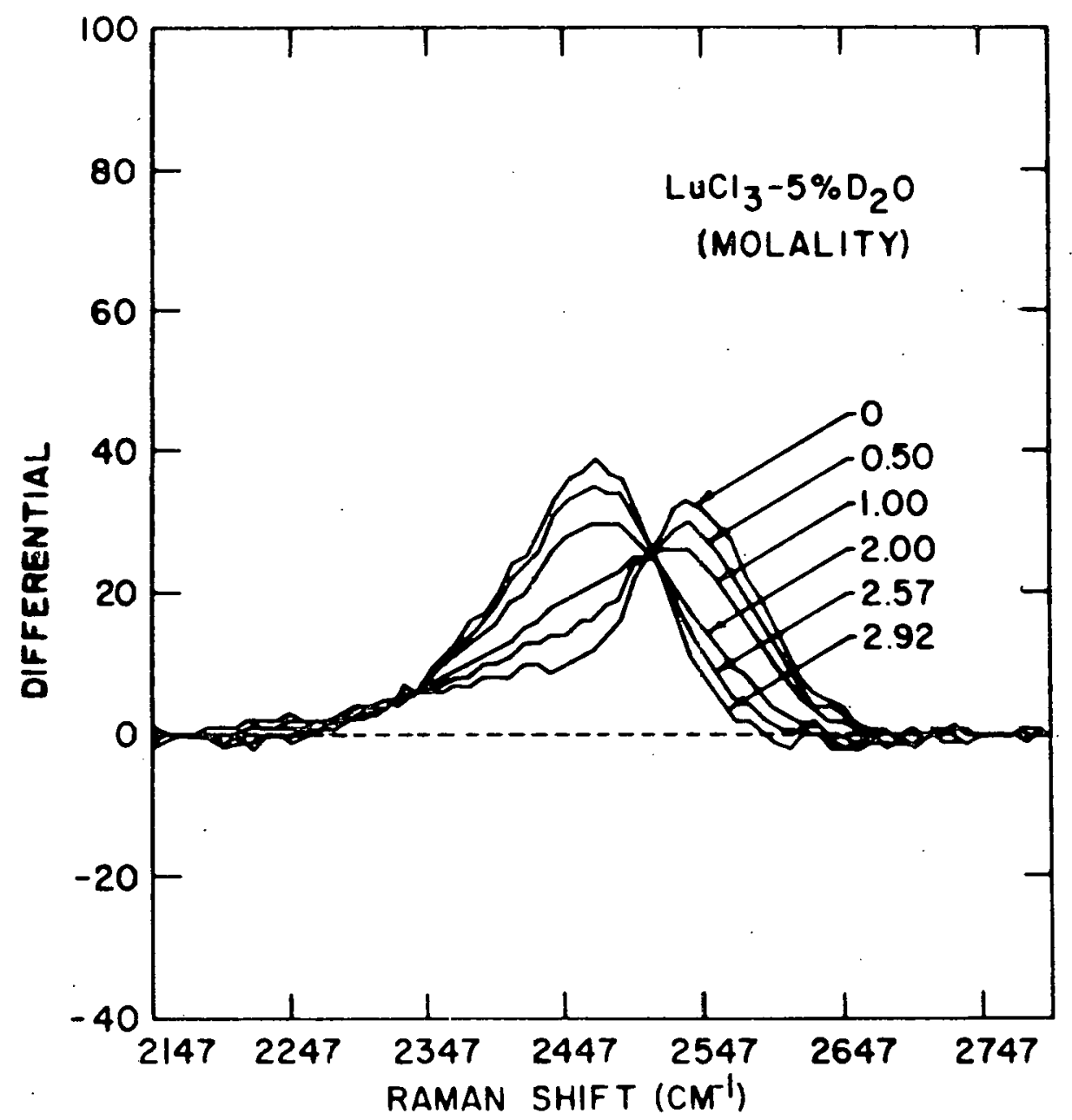

Pig. 31. The differentials of intensity with respect to molality of the anisotropic Banan band of the $O D$ stretching vibration of $B D O$ in water and aqueous solutions of $\mathrm{LuCl}_{3}$. 


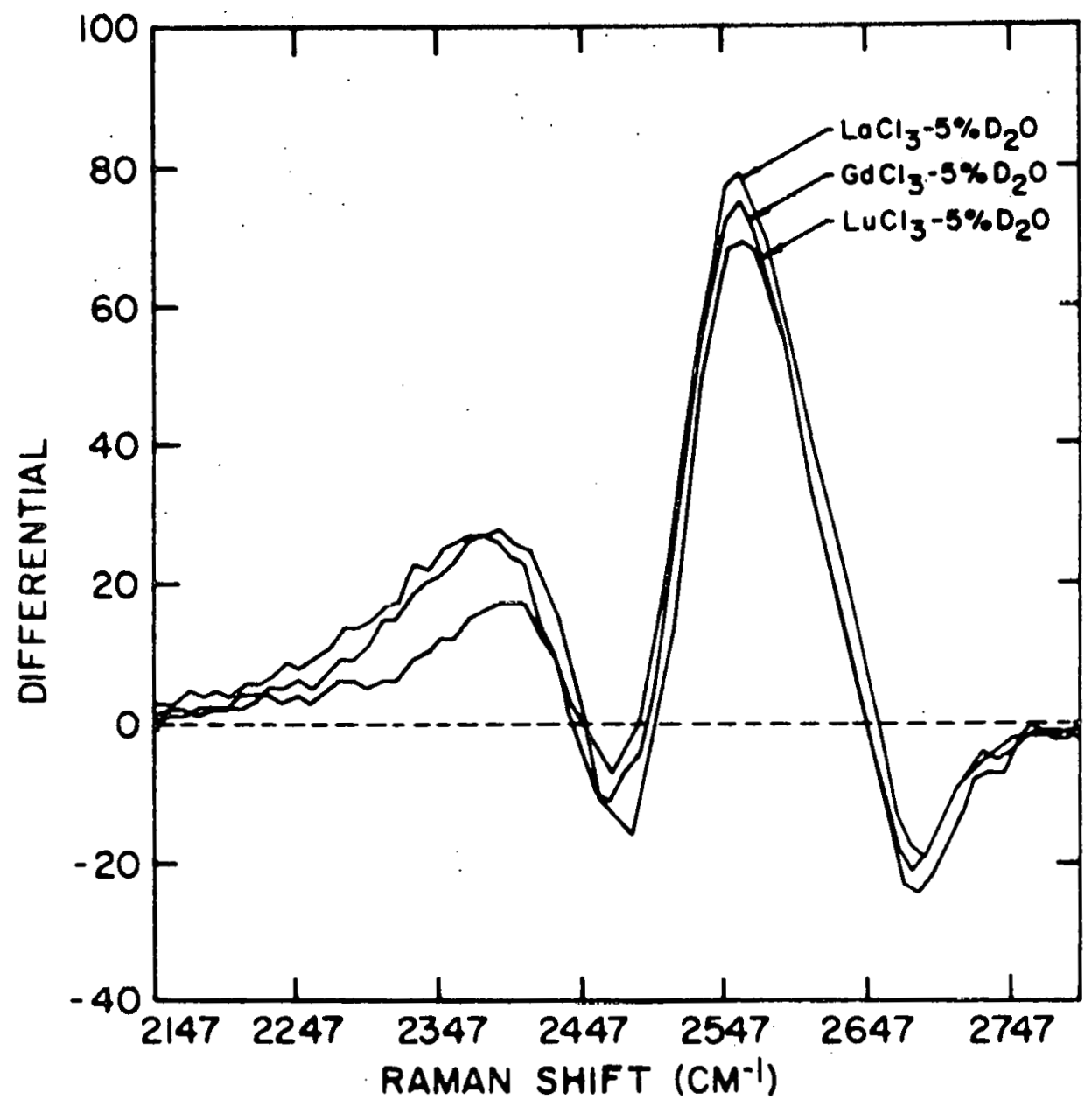

Fiq. 32. The differentials of intensity with respect to molality of the isotropic Raman band of the OD stretching vibration of HDO for $\mathrm{LaCl}_{3} \cdot \mathrm{GdCl}_{3}$ and IuCl $_{3}$ at infinite dilution. 


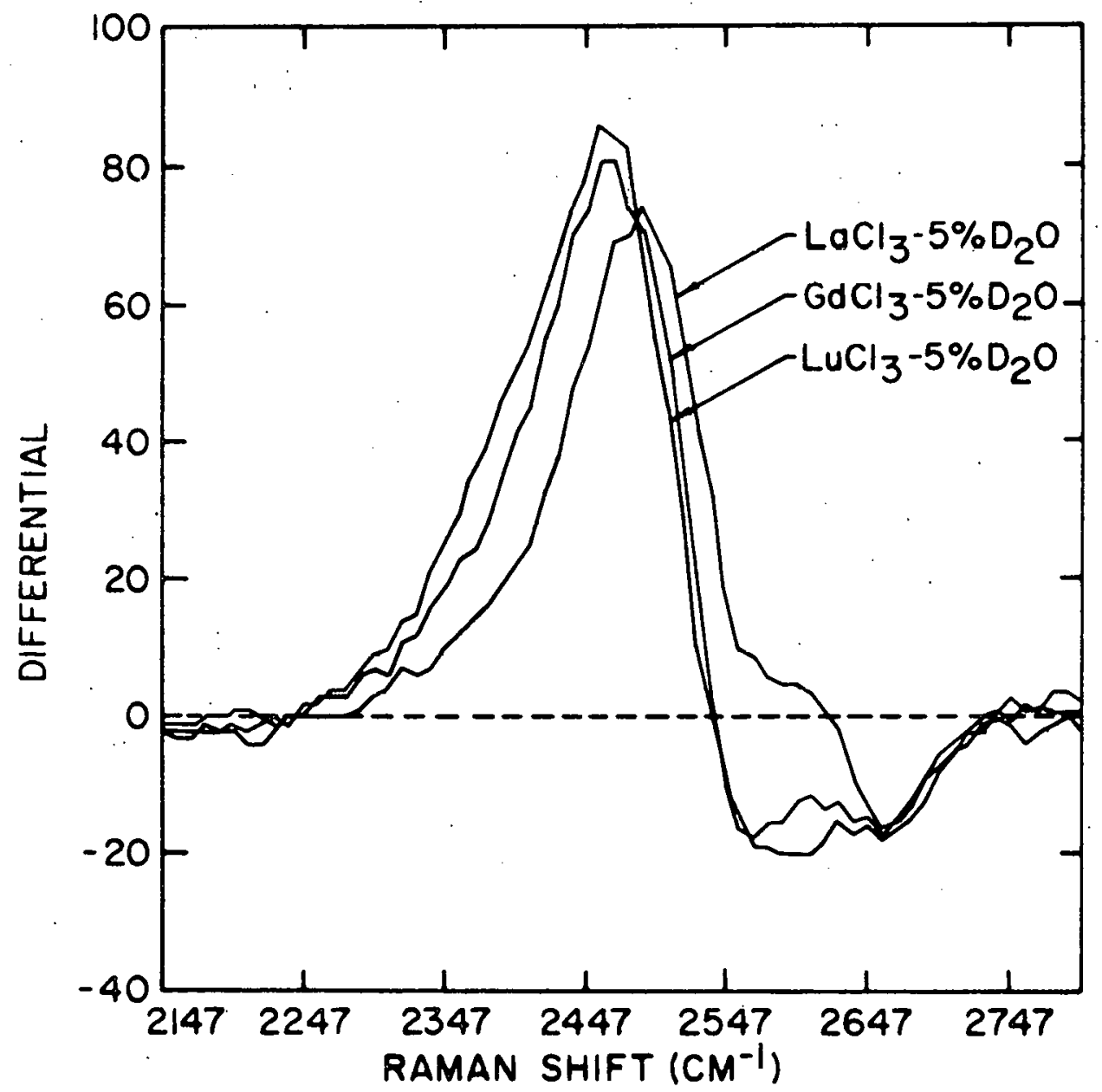

Fiq. 33. The differentials of intensity with respect to molality of the isotropic Raman band of the OD stretching vibration of $\mathrm{HDO}$ for 3.00 m $\mathrm{LaCl}_{3}$. $3.19 \mathrm{GdCl}_{3}$ and 2.92 : $\mathrm{LuCl}_{3}$. 
If this is a correct assignuent, then in the above comparison there is evidence that water molecules are affected differently by the $\mathrm{La}^{3+}$ ion than by the Gd3+ or $\mathrm{Lu}^{3+}$ ion. This could well reflect a difference in cation hydration which has been reported previously by a aumber of investigators $(55,68,70,96)$. According to these studies, La3+ seems to have a greater number of water molecules in the first hydration sphere than $\mathrm{Gd}^{3+}$ or $\mathrm{Lu}^{3+}$.

The differences, in the differential curves of $\mathrm{LaCl}_{3}$. $\mathrm{GdCl}_{3}$ and $\mathrm{IuCl}_{3}$ are consistent with the fanning out of the peak frequencies of the spectral band of these salts at high concentration noted earlier.

Incidentally, the fact that four Gaussians or three skewed-Gaussians could continue to fit the spectrua of solutions. in which there vere distinct bands associated with affected water molecules, is an additional indication that there is no physical significance to the component functions uhich fit the curves.

Pinally, attention should be called to the consistent similarity of the defolarization ratios for all of the solutions displayed in Fig. 34. While the maqnitude of these ratios is dependent on the background subtracted from the band data. the shapes of the frequency dependence of the depolarization ratios were essentially insensitive to different choices of background parameters. 

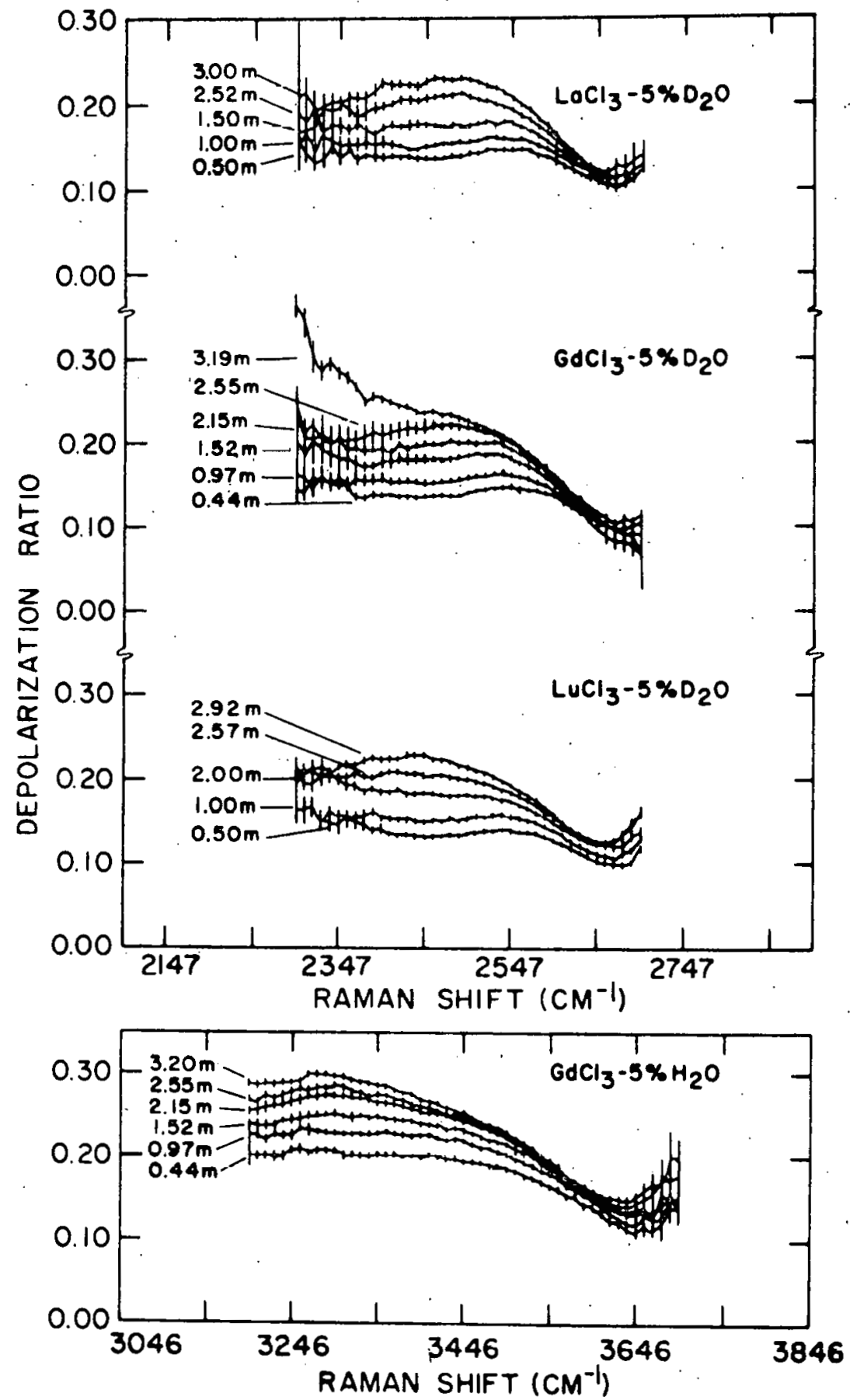

Fig. 34. Depolarization ratios of the OD stretching vibrations of $\mathrm{HDO}$ in aqueous solutions of $\mathrm{LaCl}_{3}, \mathrm{GdCl}_{3}$ and $\mathrm{LuCl}_{3}$ and of the $\mathrm{OH}$ stretching $v$ ibrations of HDO in aqueous solutions of $\mathrm{GdCl}_{3}$. 


\section{SOMGARY AND CONCLOSIONS}

The following significant results and information bave been obtained in this vork:

1) Accurate data for the $O D$ and $O H$ vibrations in water and six concentrations of $\mathrm{GdCl}_{3}$ and for the OD vibrations in five concentrations each of $\mathrm{LaCl}_{3}$ and $\mathrm{LuCl}_{3}$ vere obtained, which are independent of the exciting laser frequency. The expected standard deviation of the average at each Raman shift vas determined for botb polarizations.

2) It least four normal Gaussian curves were required to suitably fit the isotropic data, but it appears that nothing more than curve fitting equations have been obtained.

3) Parameters listed by Walrafen for a four Gaussian fit to the $O D$ stretching band of $\mathrm{BDO}$ did not fit the data obtained in this work. This may be because his data was not corrected for the response efficiency of his detection system.

4) Consistent depolarization ratios vere obtained for the $O D$ and $O H$ stretching vibrations in water and $\mathrm{GdCl}_{3}$ and the $O D$ bands in $\mathrm{LaCl}_{3}$ and $\mathrm{LuCl}_{3}$. All are similar in shape and demonstrate that this ratio is not constant across the HDO spectral bands.

5) The depolarization ratio is larger for the or band than for the $O D$ band. Also, for each of the solutions, the wagitude of this ratio increases regularly with increasing 
salt concentration.

6) Within experimental error, the wolar integrated intensity increases linearly with respect to the concentration of the rare earth chloride.

7). The frequency position of peak intensity of the $O D$ or OH band increases with increasing rare earth chloride concentration at low concentrations. Then it decreases for all salts at higher concentrations. Likewise as anticipated, at Iow concentrations tbese bands become narrower, but at high concentrations they broaden.

8) In addition, there is a cation dependent difference in the peak positions and half-uidths for both polarizations that is apparent at high concentrations of the three rare Earths.

9) Differential analysis of the data locates the frequencies of the $O D$ and $O H$ oscillators that are influenced by the cations and anions at lov concentrations. A single differential band at high concentration indicates that the vater wolecules are being affected by both salt ions.

10) This differential analysis shows that the Gdit and Iu $3+$ cations have a similar effect on water, but there is a measurable difference for La ${ }^{3+}$, as would be expected from thermodyamic data.

11) No distinct cation band is visible in the differential analysis of the anisotropic data at low concentration. 
Two major features distinguish this report. First. reproducible calibrated data have been obtained for the $O D$ and of stretching bands in water and aqueous solutions. De believe that this data is five to ten times more accurate than any reported heretofore. This accurate spectral data. together vith listed estimated standard deviations, should be a rigorous test for theoretical nodels of water. It also indicates that some widely quoted published results are of questionable value. Furthermore, the data permit for the first tive an unequivocal demonstration that the depolarization ratios of the OD and $O H$ vibrational bands of HDO do vary with Raman frequency.

The second prominent feature is the developaent and use of a differential analgsis technigue which alloved the identification of distritutions of the stretching vibrations associated with water molecules wich are clearly affected in different vay's by the rare earth and chloride ions.

Separate independent experiments on aqueous $\mathrm{Gd}\left(\mathrm{ClO}_{4}\right)_{3}$ support the validity of the differential analysis, exhibiting not only the cation effect but also indicating that the $\mathrm{ClO}_{4}^{-}$ ion complexes with yater. Though different peak freguencies and agnitudes occur, there is a qualitative similarity in the differential curves of rare earth chlorides and perchlorates. 
It appears that it vould be fruitful to look at aqueous solutions with anions in the same iso-electronic sequence as C1-. 1.e. I-, BF and F-. This should help to increase the interpretive power of the method of analysis developed here. For similar reasons it should be valuable to make raman scans of solutions with mono- and divalent cations. Finaly, it appears that this differential analysis may be applicable to electrolytic and non-electrolytic aqueous solutions in general. 


\section{BIBLIOGBAPHY}

1. Adams, D. H.. Blandamer, M. J., Symons, M. C. R. and Maddington, D.. Trans. Faraday Soc. $6 I$ (Pt. 3). 611 (1971).

2. Almenningen, A. Bastiansen, 0. and Hotzfeldt, T.. Lcta Chea. Scand. 24. 747 (1970).

3. Barrett, J. J. and Adams III, H. I., J. Opt. Soc. Am. S $_{\text {, }}$ $311(1968)$.

4. Benedek, G. B. and Britsch, K., Phys. Bev. 149, 656 (1966).

5. Ben-Naim. A.. J. Chem. Phys. 52, 5531 (1970) .

6. Berendsen, H. J. C.. Theor. Exp. Biophys. 1. 1 (1967).

7. Bernal, J. D. and Fovler, R. H.. J. Chem. Phys. 1. 515 (1.933).

8. Bernal, J. D.. Proc. Boy. Soc. A, 280, 299 (1964).

9. Bernal, J. D. and King, S. V.. Physics of siaple_hiquids. edited by H. N. V. Tamperley, J. S. Borlinson and G. S. Bushbrooke, (Nortb-bolland Publ. Co.. Aasterdan, Netherlands, 1968).

10. Bertie, J. E. and thalley, E., J. Chem. Phys. 40, 1637 $(1964)$.

11. Bevington, P. R. Eata Beduction and Error Analysis for the physical sciences. (HcGray-Hill Book Company. Hew York, 1969).

12. Bhagavantan. S. Scattering of light and the Ragan Effect. (Andhra University. Maltair. India; 1940).

13. Bonner, O. D.. J. Phys. Chea. 76, 1228 (1972) .

14. Brink, G. and Falk, H., Can. J. Chen. 48, 3019 (1970).

15. Bryan. J. B. and Curnutte, B.. J. Hol. Spectrosc. 41,512 (1972).

16. Buifs, K. and Choppin, G. B., J. Chem. Phys. 39. 2035 (1963).

17. Cardamone, H. J., Hunt, J. I. and Sterens, J. R., Chen. 
Phys. Lett. 12, 628 (1972).

18. Colles, H. J.. Halrafen, G. B. and Mecht, K. H.. Chen. Phys. Lett. $4.621(1970)$.

19. Convay, B. E., Annu. Bev. Pbys. Chen. 17, 481 (1966).

20. Cunningham, K. A., Ph. D. Thesis, Yale dniversity, 1971.

21. Curnutte, Basil and Bandekar, J., J. Mol. Spectrosc. 41 . 500 (1972).

22. Davis, C. M.. Jr. and Bradley, D. I... J. Chem. Phys. $4 \underline{5}$. $2461(1966)$.

23. Davis, C.M. and Jarzynski, J. yater and_Agueoous_solutions: Structure, Thermodynamics and Transport, edited by R. A. Horne, (Wiley-Interscience, New York, 1972).

24. Deloze, C. and Baron, M. H., Chen. Phys. Lett. 9, 103 (1971).

25. devos, J. C.. Physica 20, 690 (1954).

26. Dorsey. N. E.. Properties_of ordinary_nater-substange日. (Reinhold, New York, 1940).

27. Eisenberg. D. and Kauzmann, $D$. The structure and properties of Hater. Cxford Univ. Press, Canbridge, England. 19691 .

28. Erlander, S. B. Science Journal $\underline{5 A}, 60$ (1969).

29. Eyring, H. and Jhon, Uu Shik, Cheaistry 39, 8 (1966).

30. Falk, H. and Ford, I. A., Can. J. Cher. 44.1699 (1966).

31. Palk, H. and Hyss, H. R., J. Chem. Phys. 51, 5727 (1969).

32. Ford, T. A. and Falk, M., Can. J. Chen. 46. 3579 (1968).

33. Frank, E. U. and Both, K.. Discussions Faraday Soc. 4 壬. 108 (1967).

34. Frank, H. S. and Quist, A. S., J. Chem. Phys. 34. 604 (1960).

35. Frank. H. S.. Fed. Proc.. Suppl. 24. I (1965).

36. Prank, H. S., Science 169, 635 (1970). 
37. Fraser, B. D. B. and Suzuki, E.. Anal. Chen. 38, 1770 (1966).

38. Prenzel, C. A.. Bradley, E. B. and Matbur. H. S., Appl. spectrosc. 25, 614 (1971).

39. Gilson, T. R. and Hendra, P. J.. Laser_Raman SpectégoscopY (Hiley-Interscience, New York, 1970).

40. Gurikov, Yu. v.. J. Struct. Chem. 12, 190 (1971).

41. Haas, C. and Hornig, D. F.. J. Chem. Phys. 32, 1763 (1960).

42. Haas, Y. and Stein, G., Chem. Phys. Lett. 11, 143 (1971).

43. Hankins, D.. Moskowitz, J. M. and stillinger, F. H.. J. Chem. Phys. 53. 4544 (1970).

44. Hendra, P. J. and stratton, P. A., Chem. Bev. 69, 325 (1969).

45. Hendra, P. J. and rear, C. J., Analyst (London) 95, 321 (1970).

46. Hepler, L. G.. Can. J. Chem. 47. 4613 (1969).

47. Hester, R. E., Annu. Rep. Progr. Chem.. Sect. A 66.79 (1969).

48. Hester, B. E., Anal. Chem. 42, 231 R (1970).

49. Holtzer, A. and. Emerson M. F.. J. Phys. Chem. 23, 26 (1969).

50. Horne, B. A.. Surv. Frogr. Chem. 4. 2 (1968) .

51. Horne, R. A. The Structure of Liguid Hater, (office of Naval Research, Technical Beport No. 33, 1968).

52. Jansson, P. A. Hunt, R. H. and PIyler, E. K., J. Opt. SOC. A In. 60, 596 (1970).

53. Jones, A. F. and bisell, D. L., J. Phys. A: Gen. Phys. 3. 462 (1970).

54. Kamb, B.. Hamalton, H. C., Laplaca, S. J. and Prakash, A.. J. Chem. Phys. 5 5.1934 (1971).

55. Karraker, D. G... Inorg. Chem.. I, 473 (1968) . 
56. Recki, Z.. Dryjanski, D. and Kozlowska, E.. Rocz. Chem. 42. $1749(1968)$.

57. Kell, G. S.. Hater and Aqueous solutionsi_structurure, Thermodynanics and Transport processes. edited by R. A. Horae, (Wiley-Interscience, New York, 1972).

58. Roenig, 3. L., Research/Development, 18 (June 1969).

59. Kondilenko, I. I., Pogorelov, V. E. and Khue, K.. Opt. Spectrosc: (USSR) 28. 367 (1969).

60. Krindel, P. and Eliezer, I., Coord. Chem. Bev. 6, 217 (1971).

61. Krishnan, R. S., The Raman Effect, edited by A. Anderson, (Warcel Dekker. Inc.. Nev Pork. 1971).

62. Lippincott, E. R. and Schroeder, R., J. Chem. Phys. 23 . 1099 (1955).

63. Loader, J.. Basic Laser Baman spectroscopy. (Heyden and Son, Itd.. London. England, 1970).

64. Luck, H. A. P.. Discussions Faraday Soc. $\underline{4}$, 115 (1967).

65. Marechal, Y.. Chen. Phys. Lett. 13. 237 (1972).

66. Masri. F. N. and Fletcher, H. H.. J. Chem, Phys. 52, 5759 $(1970)$.

67. HCHurIy, H. L., Russel1, G. L. and Burgger, R. H., Nucl. Sci. Eng. 25, $248(1966)$.

68. Hoeller, T.. Martin, D. F., Thompson, L, C., Ferrus, R., Peistel, G. B. and Bandall, H. J., Chem. Bev.. 65. 1 (1965).

69. More O'Perrall, R. A.. Koeppl, G. M. and Kresge, A. J.. Rhysical and Inorg. Chem. 93. 1 (1971).

70. Morqan, L. 0., J. Chem. Phys., 38, 2788 (1963).

71. Murphy, H. F.. Bvans, M. V. and Blender, P.. J. Chem. Phys. 47. 1836 (1967).

72. Murphy, H. F. and Bernstein, H. J., J. Phys. Chem. 76, 1147 (1972).

73. Narten, A. H. and Ievy, H. A., Science 165:447 (1969). 
74. Nemetby, G., Ped. Froc., 24, Pt. III, S-38, (1965).

75. Newethy, G.. Cryobiology 3,19 (1966).

76. Nemetby, G. and Scberage, H. A.. J. Chem. Phys. 3 $_{\text {. }} 3382$ (1962).

77. O०Neil, J. B. and Adami, I. H., J. Phys. Chem. 23., 1553 (1969).

78. orr, S. F. D.. Spectroscopy, edited by D. R. Brouning, (bcGrar-Hili, Book Company. New York, 1969).

79. Ostroff, A. G.. Snowdon, B. S., Jr.. Hoessner, D. B.. J. Cheo. Phys. 73.2784 (1969).

80. Papousek, D. and Pliva, J., Collect. Czech. Chem. Commu. 30. 3007 (1965).

81. Perrat. J. M.. J. Chen. Phys. 49. 4245 (1968).

82. Perra., J. A. and Levine, S., Hol. Phys. 21. 701 (1971).

83. Pimentel, G. C. and vcclellan, A. L.. The Hydrogen_Bond.

(1. H. Preenan and Company. San Prancisco, 1960).

84. Rahman, A. and Stillinger, F. H., J. Chem. Phys. 5 5 . 3336 (1971).

85. Raman. C. V.. Indian J. Phys. 2. 387 (1928).

86. Baman, C. V. and Krishnan, K. S., Nature 121, 501 (1928).

87. Samoilov, 0. Ya. and Yastrenskii, P. S., J. Struct. Chem 12. 355 (1971).

88. Savitzky, A. and Gclay, A. J. E., Anal. Chew. 36, 1627 $(1964)$.

89. Schiffer, J. and Hornig, D. F.. J. Chen. Phys. 49 , 4150 (1968).

90. Schroetter. H. H. Raman Spectroscopy, Vol. 2, edited by H. A. Szquansi. (Plenum Press, New York, 1970).

91. Schuiesow, R. L.. J. Opt. Soc. An. 59. 1285 (1969).

92. Senior, W. A. and Verrall, B. E., J. Phys. Chea. I 3,4242 (1969). 
93. Sloane, H. J.. App1. Spectrosc. 25. 430 (1971) .

94. Smekal, A.. Naturwiss. 11. 873 (1923).

95. Suith, R. A. Contenp. Phys. 12, 523 (1971).

96. Spedding, F. H. Pikal, H. J. and Agers, B. O.. J. Phys. Cher.. 70, 2440 (1966).

97. Strey, G., Spectrochim. Acta, Part A 25, 163 (1969).

98. Tang. J. and Albrecht, A. C. Raman_spectroscopy, Vol. 1, edited by H. A. Szymanski. (PIenum Press. Ney York, 1970).

99. Vdovenko, V. M.. J. Struct. Chea. 6. 786 (1965).

100. Vdovenko, V. M.. J. Struct. Chen. I. 765 (1966).

101. Vdovenko, V. M.. J. Struct. Chem. 10.486 (1969).

102. Vinogradov, S. N. and Linnell, R. H. Hydrogen_Bonding. (Van Vostrand Beinhold Co.. New York, 1971).

103. Hall, T. T. and Hornig, D. F., J. Chem. Phys. 43, 2079 (1965).

104. Hal1; T. T. and Hornig. D. F.. J. Chem. Phys. 47. 784 (1967).

105. Mal1, T. T., J. Chen. Phys. 51, 113 (1969).

106. Mall, T. T., J. Cben. Phys. 52. 2792 (1970).

107. Malrafen, G. E.. J. Chen. Phys. 36, 1035 (1962).

108. Walrafen, G. E.. J. Chem. Phys. 40.3249 (1964).

109. Walrafen. G. E.. J. Chem. Phys. $44 ., 1546$ (1966).

110. Walrafen, G. E.. J. Chem. Phys. 47, 114 (1967).

111. Walrafen, G. E.. Hydrogen-Bonded Solvent syst. Proc. Symp.. 9 (1968).

112. Dalrafen, G. E., J. Chem. Phys. 48, 244 (1968).

113. Halrafen, G. E., J. Chem. Phys. 50, 560 (1969).

114. Walrafen, G. E.. J. Chem. Phys. 52. 4176 (1970). 
115. Mairafen, G. E.. J. Chem. Phys. 55, 768 (1971) •

116. Halrafen, G. E.. J. Chem. Phys. 55, 5137 (1971).

117. Malrafen, G. E. and Blatz, L. A., J. Chen..Phys. 56, 4216 (1972).

118. Hyss and Balk, Can. J. Chew. 48, 607 (1970).

199. Yellin. H. and Courchene, N. I.. Nature 219,852 (1968).

120. Young, R. P. and Jones, R. N.. Chem. Rev. 71. 219 (1971). 
ACKNOQLEDGEUENTS

Anong the people who contributed to the success of this work, the athor is especially grateful to:

Dr. F. H. Spedding for his even tesper, support, advice and discussions:

Dr. W. J. Has for discussions and encouragement;

Dr. A. A. Hohs and Mr. L. B. Schiers for solution preparation:

Dr. A. A. Brown and Mrs. P. A. Crop for assistance with computer programs;

(Drs. M. A. Brown and M. A. Mohs also were of special assistance in preliainary work.)

Dr. b. Gutierres for accese to his data and results on $\mathrm{Gd}\left(\mathrm{ClO}_{4}\right)_{3}^{-5 \times D_{2}} \mathrm{O}$;

His uife, Susi, for assistance in preparation of this manuscipt, encouragement, self-sacrifice and patience. 